\title{
Algae-associated bacteria in photobioreactors
}

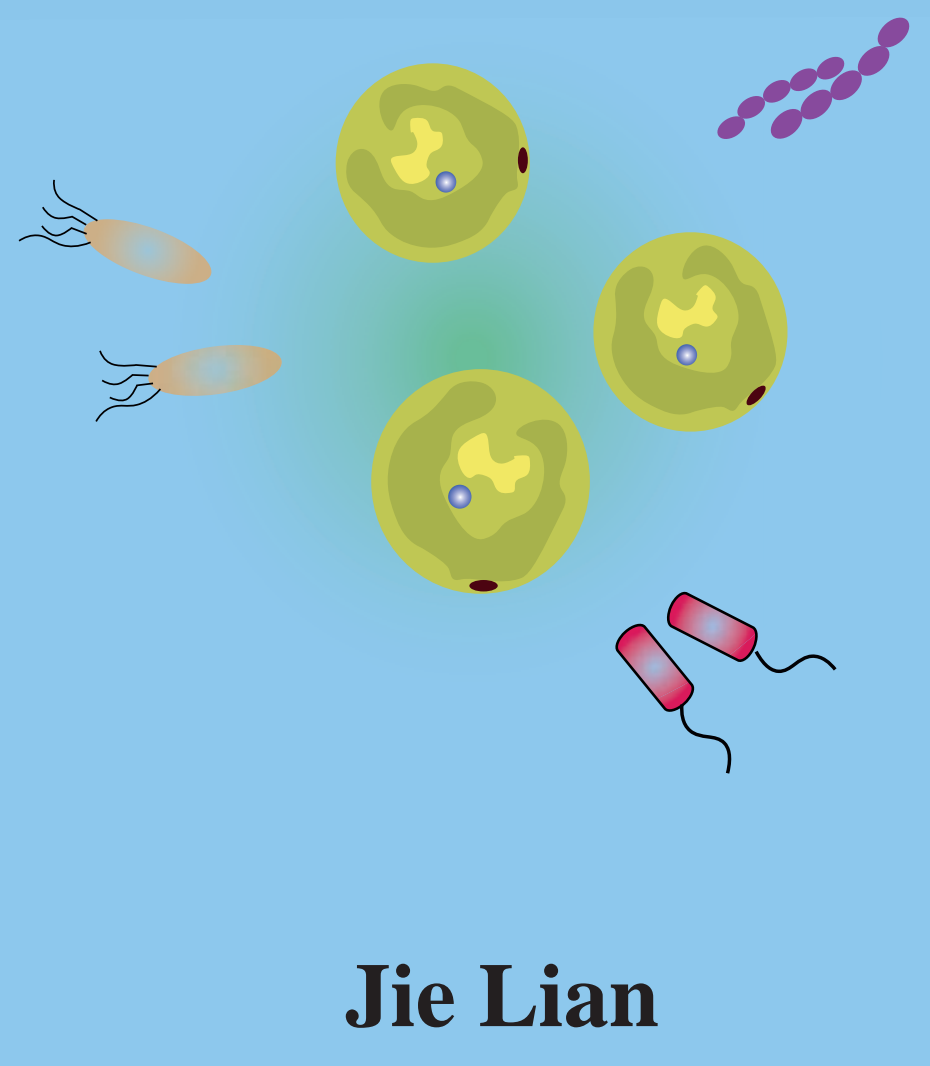



Algae-associated bacteria in photobioreactors

JieLian 


\section{Thesis committee}

\section{Promotors}

Prof. Dr HaukeSmidt

Personal chair, Laboratory of Microbiology

Wageningen University \& Research

Prof. Dr ReneWijffels

Professor of Bioprocess Engineering

Wageningen University \& Research

\section{Co-promotor}

Dr Detmer Sipkema

Associate professor, Laboratory of Microbiology

Wageningen University \& Research

\section{Other members}

Prof. Dr Eddy Smid, Wageningen University \& Research

Dr Dedmer van de Waal, Netherlands Institute of Ecology (NIOO-KNAW), Wageningen

Dr Alette Langenhoff, Wageningen University \& Research

Dr David Green, The Scottish Association for Marine Science (SAMS), Oban, UK

This research was conducted under the auspices of the Graduate School VLAG

(Advanced studies in Food Technology, Agrobiotechnology, Nutrition, and Health Sciences) 


\title{
Algae-associated bacteria in photobioreactors
}

\author{
JieLian
}

Thesis

submitted in fulfilment of the requirement for the degree of doctor at Wageningen University

by the authority of the Rector Magnificus,

Prof. Dr A.P.J. Mol,

in the presence of the

Thesis Committee appointed by the Academic Board

to be defended in public

on Thursday 2 July 2020

at 11 a.m in the Aula. 
J ie Lian

Algae-associated bacteria in photobioreactors,

164 pages.

$\mathrm{PhD}$ thesis, Wageningen University, Wageningen, the Netherlands (2020)

With references, with summary in English

ISBN: 978-94-6395-375-7

DOI : https://doi.org/10.18174/519713 


\section{T able of contents}

$\begin{array}{lll}\text { Chapter } 1 & \text { General introduction and thesis outline } & 1\end{array}$

$\begin{array}{lll}\text { Chapter } 2 & \text { The effect of the al gal microbiome on industrial }\end{array}$

Chapter 3 Associated bacteria of Botryococcus braunii 33 (Chl orophyta)

Chapter $4 \quad$ Bacterial diversity in different outdoor pilot

55 plant photobioreactor types for production of the microal ga Nannochloropsis sp. CCAP211/78

Chapter 5 Different co-occurring bacteria enhance or

89 decrease the growth of the microal ga Nannochl oropsis sp. CCAP211/78

Chapter 6

General discussion

115

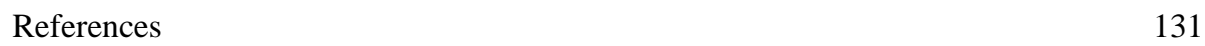

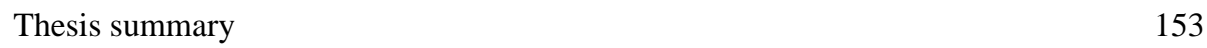

$\begin{array}{ll}\text { Appendices } & 157\end{array}$ 



\section{Chapter 1}

\section{General introduction and thesis outline}




\subsection{Symbioses of algae and bacteria}

Algae are prominent primary producers in aquatic ecosystems [1, 2]. Approximately $50 \%$ of global photosynthesis is attributed to al gae that consequently play pivotal roles in the gl obal carbon cycleand oxygen flux [3, 4]. They are theancestors of land plants and can be dated back to $450-470$ million years ago [5]. However, research on plant-microbe interactions has drawn much more attention than algaemicrobe interactions. Plant-microbe interactions have been investigated with a major focus on plant pathogens, symbiotic nitrogen-fixing rhizobia and plant-associated arbuscular mycorrhizal fungi [6-8]. In recent years, it has been shown that multipartite interactions continuously take place in and on plants, and that plant-associated microorganisms provide a range of benefits for plant growth and health through influencing nutrient uptake, affecting plant-pathogen interactions and increasing the tolerance to biotic/abiotic stresses [9-12].

In plant biology, the most intensively studied biome is the rhizosphere. The term rhizosphere was first introduced in 1904 to describe the narrow region of soil which is subjected to the influence of plant roots $[13,14]$. The microenvironment surrounding al gal cells where al gae and bacteria interact is anal ogous to the plant rhizosphere; thus Bell and Mitchell [15] coined the term phycosphere to fit an aquatic equival ent.

The long coevolutionary history of algae and bacteria has led to multifaceted and highly sophisticated interactions [16, 17]. Lucas [18] first pointed out that there are non-predatory relationships in water between al gae and bacteria based on the release of metabolites, ranging from toxins to vitamins and hormones. Provasoli [19] went astep further to suggest that bacteria can enhance the growth of algae. Following Provasoli's review numerous papers provided ample evidence of al gal-bacterial interactions [20-24]. These interactions span a wide range of ecological relationships from mutualism to commensalism and parasitism [25]. Mutualistic interactions between al gae and bacteria are characterised by bacterial provision of growth- 
limiting factors to algae in exchange for organic carbon. Two well-studied examples are that Halomonas sp. and Mesorhizobiumsp. supply vitamin $B_{12}$ to themarinered al ga Porphyridium purpureumand thegreen al gaChlamydomonas nival is, respectively [26, 27]. A nother example is that the nitrogen fixing bacterium Bacillus pumilus ES4 provides nitrogen to the green microal ga Chlorella vulgaris in oligotrophic environments [28]. Cho, Ramanan [29] noted that other bacteria in the phycosphere of Chlorella vulgaris might be commensals, residing in the al gal sheath for carbon and shelter. Commensal ism differs from mutualism in that only one partner directly benefits from the interaction. However, in most cases it is ambiguous whether mutualistic or commensal interactions prevail; or as Zapal ski [30] pointed out, commensal s can be regarded as non-interacting partners and it is difficult to prove absence of interaction.

In contrast to mutualism and commensalism, antagonism/parasitism has been rather well investigated [31-34]. Multiple bacteria can negatively affect algal growth, which has encouraged research into possible applications of these adverse effects to lyse microal gal and cyanobacterial cells that cause harmful algal blooms [35-37]. For instance, the filtrate of Rhodococcus sp. cultures showed cyanobactericidal activity on Microcystis aeruginosa and Anabaena variabilis [37], and Brevibacteriumsp. was shown to produce al gicidal compounds to kill the toxic dinoflagel lateAlexandriumtamarense[38]. This research has seen an increased attention, because algal blooms occur more frequently in recent years [25, 39, 40]. Toxins produced by these harmful al gae can accumulate throughout the food chain, which has great impact on aquatic ecology, public heal th and local economy [41-43].

\subsection{O mics methods for studying host-microbe interactions}

The specificity and extent of most al gal-bacterial interactions still remains to becharacterized [44]. Standard microbiology methods and biochemical analysis are still indispensable in deciphering algal-bacterial interactions (Figure 1.1). For instance, bacterial production of 
micronutrients such as vitamin $B_{1}$ or $B_{12}$ has been demonstrated in defined co-cultures of bacteria and al gae with standard microbiol ogical approaches [26, 45], and mutual istic/parasitic relationships between Emiliana huxleyi and Phaeobacter gall aeciensis werestudied by detailed biochemical analysis [46]. More recently, the rapid advances in omics technologies offer alternative ways to study interactions between al gae and bacteria [47].

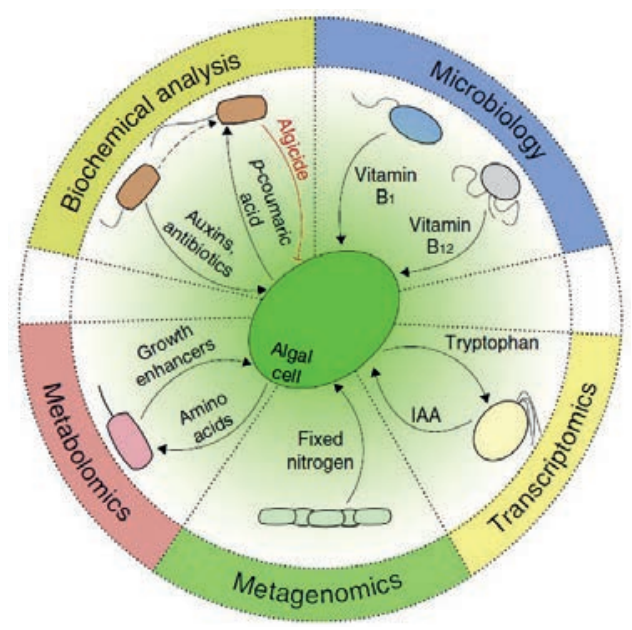

Figure 1.1. Different approaches used to characterize algal-bacterial interactions, including examples for their application. Adapted from Cooper and Smith [48].

Combining metagenome, transcriptome and metabolome data is powerful for identifying the major bacterial groups associated with algae and characterization of the pathways and molecules involved in trophic exchange or signalling processes (Figure 1.1). Together with mechanistic examinations of algal physiology and biochemistry [17], these omics-enabled analyses will allow unravelling how algae sense and cooperate with bacteria, and how interactions change in response to fluctuating conditions or chemical signals. At the moment, multi-omics approaches for the study of al gae and their associated bacteria are in their initial stages, but a number of successful cases exist al ready. For example, a metagenomics approach was used to elucidate the range of al gal-bacterial species engaged in nitrogen-based symbi oses 
in the Attantic Ocean [49]. Furthermore, transcriptomic analysis of a co-culture of the diatom Pseudonitzschia multiseries and Sulfitobacter sp. SA11 revealed up-regulation of tryptophan biosynthesis genes in the al ga and indole 3 -acetic acid (IAA) production in the bacterium The produced IAA, an auxin, was found to promote cell division in the diatom [16].

\subsection{M icroalgae production}

Microalgal biomass is a promising source for chemicals, food and feed supplements, and biofuels [50,51]. High areal yields, high oil content, low water consumption and the possibility of production on non-arable land makemicroal gae more compel ling than many other crops [52, 53]. Currently, only al gal specialties or high value products, for instance, unsaturated fatty acids and pigments, arecommercial ly profitable[54,55]. For commercial production of commodities fromal gal biomass the production costs should decrease to less than $1 € / k g$ dry weight $[52,56]$, while with state of the art technology the current cost can be around $3 € / \mathrm{kg}$ as estimated in techno-economic models for a 100 ha facility [57].

A major parameter affecting microal gal production cost is photosynthetic efficiency [56, 57]. Photosynthetic efficiencies obtained under outdoor conditions (3\%) are lower than values obtained under laboratory conditions (6\%) [52]. At least in part this is caused by the continuously changing weather conditions occurring under outdoor conditions where critical cultivation parameters such as light intensity cannot be controlled and temperature can only partly becontrolled.

\subsubsection{M icroalgae production systems}

One of the key factors for commercially viable microal gal production is the design of a suitable reactor system. The open raceway pond, horizontal and vertical tubul ar photobioreactors, and flat panel photobioreactors arethe most often used designs at a semi-industrial scale [58]. Each of the reactor designs has its own advantages and disadvantages, which are outlined below. 


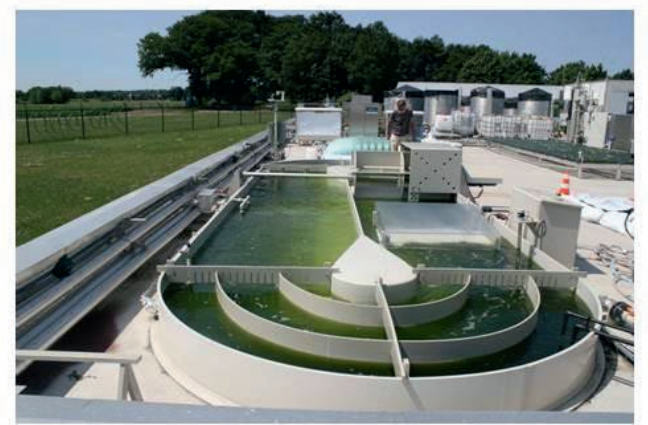

Raceway pond

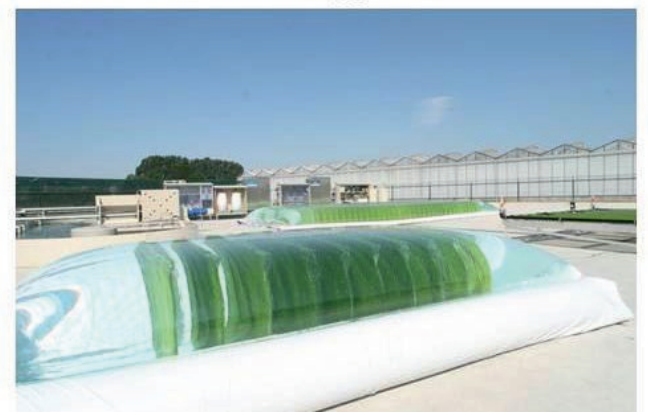

Flat panel PBR

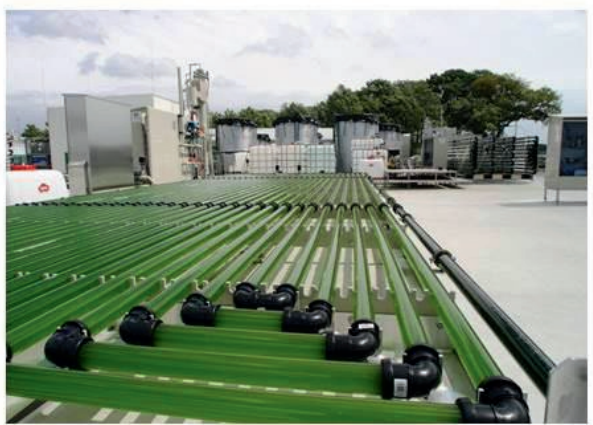

Horizontal tubular PBR

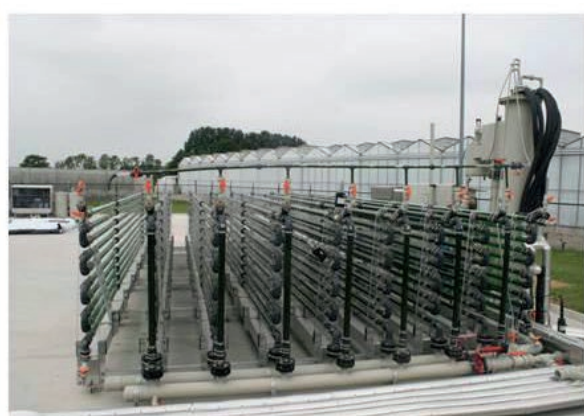

Vertical tubular PBR

Figure 1.2. Overview of cultivation systems installed at the AlgaePARC pilot facility (Wageningen, the Netherlands). PBR: photobi oreactor. Adapted from[59].

\subsubsection{Open ponds}

Open ponds (natural waters and artificial ponds or containers) are the most commonly used systems to grow al gae at large scale $[58,60]$. Open ponds are equipped with paddle wheels to mix algal cultures through long channels. One of the major advantages of open ponds is that they are cheaper and easier to build and operate than most closed photobioreactors [61, 62]. However, open systems are subject to a range of limitations such as poor light utilization by algal cells, water evaporation and diffusion of $\mathrm{CO}_{2}$ to the atmosphere

\subsubsection{Closed tubular photobioreactors}


In closed tubular photobioreactors algal cultures are confined in transparent glass- or plastic tubes and circulated by a centrifugal pump [63]. Tubular photobioreactors can be found as a single horizontal plane or multiplevertical planes (Figure 1.2). Typical ly, theliquid velocity in tubular systems is $0.3-0.6 \mathrm{~ms}^{-1}$, while higher vel ocity $\left(0.6-0.9 \mathrm{~ms}^{-1}\right)$ is used to prevent foul ing. The degasser is an important part of any tubular systemand is used to remove dissol ved oxygen produced by photosynthesis. Accumulation of dissolved oxygen is known to negatively affect al gal growth [64]. The closed tubular system is one of the most suitable photobioreactors for outdoor mass cultures because of its large illumination surface area [58]. Nevertheless, temperature is difficult to control in outdoor tubular photobioreactors, and long tubul ar systems are characterized by gradients of oxygen and $\mathrm{CO}_{2}$ concentrations al ong the tube [65].

\subsubsection{Flat panel photobioreactors}

Flat panel photobi oreactors are compact rectangular vertical vessels that aremade of transparent materials: glass, plastic plates or plastic films [66]. Due to the design, mixing takes place along the vertical axis, whereas there is limited mixing capacity al ong the horizontal axis. Insufficient horizontal axis mixing makes the width of separate units of this system shorter than that of tubular systems, and as a result, more labour and infrastructure are required to construct and operatea commercial plant with flat panels in comparison to tubul ar systems [59]. A succesfful example of flat panels designs that have solved these issues is the ProviAPT system designed by Proviron (Proviron Holding NV, Belgium) (Figure 1.2).

\subsubsection{Bacteria in algae production systems}

In addition to above-mentioned factors, another important aspect of photobioreactor design for cultivation of microal gae is to reduce the risks of microbial contamination. Contamination by algal predators (ciliates and flagellates) and other fast growing heterotrophic bacteria have restricted the commercial production of al gae $[67,68]$. In contrast to closed bioreactors, open 
ponds are exposed to their ambient environment, and thus are more prone to contamination in general [69]. Therefore, only a few of the algal species that can be grown under extreme conditions (high salinity, low pH, etc.) that hinder successful invasion of ambient microorganisms are suitable to begrown in open ponds [67]. Although it is a general consensus that open ponds are more easily contaminated than closed bioreactors, studies that simultaneously compare bacterial diversity and abundance in open ponds and enclosed bioreactors are limited in literature. On the other hand, for large-scal e production of microal gae it is neither practical nor economical to completely sterilize the growth media. Therefore, it is inevitable that all large-scale microal gae production systems contain a number of non-target organisms $[70,71]$.

\subsection{Targeted algal species and their associated bacteria}

\subsubsection{Botryococaus braunii}

Botryococcus braunii (Chlorophyta) is of industrial interest for its ability to produce significant amounts of long-chain hydrocarbons $\left(\mathrm{C}_{30}-\mathrm{C}_{40}\right)$ and exopolysaccharides [72-74]. B. braunii can besubclassified into four races depending on thetypes of hydrocarbons and exopolysaccharides produced $[75,76]$. Another trait of $B$. braunii is that it secretes the majority of hydrocarbons and polysaccharides, facilitating the harvesting of these products. However, wild type strains of $\mathrm{B}$. braunii are slow growers with a productivity of $-0.1-0.2 \mathrm{~g} \mathrm{~L}^{-1} \mathrm{~d}^{-1}[77,78]$.

The majority of B. braunii cultures are not axenic [75, 79], but co-exist with various microbes [80, 81]. Earlier research has reveal ed the presence of Pseudomonas spp. and Flavobacterium spp. among other bacteria in B. braunii cultures [82]. Metagenomic profiling showed that B. brauni i-associated bacteria include representatives of Bradyrhizobium and Methylobacterium (both members of the order Rhizobiales), Dyadobacter, Achrombacter and Asticcacaul is [81]. Furthermore, the addition of selected bacterial species (Rhizobium sp.) to axenic cultures 
resulted in an increase in biomass productivity and hydrocarbon yield of B. braunii [80]. More recent growth experiments indicated that B. braunii Ba10 has a higher biomass (1.8-fold) and hydrocarbon (1.5-fold) yield in the presence of "Candidatus Phycosocius bacilliformis" [83]. However, the precise reasons for this increase remain unknown. Contrasting these reports, Gouveia et al. [84] found that biomass productivity and extracellular carbohydrate production of B. braunii were significantly enhanced after removal of its associated bacteria with UV-C, which indicates that bacteria can al so be antagonistic to microal gae in this respect.

\subsubsection{Nannochloropsis}

Species of the genus Nannochloropsis (Ochrophyta) possess a high ability to produce triacylglycerols under nitrogen limitation. Therefore these oleaginous species are considered promising candidates for biofuel production [85]. Additionally, Nannochloropsis is an important source of the essential $\omega-3$ LC-PUFA eicosapentaenoic acid (EPA; 20:5 5-3), which is an important ingredient in marine aquaculture nutrition [86].

In a small photobi oreactor system bacterial counts were shown to outnumber Nannochl oropsis cell counts by 10- to 100-fold [87]. Investigating Nannochloropsis-associated bacteria received attention because Nannochloropsis is widely used as nutritional source in fish hatcheries, and the bacterial community structure is a key factor affecting the survival of fish larvae [88, 89]. Nakase and Eguchi [90] applied direct viable counts and fluorescence in situ hybridization and reveal ed that the most abundant bacteria in a Nannochloropsis sp. culture were members of the Alphaproteobacteria and the Cytophaga-Flavobacterium cluster. In another bacterial community analysis of largescale cultures of Nannochloropsis salina, the most abundant bacterial taxon was a member of Deltaproteobacteria [91]. In addition, a recent investigation of the bacterial communities in small, mediumand large cultivation setups of Nannochloropsis 
salina showed that more than $70 \%$ of all $16 \mathrm{~S}$ ribosomal RNA gene sequences belonged to Saprospirae, Cytophagia, Flavobacteria and Al phaproteobacteria [69].

In addition to bacterial community profiling of Nannochloropsis cultures, specific bacterial interactions with Nannochloropsis have been found. For example, Nannochloropsis oculata was found to enhance the ability of a member of the Roseobacter clade to inhibit the fish pathogen Vibrio anguillarum [92]. In addition, bacterium HW001 (Pseudomonadales) was shown to cause aggregation of Nannochloropsis oceanica IMET1 cells, which provides a novel approach for the harvest of al gal biomass [87].

\subsection{Research aim and outline of the thesis}

Understanding of interactions between al gae and bacteria is important both for aquatic ecology and for biotechnological purposes as a result of a growing interest in exploiting algae as a biotechnological platform for production of high-val ue molecules. However, knowledge on al gae-associated bacteria is still rather limited, especially in large-scal e cult tivation systems.

The aim of this thesis is therefore to improve our understanding of interactions between microal gæe and bacteria in photobi oreactors in order to improve microal gae cult tivation at the large scale. Here we focussed on bacterial community composition dynamics of two common microalgal species, Botryococcus braunii and Nannochloropsis sp. In addition, this thesis explores how bacterial isolates affect the growth of Nannochloropsis sp., which may have potential biotechnological implications.

Chapter 2 reviews recent research progress on algal-bacterial interactions. We aim to summarize the general trend of bacterial community composition in association with different microalgal species and to understand physiological and molecular mechanisms behind beneficial and adverse algal-bacterial interactions. In addition, we discuss a wide range of examples on how principles of al gal-bacterial interactions can beapplied in al gal biotechnology. 
Chapter 3 investigates the bacterial community of 12 strains of Botryococcus braunii originating from six culture collections. In this chapter we aim to identify the bacterial core community of B. braunii strains. Furthermore, we try to correlate specific bacterial communities to the different races of B. braunii, and discuss the possible roles of the most abundant bacterial species in their interaction with $\mathrm{B}$. braunii.

Chapter 4 compares the bacterial community of Nannochloropsis sp. CCAP211/78 cul tivated in different types of reactors (lab scal e vs pil ot scale, indoor reactors vs outdoor reactors) and bacterial community dynamics during different algal growth stages, and delves into how prevailing environmental/chemical factors correlate to bacterial community composition and abundance.

Chapter $\mathbf{5}$ describes experimental approaches for the isolation of bacteria from two outdoor bioreactors and generation of an axenic culture of Nannochloropsis sp. CCAP211/78. In addition, experiments are designed to screen how Nannochloropsis sp. CCAP211/78 responds to the addition of isol ated bacterial strains in 24-well microplates illuminated by a custom-made LED (light-emitting-diode) box.

Finally, chapter 6 provides a general discussion by summarising thefindings of this PhD thesis and discussing the potential of bacterial-algal co-cultures for further improvement of al gal production and how we can better understand al gal-bacterial interactions by new state of art technology. 



\section{Chapter 2}

The effect of the algal microbiome on industrial production of microalgae

JieLian, Rene H. Wijffels, Hauke Smidt, Detmer Sipkema 


\section{Abstract}

Microbes are ubiquitously distributed and they are also present in algae production systems. The al gal microbiome is a pi votal part of the al ga holobiont and has a key role in modulating al gal populations in nature. However, there is a lack of knowledge on the role of bacteria in artificial systems ranging from laboratory flasks to industrial ponds. Co-existing microorganisms, and predominantly bacteria, are often regarded as contaminants in algal research, but recent studies manifested that many algal symbionts not only promote algal growth but also offer advantages in downstream processing. Because of the high expectations for microalgae in a bio-based economy, better understanding of benefits and risks of algalmicrobial associations are important for the al gae industry. Reducing production cost may be through applying specific bacteria to enhance al gae growth at large scale as well as through preventing the growth of a broad spectrum of al gal pathogens. In this review, we highlight the latest studies of algaemicrobial interactions and their underlying mechanisms, discuss advantages of large scale al gal-bacterial co-cultivation and extend such knowledge to a broad range of bi otechnological applications.

Keywords: microal gae-associated bacteria; al gae-bacteria interaction; co-cultivation; al gal biotechnology 


\subsection{Introduction}

During the last forty years efforts have been undertaken to realize the high potential of al gal products for industrial applications. Algae have been widely recognized for their capacity to produce polysaccharides, lipids, pigments and other val uable compounds in significantamounts [56]. Algae are used for producing heal thy food and food supplements, and as an ingredient in aquaculture, animal feed and as soil bio-fertilizer [93, 94].

Most algae, if not all, live in symbiosis with multiple associated microorganisms throughout their lifespan [47]. In many cases, attempts to remove bacteria or fungi from microal gae have failed. Even in cases where such attempts were successful, microbiota-deprived al gae usually exhibited poorer growth or aberrant phenotypes compared to the original strains, which indicates that the association between algae and other microorganisms is important for their existence [95].

Algae are known to release dissol ved organic matter or signal ling molecules to nurture specific bacterial communities in the phycosphere [96]. Close interactions in the phycosphere influence algal evolution and ecology in various ways. First of all, algae such as the diatoms Phaeodactylumtricornutumand Thalassiasira pseudonana have been shown to have acquired hundreds of genes predicted to be involved in nitrogen and organic carbon utilization, cell wall assembly, DNA recombination and the ornithine-urea cycle from co-occurring bacteria during more than 200 million years [97]. Secondly, bacteria synthesize important compounds for al gal growth stimulation, spore germination, morphogenesis and pathogen resistance [16, 25, 96]. These compounds include micronutrients, siderophores, growth stimulants and antibiotics [46, 98-102]. In addition, symbiotic microorganisms help their al gal hosts to cope with changing environmental conditions [24, 103]. 
On the other hand, many microbes have been reported to negatively affect al gal growth [104, 105] and constitute big constraints for translating laboratory experiments to industrial practice. Unlike conventional microbial fermentation, largescale al gal cultivation is driven by light and mostly operated in fully exposed open ponds for microal gae and in open sea for macroalgae. However, open ponds are more susceptible to biological contaminations, such as viruses, predators/grazers, and parasites of various sources [106]. Therefore, stable production of al gae in open systems is only possible when contaminants and infections are well studied so that monitoring and contingency measures can beimplemented [107].

A part from playing a role in enhancing microal gae production, associated bacteria can help the al gae to performmore complex tasks with di verseapplications. For instance, al gae and bacteria cooperate in faster and more efficient removal of organic and inorganic waste and hazardous substances in wastewater treatment [108-110]. In tum, bacterial and viral pathogens are able to weaken or decompose the al gal cell wall, which is a crucial step in algal-based extraction of chemicals and could al so be explored to tackle frequently occurring harmful al gae bl ooms at an early stage of the bloom[111, 112]. Furthermore, proteins or secondary metabol ites of al gicidal bacteria are potential biological agents in algal biomass harvest and cell disruption prior to biorefinery [113].

The aim of this review is to provide an overview of both beneficial and antagonistic algalmicrobial interactions in natural and artificial systems, as well as to provide new perspectives about how to utilise such knowl edge in al gal biotechnology (Figure2.1). 


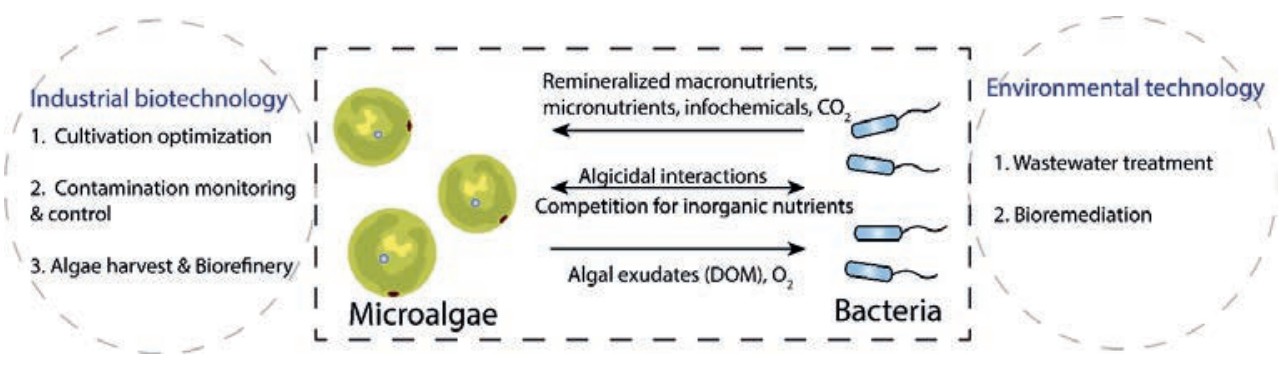

Figure 2.1. Potential applications of algal-bacterial interactions in industrial biotechnology and environmental biotechnol ogy. DOM is dissolved organic matter.

\subsection{Alga-associated bacteria in algae production systems}

Although next generation sequencing (NGS) has led to an explosion of microbial diversity studies in microbial ecology research, only a limited number of studies have been published on NGS-based microbiota anal ysis in the context of microal gal production systems. In fact, most knowledge of al ga-bacteria communities in applied settings come from wastewater treatment studies [114-116]. However, those systems are too different to microal gae production systems due to the presence of high concentrations of organic and inorganic material to expect a large overlap in microbial communities in wastewater treatment systems and algae production facilities. For that reason wastewater treatment with algae-bacteria consortia is treated separately in section 6. The molecular survey of bacterial diversity in three cultures (Nannochloropsis salina from a raceway pond and a closed photobioreactor respectively, and Botryococcus braunii from laboratory flasks) $[69,81,91]$ and one biofilm sample from an outdoor photobioreactor (mixture of Chlorella vulgaris and Scenedesmus obliquus) [117] revealed that Deltaproteobacteria and Gammaproteobacteria in raceway pond and Al phaproteobacteria and Bacteroidetes in closed bioreactor were dominant in N. salina whereas Gammaproteobacteria, Betaproteobacteria and Firmicutes were the most prominent phyla in B. braunii. Alphaproteobacteria, Bacteroidetes, Betaproteobacteria and Gammaproteobacteria made up nearly three quarter of the biofilm bacterial community. Based 
on this limited number of studies, Proteobacteria, and Gammaproteobacteria in particular, are found associated to cul tured microal gae. Cytophagales and Flavobacterial es weretheonly two common bacterial orders among four studies. Several other taxa such as Pseudomonadales, Burkhol deriales, Caul obacterales and Rhodobacterales were shared between either two studies. Our limited knowledge of bacterial communities associated to microalgae that is based on cultivation-independent studies currently prevents general statements about bacteria that are frequently found associated to microalgae, but finding correlations between algae and associated bacteria will be a good starting point for coming up with hypotheses on functional relationships. Therefore, morestudies of bacterial communities found in microal gae bi oreactors are urgently needed to obtain a clearer view on the species and genera that are commonly associated to al gae.

\subsection{Beneficial roles of bacteria}

Although for most of the bacteria detected in microal gae production systems it is not known if/how they interact with themicroal gae, recent observations have demonstrated that mutual istic algal-bacterial interactions are prevalent [2]. Multiple bacteria have been tested in cocultivation to evaluate the effects on the growth of microalgae [104, 118, 119], or more specifically looked at the exchange of metabolites and how bacteria may lead to more robust al gal cultures that can better withstand environmental perturbations.

Table 2.1. Impact of added bacteria on microal gae growth.

\begin{tabular}{|c|c|c|c|c|}
\hline Microalga & Added bacteria & E ffect & $\begin{array}{l}\text { M ethodology to prepare axenic } \\
\text { algae }\end{array}$ & Reference \\
\hline $\begin{array}{l}\text { Chlorella } \\
\text { vulgaris }\end{array}$ & Bacillus pumilus & $\begin{array}{l}\text { Final cell density increased } \\
\text { by } 150 \% \text { in } \mathrm{N} \text {-freemedium }\end{array}$ & Axenic but methor & [28] \\
\hline $\begin{array}{l}\text { Chlorella } \\
\text { vulgaris }\end{array}$ & $\begin{array}{l}\text { Flavobacteriumsp., } \\
\text { Rhizobiumsp., } \\
\text { Hyphomonas sp., } \\
\text { Sphingomonas sp. }\end{array}$ & $\begin{array}{l}\text { Cell density increased by } \\
\text { more than } 100 \%\end{array}$ & $\begin{array}{l}\text { Ultra-sonication, fluorescence } \\
\text { activated cell sorter and micro- } \\
\text { picking }\end{array}$ & [29] \\
\hline $\begin{array}{l}\text { Chlorella } \\
\text { vulgaris }\end{array}$ & Rhizobiumsp. & $\begin{array}{l}\text { Cell count increased } 72 \% \text {, } \\
\text { growth rate increased by } \\
11 \%\end{array}$ & Not axenic & [105] \\
\hline
\end{tabular}




\begin{tabular}{|c|c|c|c|c|}
\hline $\begin{array}{l}\text { Chlorella } \\
\text { vulgaris }\end{array}$ & $\begin{array}{l}\text { Multiple bacteria } \\
\text { from tap water }\end{array}$ & Higher growth rate & Not axenic & [120] \\
\hline $\begin{array}{l}\text { Chlorella } \\
\text { ellipsoidea }\end{array}$ & Brevundimonas sp. & \multicolumn{2}{|c|}{$\begin{array}{l}\text { Algal cell density increased } \\
\text { threetimes after seven days }\end{array}$} & [121] \\
\hline $\begin{array}{l}\text { Chlorella } \\
\text { sorokiniana } \\
\text { IAM C-212 }\end{array}$ & $\begin{array}{l}\text { Microbacterium } \\
\text { trichotecenolyticum }\end{array}$ & \multicolumn{2}{|c|}{$\begin{array}{c}\text { Streptomycin, gentamicin, } \\
\text { Growth rate increased } 16 \% \text { penicillin G, vancomycin and } \\
\text { pimaricin } \\
\text { Ampicillin, }\end{array}$} & [20] \\
\hline \multirow{2}{*}{\multicolumn{2}{|c|}{$\begin{array}{l}\text { Dunaliella sp. } \\
\text { SAG } 19.3\end{array}$}} & Biomass enhanced by $22 \%$, & gentamicin, & \multirow{2}{*}{ [104] } \\
\hline & & $26 \%$ & $\begin{array}{l}\text { kanamycin, } \\
\text { neomycin }\end{array}$ & \\
\hline $\begin{array}{l}\text { Botryococcus } \\
\text { braunii }\end{array}$ & BOTRYCO-2 & $\begin{array}{l}\text { Grow faster and biomass } \\
\text { enhanced by } 80 \%\end{array}$ & Ampicillin & [83] \\
\hline $\begin{array}{l}\text { Lobomonas } \\
\text { rostrata }\end{array}$ & Mesorhizobiumloti & Providing vitamin $B_{12}$ & Axenic but method not mentioned & {$[22]$} \\
\hline $\begin{array}{l}\text { Scrippsiella } \\
\text { trochoidea }\end{array}$ & $\begin{array}{l}\text { Marinobacter sp. } \\
\text { strain DG879 }\end{array}$ & \multicolumn{2}{|c|}{$\begin{array}{l}\text { Cell density increased over Streptomycin } \\
6 \%\end{array}$} & [98] \\
\hline $\begin{array}{l}\text { Thalassiosira } \\
\text { rotula }\end{array}$ & $\begin{array}{l}\text { Roseobacter sp. and } \\
\text { Hyphomonas sp. }\end{array}$ & $\begin{array}{l}\text { Earlier start of growth, } \\
\text { higher al gal cell numbers }\end{array}$ & Axenic but method not mentioned & [122] \\
\hline \multicolumn{4}{|c|}{$\begin{array}{l}\text { Phaeodactylu Al phaproteobacteriq Cell density increased up to } \text { Axenic but method not mentioned } \\
\text { mtricornutum sp. strain } 29 \quad 55 \% \\
\begin{array}{ll}\text { Utex } 646 & 5\end{array}\end{array}$} & [123] \\
\hline
\end{tabular}

\subsubsection{Alga-associated bacteria that enhance algal growth}

Using either axenic or non-axenic algal cultures, a number of different bacteria ranging from specific isolates to microbial communities present in tap water have been eval uated for their effects on microal gæe growth (Table 2.1). The best studied al gae with respect to associated bacteria are members of the genus Chlorella (Table 2.1). Bacteria that have been shown to be beneficial to Chlorella vulgaris include members of the genera Bacillus, Flavobacterium Rhizobium Hyphomonas and Sphingomonas. Bacillus pumilus ES4 was shown to promote Chlorella vulgaris growth by providing fixed atmospheric nitrogen [28]. In another study when Chlorella vul garis was cultivated with four different bacteria, maximum al gal growth rate and final cell mass increased from 0.22 day ${ }^{-1}$ to 0.47 day $^{-1}$ and from $1.3 \mathrm{~g} / \mathrm{L}$ to $3.31 \mathrm{~g} / \mathrm{L}$, respectively (Table 2.1). This increased growth was furthermore accompanied by a slight rise in al gal lipid content from $22.4 \%$ to $28 \%$ [29]. 
Si milar to Chl orella, al so for other green al gae, such as thosebel onging to thegenera Dunaliella, Botryococcus and Lobomonas beneficial effects were observed when adding specific bacterial partners to axenic cultures (Table 2.1). Biomass accumulation of Botryococcus braunii was al most doubled compared with that of axenic cultures [83]. Similarly, biomass production of Dunaliella sp. SAG 19.3 increased by $22 \%$ and $26 \%$ when co-cul tivated with Alteromonas sp. or Muricauda sp., respectively [104]. Furthermore, it could be shown that the vitamin $B_{12}$ synthesizing bacterium Mesorhizobium loti is indispensable for the survival of Lobomonas rostrata under conditions wheretheal ga is cul tivated without exogenous vitamin $B_{12}$ [22]. Two diatoms and one dinoflagellate were all observed to benefit from co-existing bacteria (Table 2.1), as indicated by ei ther higher cell numbers or a faster growth rate of theal gae. The strongest stimulation of growth was reported for Phaeodactylum tricornutum in the presence of the Al phaproteobacteriumstrain 29, as demonstrated by a 55\% rise in cell density [123].

\subsubsection{M icrobial associated salinity acclimation and thermal tolerance}

Sal inity is the maj or environmental factor that determines the distribution and performance of marine al gae [124, 125]. Interestingly, in addition to their more direct ecophysiological roles, bacteria can also present a gene reservoir for al gal evolution towards adaptation to different environmental conditions via horizontal gene transfer. The green alga Picochlorum sp. SENEW3 has a wide salt tolerance from at least $0.35 \%$ to $10.8 \%$ [126]. Compared to its less hal otolerant sisters, the genome of the salt-tolerant strain was found to contain a suite of additional functional genes, twenty-four of which were derived from bacterial sources and were functional in responseto salt stress [127]. Although not a microal ga, it is interesting to notethat the transition of the brown macroal ga Ectocarpus sp. strain 371 from seawater to freshwater medium greatly depended on the associated bacterial community. Strain 371 is a small filamentous brown al ga with broad range salinity tolerance that is mediated by adjusting cel wall structureand metabolism[128-130]. Cultures deprived of associated microbes were unable 
to survivea sali inity change, whil ethis capability coul d berestored by restoring their microbiota [103].

Temperature is another important factor affecting growth and survival of algae [124]. This is relevantas industrially grown al gal strains in shall ow production ponds or flat panel bioreactors are exposed to considerable temperature fluctuations. The unicellular microalga Chlamydomanas reinhardtii grows best at a temperature between $20-32{ }^{\circ} \mathrm{C}$ [131]. The direct transfer of $\mathrm{C}$. reinhardtii from an optimum $\left(25^{\circ} \mathrm{C}\right)$ to a rather high temperature $\left(45^{\circ} \mathrm{C}\right)$ results in chlorosis and cell death, which are caused by the repression of cobalamin-independent methionine synthaseduring heat stress. Through adding exogenous cobalamin or co-cultures of theal ga with a cobal amin-producing bacterium (Sinorhizobi ummeli lot ), cobal amin-dependent methionine synthase mediated methionine biosynthesis could be reactivated, thereby preventing death of algal cell [24].

Hence, a better understanding of adaptation and acclimation of both host and microbial symbionts to environmental changes may provide leads to improve robustness of large-scale cultivation of algae where environmental conditions cannot be as tightly controlled as in laboratory-based experiments.

\subsubsection{Nutrient provision}

Algae mainly need $\mathrm{CO}_{2}$ and inorganic sources of nitrogen and phosphatefor growth al ong with some micronutrients and cofactors [132]. Since fertilizer-grade nutrient input accounts for a major proportion of cost in algal cultivation, recycling or provision of these nutrients via bacteria may eventually make large-scale al gal biomass production more economically viable [133].

\subsubsection{M acro-nutrients}


$\mathrm{CO}_{2}$ is often the limiting substrate in large-scal e al gal ponds because gas transfer efficiency is limited from ambient air [134]. The main strategy to boost low $\mathrm{CO}_{2}$ concentrations in algal cultures is to use $\mathrm{CO}_{2}$-enriched gases, but additional supply of $\mathrm{CO}_{2}$ comes with a significant cost [133]. Bacterial degradation of organic compounds released by algae contributes an additional source of $\mathrm{CO}_{2}$ for al gal growth, especially during $\mathrm{CO}_{2}$ limiting conditions as this $\mathrm{CO}_{2}$ can be fixed again by algae $[135,136]$. This is exemplified with the case of a Chlorella sp. where carbon limitation was overcome when heterotrophic bacteriafrom a domestic wastewater treatment reactor were added to the al gae cul ture and increased productivity of al gal biomass by respectively 4.8 and 3.4 fold in two independent experiments [137].

Nitrogen fixing bacteria reduceatmospheric dinitrogen to ammoni um that is the maj or preferred nitrogen source for al gae growth [132]. For example, Bacillus pumilus ES4 is a plant-growth promoting bacterium that fixes nitrogen to enhance growth of Chlorella vulgaris [28]. Symbiotic nitrogen fixers are also present in coral holobionts, where they co-occur with Symbiodinium that is the most commonly coral-associated di noflagel late genus [138]. Studies have revealed a strong positive correlation between the cell density of Symbiodiniumand the number of nitrogen fixation gene copies from nitrogen-fixing bacteria, which partly demonstrate how corals and their dinoflagellate partners could survive in low-nutrient conditions [139]. The filamentous cyanobacteria Richelia intracellularis and Calothrix rhizosoleniae are close partners with diatoms living in the oligotrophic open ocean [140]. Higher growth rates were observed for diatoms with cyanobacteria as compared to diatoms without their nitrogen-fixing cyanobacterial partners. Moreover, using single cell resolution analyses it was shown that the $\mathrm{N}_{2}$ fixation rates of cyanobacteria increased by $171-420$ fold in symbiotic heterocystous cells associated with the corresponding diatoms as compared to freliving cyanobacteria [141]. 
Phosphorus is an essential nutrient for al gal growth. In most cases algae can only take up inorganic phosphorus $\left(\mathrm{P}_{\mathrm{i}}\right)$ derived from hydrolysis of organic phosphorus $\left(\mathrm{P}_{\mathrm{o}}\right)$ [142]. Bacteria are the main agents involved in decomposing and mineralizing Po through the secretion of phosphatases [143], and Po from deteriorating al gal cells can then be recycled to optimiseal gal yield on phosphate added. This process has been shown to occur with Gordonia sp. txj1302RI and Burkholderia sp. txj1302Y 4, which degraded dissolved $P_{0}$ to provide Microcystis aerugi nosa with $P_{i}$ needed for its growth in eutrophic lakes with abundant $P_{0}$ but limited $P_{i}$ [144].

\subsubsection{Vitamins, phytohormones, iron-siderophore and antibiotics}

Bacteria are not only capable of minimizing the requirement for external $\mathrm{CO}_{2}$ and major essential nutrients (N, P) for al gae cultivation through regeneration or fixation [139], but al so provideal gal hosts with vitamins [22, 26], phytohormones [16, 96, 145, 146], siderophores [98] and antibiotics [147]. The heterotrophic bacterium Dinoroseobacter shibae DFL12 ${ }^{\top}$ has been demonstrated to provide growth-limiting vitamins $B_{1}$ and $B_{12}$ to its di noflagel late host. Based on a survey of 326 al gal species, it was shown that vitamin $B_{12}$ is required by more than half of the al gal species [26]. Epi phytic bacteria on seaweed (Bacteroidetes strain Y M2-23) produce the compound thallusin, which is essential for inducing growth, development and morphogenesis of Monostroma oxyspermumand other Ulva species [148, 149]. Sulfitobacter sp. SA11 promotes diatom cell division via synthesis of the hormone indole-3-acetic acid [16]. A Marinobacter sp. that lives in close association with Scrippsiella trochoidea is able to produce an unusual siderophore that promotes algal assimilation of iron [98]. The marine bacterium Phaeobacter gallaeciensis produces growth hormones (phenylacetic acid) and a broad spectrum antibiotic (tropodithietic acid) against pathogenic bacteria while the algal host (Emiliania huxleyi) provides fixed carbon in exchange [46]. 
Growing a particul ar strain of microal gae in an appropriate medi um or adjusting media recipes for different al gal growth-stages remains a complicated task. In practice, most investigators tend to use a medium that works for their al gae, but might not necessarily be the best one[150]. Understanding the symbi osis between microal gae and bacteria could lead to identification of missing medium components that could possibly be provided by co-cultivation with bacteria.

\subsection{Harmful microbes in algal mass culture}

One of the major risks of large-scale intensive al gae production is the emergence of viruses, parasites and bacterial pathogens [151]. Despitecurrent advances in long-termal gae cull tivation systems and farm management, it is neither cost-effective nor achievable to completely avoid undesired contaminants at industrial scale [48]. An increasing number of pathogens and parasites have been discovered in recent years, and undoubtedly, this number will continue to grow as investment increases in al gal farming [152, 153].

As with terrestrial plants, al gaeare susceptibleto infection by a wide range of viruses, bacteria, protists and fungi (Figure2.2)[106]. Oceanic al gae are likely living with a multitude of viruses, however, only few al gal viruses havebeen reported and characterized so far [154]. For example, the large doublestranded DNA coccolithovirus (EhV, Phycodnaviridae) is able to terminate Emiliania huxleyi blooms [111, 154, 155]. Algae are al so adversel y affected by a wide range of bacteria, however, underlying mechanisms remain underexplored. Algae-associated bacteria bel onging to the families Rhodobacteraceae, Saprospiraceae and Flavobacteriaceaehave been implicated in bleaching of the seaweed Delisea pulchra [156]. Gram negative bacteria such as members of the genera Alteromnas, Cytophaga, Flavobacterium Pseudomonas, Saprospira, Vibrio and Pseudoalteromonas are mainly responsible for rot symptoms [157] and galls on seaweeds [158]. Furthermore, Microbacteriumsp. LB1 was shown to be responsible for al gal 
cell lysis and damaged laboratory cultures of the green al ga Choricistis minor, leading to dry weight reduction of $34 \%$ after $120 \mathrm{~h}$ of cultivation [32].

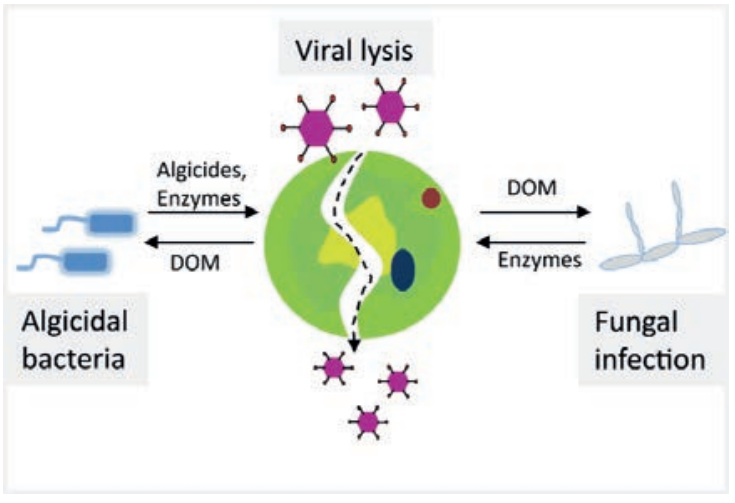

Figure 2.2. Illustration of antagonistic interactions between microal gae and microbes. DOM is dissolved organic matter.

Eukaryotic pathogens are prevalent but poorly understood, mostly because the strategies for detection, isolation and cultivation remain problematic [159]. A newly isolated al gaelytic protist, Pseudobodo sp. KD51 the 18S rRNA gene of which shares 99\% similarity with that of Pseudobodo tremulans, was shown to cause more than $50 \%$ decrease in chlorophyll content of Chlorella vulgaris after inoculation within three days. In addition to inhibition of Chlorella vulgaris, Pseudobodo sp. KD51 displayed a wide predatory spectrum and negatively affected the growth of Dunaliela salina, Platymonas subcordiformis and the cyanobacterium Microcystis aeruginosa [112]. Rotifer grazers and ciliates prey on algal cells and can greatly decrease al gal cell densities $[160,161]$. Fungi are known to parasitize microal gæe and often caused lethal epidemics in al gal cultures in which infection rates can reach 100\% [152]. So far, chytrid fungi have been reported to infect microalgae cultures of Scenedesmus [162], Chlamydomonas [163] and Haematococcus pl uvialis [152].

\subsubsection{Identification and monitoring}


Algal biomass losses due to contaminants such as chytrid parasites can be rapid [162]. Therefore, fast and cost-effectivemethods to identify and control potential ly harmful organisms in al gal production systems are necessary. However, microbial community composition inal gal cultures is complex and dynamic. The composition may vary with location, cultivation cycle stage or method and season [162]. Owing to the development of next generation sequencing methods, microbial identification can be carried out in a faster and less labour intensive way [164] and had been shown to effectively identify specific contaminants in al gae cultivation reactors [165] or toxic algal species [166]. When pond or photobioreactor performance is abnormal, a retrospective analysis of the archived samples could reveal harmful contaminants and inappropriate operation strategies. Knowledge from long-term operation allows for identifying the most common and prevalent contaminants and this also gives operators predictive ability to some extent [106]. Systematic analysis and characterization of contaminants can be used for the devel opment of specific probes, primers or other biomarkers for rapid monitoring of algae production systems. For instance, before initiating largescale al gae production, bacteriain al gal inoculation stocks and the surrounding environments (water, soil, etc.) of the al gae farm should be assayed for the presence of biological risks. A specific microbial pathogen library can be established and molecular tools can then be used to track harmful organisms of interest, and improving cultivation management.

\subsubsection{Contamination and disease control}

There is an increasing focus on preventing contamination to decrease major productivity losses in established systems [167]. Early detection and quantification of contaminants of algal cultures enables a fast response to infections. To protect al gal cells from various contaminants, conventional methods such as physical filtration [106], applying decreased or elevated pH and temperatures [168] and chemical agents [169] are neither effective nor economical in al gal industry, and hence new and efficient methods to combat contaminations are urgently needed. 
Phaeobacter inhibens reciprocally exchanges beneficial molecules with the microalga Emiliania huxleyi. Among these molecules is the antibiotic tropodithietic acid thought to kill other bacteria [170]. In addition, a large screening of microbes indigenous to al gae-cul tivation systems has led to the discovery of an anti-fungal protein produced by the bacterium Streptomyces sp. strain AP77. This protein has been used to cure red rot disease of Porphyra spp. seaweeds caused by Pythium porphyrae [171]. Hence it is proposed that bacterial metabolites or bacteria that produce antimicrobial compounds could be supplied to bulk al gal cultures in order to cost-effectively achieve more robust cultures that are less prone to harmful invaders.

\subsection{Downstream processing of algal biomass using symbionts}

Traditional mechanical or chemical pretreatment methods that are used to harvest algal biomass and disrupt al gal cells requi rea large energy input and are cost intensive[172]. To this end, al gae-associated microbes offer several new altematives for microal gae harvest and cell wall disruption.

Harvesting al gal biomass is one of most important economic factors in producing compounds with microal gae [151]. Harvesting al gal cells is different from harvesting seeds of oil-bearing plants, and oil extraction processes based on dry al gal biomass are unlikely to be economical because of the high energy inputs needed to obtain dry al gal biomass [151, 173]. Currently, up to $50 \%$ of total cost of biodiesel production is spent on havesting because of the high energy input and/or the addition of expensive chemicals. Energy-intensive processes such as centrifugation are possible for high-val ue products but are too costly for biofuel applications. In addition, other methods such as extensive use of chemical flocculants can be applied to aid in the harvesting process, but could only be cost effective when the requi red amount is small 
[151]. Therefore, development of economic and high efficiency harvesting techniques is important for al ga bulk products, such as biofuels [174].

Bacteria can play an important role in microal gae aggregation [175, 176]. Diatom-attached bacteria are capable of increasing diatom aggregate formation leading to the settling of photosynthetically active Thalassiosi ra weissflogii, while freeliving bacteria are not invol ved in this process [177]. In another study, mass cul tures of Nannochl oropsis were observed to form aggregates that consisted of algal cells, bacteria and debris that together resulted in a complex structure [178]. Wang et al. isolated a novel bacterium HW001 from Permian groundwater and demonstrated that this strain is able to stimulate aggregation of both Nannochloropsis oceanica IMET1 and other potential biofuel-producing green microal gae, diatoms and cyanobacteria[87]. In addition, two potent bioflocculants have been discovered from culture supematant of Burkholderia cepacia [179] and Bacillus licheni formis CGMCC 2876 [180]. High flocculation efficiency of Desmodesmus brasiliensis ( $>98 \%$ ) was achieved at pilot-scale treatment with poly- $\gamma$-glutamic acid, a biofloccul ant produced by Bacillus licheniformis CGMCC 2876 [179].

Besides bacteria, a number of filamentous fungal strains have also been reported to promote flocculation of microalgae [181-183]. Muradov et al. tested the fungal species (Aspergillus fumigatus) in co-culture with freshwater and seawater algal species and showed up to $90 \%$ flocculation after $24 \mathrm{~h}$ of cultivation, while no aggregates were formed in the absence of the fungus. Furthermore, algal-fungal co-pelletization improved oil extraction efficiency because fungal secreted hydrolytic enzymes disnupted the thick cell walls of Tetrasel mis suecica [184]. The same was seen between Aspergillus lentul us FJ 172995 and Chroococcus sp., where al gal and fungal cells formed a pellet, and nearly $100 \%$ of biomass settled down within $6 \mathrm{~h}$ at an optimized fungal/al gal ratio of 1:3 [185].

\subsection{Algae-bacteria based wastewater treatment}


High biomass production costs obstruct the economic feasibility and competitiveness of al gal biofuels [186]. The application of a combination of al gae cultivation and wastewater treatment could provide a win-win solution to this problem [151, 187]. Wastewater from municipal sources, pig production, aquacul ture and dairy cattlefarming is rich in nutrients such as nitrates, ammonia and phosphates, which can be used for al gae cultivation [132]. Mixed al gal-bacterial populations in wastewater can not only perform more diverse tasks than single strains but are also better equipped to tolerate environmental fluctuations and pathogen invasions [136]. Moreover, the combination of algae and bacteria improves water treatment efficiency, and simultaneously the harvested al gal biomass as by-product has been considered a promising sourcefor feeds, biofuels and fertilizer [187, 188].

\subsubsection{Carbon, nitrogen and phosphate removal}

Algae produce oxygen during photosynthesis that is used by bacteria to mineralize organic matter [189]. Carbon dioxide released by bacteria during mineral ization can in turn be utilised by algae [190]. Concurrently, abundant compounds in wastewater, such as ammonium and phosphate are el iminated by al gal uptake [191]. Su et al. noted that the synergistic cooperation between photosynthetic organisms, including al gæe and cyanobacteria, and activated sludge bacteria enhanced organic carbon removal efficiencies [108]. More than $91.2 \%$ of chemical oxygen demand was removed, and thehighest total nitrogen and phosphorus removal rates were $91.0 \pm 7.0 \%$ and $93.5 \pm 2.5 \%$, respectively. Chlorella sorokiniana [192] and Euglena viridis [193] were also shown to enhance removal of carbon, nitrogen and phosphorous from piggery waste water when mixed with bacteria fromactivated sludge.

\subsubsection{Removal of heavy metals and toxic organic compounds}

In addition to enhanced removal of excessive nutrients, al gal-bacterial consortia were also shown to be capable of removing heavy metals and toxic organic compounds from wastewater 
[190]. Algal cel ls not only providestable habitats for the bacteria but al so concentrate pol lutants to enhance bioavailability for bacterial degradation [194]. Algal-bacterial consortia successfully achieved higher biodegradation or removal rates of pollutants than single species [109].

Heavy metals belong to an important group of contaminants that pose global environmental risks [195]. Co-cultures of bacteria and al gae were capable of removing $80 \%$ of the copper and $100 \%$ of the cadmiumfrom wastewater in a continuous flow-through column [136]. In addition, a biofilm with immobilised algae (Ulothrix sp.) and bacteria in a photo-rotating biological contactor removed $20-50 \%$ of a large variety of metals ( $\mathrm{Cu}>\mathrm{Ni}>\mathrm{Mn}>\mathrm{Zn}>\mathrm{Sb}>\mathrm{Se}>\mathrm{Co}>\mathrm{Al}$ ) within a ten-week period [196].

Polycyclic aromatic hydrocarbons are ubiquitous pollutants in various niches that might cast high risks on human and animal health [197]. A co-culture of the al ga Chl orella sorokiniana and Pseudomonas migulae demonstrated higher phenanthrene degradation rates than most of the values reported in literature [198]. Luo et al established a consortium consisting of microal gæe (Selenastrumcapricornutum) and a bacterium (Mycobacteriumsp. strain A1-PYR) that achieved faster degradation of pyrene than the systems that used al gae or bacteria al one [109]. The same result was obtai ned by a synthetic consortium combining Synechocystis sp. and pyrene-degrading bacteria (Pseudomonas sp. and Bacillus sp.). The combination increased both al gal growth and degradation of the polycyclic aromatic hydrocarbon [199].

Given the abovementioned advantages, integration of al gae and bacteria has a large potential for wastewater treatment, especially under aerobic conditions. Oxygen produced by al gae in the system can reduce the aeration demand in conventional activated sludge systems, which accounts for nearly $50 \%$ of the total energy input of thewater treatment plants [200]. In addition, 
removing nutrients from wastewater with a combination of al gae and bacteria can increase the removal efficiency, system robustness and application potential of the sludge.

\subsection{Outlook}

Unravelling the complex biological mechanisms of algal-microbial interactions represents a largely understudied real $m$ to improve production of high-value products and bi ofuels through largescale cultivation of microal gae. Protective bacteria could inhibit growth of bacterial or fungal contaminants, which cause fouling or negatively affect al gal growth. Macro fertilizers and expensivemicronutrients supplied by bacterial metabolismcan reducetheneed for external input. Some bacteria are able to enhance synthesis of desired al gal metabolites, for instance, lipids. However, currently our knowledge on algae bacteria interactions is too scattered to identify generalities with respect to bacterial species that are suitable for co-culture with microal gae. Alga species-specific knowledge would logically be first developed for industrial working horse species, such as Arthrospira spp., Chlorella spp., Scenedesmus spp., Nannochloropsis spp. and Botryococcus spp.[201]. In addition, the desired microbial community in al gae cultures may depend on the required product specifications (bi ofuel, feed and food, finechemicals) and harvesting methods applied. 


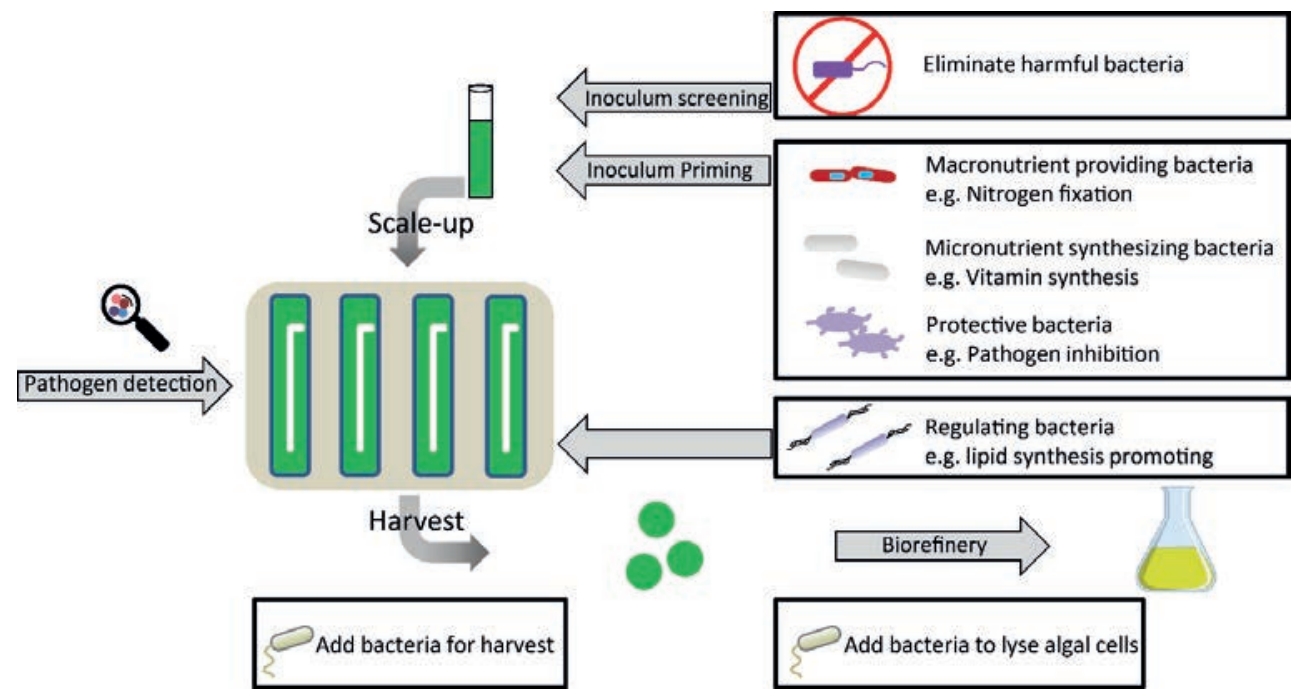

Figure 2.3. Potential integration strategies for including microbial community management into photobioreactor operations.

Further insights into evolution and establishment of mutualistic interactions allow for devel oping more resilient synthetic co-cultures (Figure. 2.3). Real time monitoring techniques are important to maintain stable and healthy mixed cultures in outdoor ponds exposed to changing weather and ubiquitous invaders. The main challenges for the application of bacteria in al gal cultivation are to steer the bacterial community to its desired composition and how to maintain this balance during different modes of operation, different reactor types and fluctuations in outdoor conditions. The establishment and maintenance of optimized al gaebacterial co-cultures may requi re bioreactor operation management strategies that are extended beyond the performance of microal gae in the system, but consider and value the community present as a whole. 


\title{
Chapter 3
}

\author{
A ssociated bacteria of Botryococaus braunii (C hlorophyta) \\ Joao D. Gouveia, J ie Lian, Georg Steinert, HaukeSmidt, Detmer Sipkema, Rene \\ H. Wijffels, MariaJ . Barbosa
}

Published in PeerJ 


\section{Abstract}

Botryococcus braunii (Chl orophyta) is a green microal ga known for producing hydrocarbons and exopolysaccharides. Improving the biomass productivity of B. braunii and hence, the productivity of the hydrocarbons and of the exopolysaccharides, will make B. braunii more attractive for industries. Microal gae usually cohabit with bacteria which leads to the formation of species-specific communities with environmental and biological advantages. Bacteria have been found and identified with a few B. braunii strains, but little is known about the bacterial community across the different strains. A better knowledge of the bacterial community of B. braunii will help to optimize the biomass productivity, hydrocarbons and exopolysaccharide accumulation. To better understand the bacterial community diversity of B. braunii, we screened 12 strains from culture collections. Using 16S rRNA gene analysis by MiSeq we described the bacterial diversity across twelveB. braunii strains and identified possibleshared communities. We found three bacterial families common to all strains: Rhizobiaceae, Bradyrhizobiaceae and Comamonadaceae. Additionally, the results also suggest that each strain has its own specific bacteria that may be the result of long-term isolated culture.

Keywords: Botryococcus braunii; associated bacteria; al gal-bacterial interactions; 16S rRNA sequencing 


\subsection{Introduction}

In recent decades many studies have focused on the physiology and cultivation process of several microalgae with potential for large scale production [202-206]. One microalga of interest for large scale cultivation is B. braunii because it can produce and secrete long chain hydrocarbons and exopolysaccharides (EPS) $[73,75,79]$. Hydrocarbons arenatural ly occurring compounds consisting entirely of hydrogen and carbon, and are one of the most important energy resources [207]. B. braunii is differentiated into different races (race A, B, L and S) depending on the type of hydrocarbons secreted $[75,76]$. Race A strains synthesize oddnumbered alkadienes and trienes ( $C_{25}$ to $C_{31}$ ), race $B$ strains synthesize isoprenoid type compounds termed botryococcenes ( $C_{30}$ to $C_{37}$ ), and methylated squal enes ( $C_{31}$ to $\left.C_{34}\right)$, race $L$ strains synthesize lycopadiene $\left(\mathrm{C}_{40}\right)$, and race $S$ strains synthesize $\mathrm{C}_{18}$ epoxy-n-al kanes and $\mathrm{C}_{20}$ saturated n-al kanes [75-77, 79]. EPS can have a range of applications, for example it can be applied as stabilisers and gelling agents in food products. In addition, it has applications in the pharmaceutical and cosmeceutical industries [208-210]. B. braunii comprises of a variety of strains from diverse parts of the world. The strains can differ in the hydrocarbon and exopolysaccharide content $[72,74,77,79,211-214]$.

Bacteria can grow in close proximity to the microalgal cells due to the presence of EPS substances secreted by the microal gae [15]. The presence of bacteria within, or close to this EPS layer can lead to mutually beneficial interactions as well as interactions that are antagonistic in nature Beneficial interactions for microal gae normally provide environmental advantages, such as nutrient exchange and community resilience to invasion by other species [215-218]. Antagonistic interactions will usually result in inhibition of the microal gal growth, either causing cell lysis, or directly competing for nutrients [48, 146, 219]. Studies investigating interactions of microal gae with bacteria show how important these interactions can be for the cultivation process $[27,105,220,221]$. Understanding the interactions of microalgae and 
bacteria, and how it can enhance the cultivation for industrial process, could lead to increased biomass productivity.

So far the bacterial community of B. braunii species is described in only a few studies. The earliest work is from Chirac and colleagues who described the presence of Pseudomonas sp. and Flavobacteriumsp. in two strains of B. braunii [222]. Rivas and colleagues identified in theB. braunii UTEX strain the presence of Pseudomonas sp. and Rhizobiumsp. [80]. Onestudy using the B. braunii Bal0 strain showed the presence of rod shaped bacteria in the rim of the colony aggregations and proposed it is as growth promoting bacteria closely related to Hyphomonadaceae spp. [83]. One important finding was that B. braunii is a vitamin $B_{12}$ autotroph, so it does not depend on bacteria for the synthesis of this important metabolite[223]. A more recent study using a B. braunii (race B) strain, revealed the presence of several Rhizobiales such as Bradyrhizobium and the presence of Bacteroidetes sp [81]. So far, all studies have focused on only a few strains making it difficult to have a good overview of what bacterial community dominates $\mathrm{B}$. braunii.

In this study we looked at twel vestrains of B. braunii obtained from several culturecollections to investigate the bacterial community composition that is associated with B. braunii.

\subsection{M aterials and methods}

\subsubsection{Strain collections and media preparation}

Twelve B. braunii strains were obtained from culture collections (Table 3.1) and transferred to Erlenmeyer flasks with modified Chu 13 medium [224] without citric acid or vitamins, with the following composition: $1200 \mathrm{mg} \mathrm{L}^{-1} \mathrm{KNO}_{3}, 200 \mathrm{mg} \mathrm{L}^{-1} \mathrm{MgSO}_{4} .2 \mathrm{H}_{2} \mathrm{O}, 108 \mathrm{mg} \mathrm{L}^{-1} \mathrm{CaCl}_{2} .2 \mathrm{H}_{2} \mathrm{O}$, $104.8 \mathrm{mg} \mathrm{L}^{-1} \mathrm{~K}_{2} \mathrm{HPO}_{4}, 20 \mathrm{mg} \mathrm{L}^{-1} \mathrm{FeNa}{ }_{2} \mathrm{EDTA}, 9.4 \mu \mathrm{g} \mathrm{L}^{-1} \mathrm{Na}_{2} \mathrm{O}_{4} \mathrm{Se}, 2.86 \mathrm{mg} \mathrm{L}^{-1} \mathrm{H}_{3} \mathrm{BO}_{3}, 1.8$ $\mathrm{mg} \mathrm{L}^{-1} \mathrm{MnSO}_{4} .4 \mathrm{H}_{2} \mathrm{O}, 220 \mu \mathrm{gL}^{-1} \mathrm{ZnSO}_{4} .7 \mathrm{H}_{2} \mathrm{O}, 90 \mu \mathrm{g} \mathrm{L}^{-1} \mathrm{CoSO}_{4} .7 \mathrm{H}_{2} \mathrm{O}, 80 \mu \mathrm{gL}^{-1} \mathrm{CuSO}_{4} .5 \mathrm{H}_{2} \mathrm{O}$, $60 \mu \mathrm{L} \mathrm{L}^{-1} \mathrm{Na}_{2} \mathrm{MoO}_{4} .2 \mathrm{H}_{2} \mathrm{O}, 10 \mu \mathrm{LL}^{-1} \mathrm{H}_{2} \mathrm{SO}_{4}$. The final pH was adjusted to $\mathrm{pH} 7.2$ with $\mathrm{NaOH}$ 
and $\mathrm{NaHCO}_{3}$ was added to a final concentration of $5 \mathrm{mM}$. The 12 strains were grown in Infors HT Multriton incubators in $250 \mathrm{~mL}$ conical flasks and a volume of $150 \mathrm{~mL}$. The temperature was set at $23^{\circ} \mathrm{C}$, with $2.5 \% \mathrm{CO}_{2}$ enriched air and shaking at $90 \mathrm{rpm}$ Illumination was provided by Phillips lamps FL-Tube L 36W/77, with $150 \mu \mathrm{mol}$ photon $\mathrm{m}^{2} \mathrm{sec}^{-1}$, and a light:dark photoperiod of 18:6 h. Flasks were inoculated with B. braunii growing in the active growing phase, such that the initial absorbance at $680 \mathrm{~nm}$ was 0.2 . The Erlenmeyer flasks were capped with aeraseal sterile film (Alphalabs). Samples were taken at day 1, 4, 8 and 11, for 165 rRNA gene analyses.

Table 3.1. Information of the culture collections providers of Botryococcus braunii strains and location of origin.

\begin{tabular}{|c|c|c|c|c|c|}
\hline Culture collection & $\begin{array}{l}\text { Botyococaus braunii } \\
\text { Strain (our } \\
\text { abbreviation) }\end{array}$ & Race & L ocation & $\begin{array}{l}\text { I solation, date of } \\
\text { isolation }\end{array}$ & f $\mathbf{R}$ eference \\
\hline Berkeley & Showa & Race B & $\begin{array}{l}\text { culturing tanks, } \\
\text { Berkley }\end{array}$ & $\begin{array}{l}\text { by unknown, } \\
1980\end{array}$ & [225] \\
\hline $\begin{array}{l}\text { Scandinavian Culture } \\
\text { Collection of Algae } \\
\text { and Protozoa (SCCAP) }\end{array}$ & K1489 & Race A & Belgium, Nieuwoort & $\begin{array}{l}\text { by G. Hansen, } \\
2008\end{array}$ & No reference \\
\hline $\begin{array}{l}\text { UTEX Culture } \\
\text { Collection of Algae }\end{array}$ & UTEX LB572 (UTEX) & Race A & Cambridge, England & $\begin{array}{l}\text { by M. R. Droop, } \\
1950\end{array}$ & {$[77]$} \\
\hline $\begin{array}{l}\text { Culture Collection of } \\
\text { Autotrophic } \\
\text { Organisms (CCALA) } \\
\text { check }\end{array}$ & CCALA778 (CCALA) & unknown & $\begin{array}{l}\text { Serra da Estrela } \\
\text { (Barragem da Erva da } \\
\text { Fome) Portugal }\end{array}$ & by Santos, 1997 & No reference \\
\hline \multirow[t]{4}{*}{$\begin{array}{l}\text { Culture Collection of } \\
\text { Algae and Protozoa } \\
\text { (CCAP) }\end{array}$} & CCAP807/2 (CCAP) & Race A & $\begin{array}{l}\text { Grasmere, Cumbria, } \\
\text { England }\end{array}$ & $\begin{array}{l}\text { by J aworski, } \\
1984\end{array}$ & [226] \\
\hline & AC755 & Race A & $\begin{array}{l}\text { Lingoult-Morvan, } \\
\text { France }\end{array}$ & $\begin{array}{l}\text { by Pierre } \\
\text { Metzger, } 1981\end{array}$ & [227] \\
\hline & AC759 & Race B & Ayame, Ivory Coast & $\begin{array}{l}\text { by Pierre } \\
\text { Metzger, } 1984\end{array}$ & [212] \\
\hline & AC760 & Race B & Kossou, Ivory Coast & $\begin{array}{l}\text { by Pierre } \\
\text { Metzger, } 1984\end{array}$ & {$[212]$} \\
\hline \multirow[t]{4}{*}{ ALGOBANK-CAEN } & AC761 & Race B & $\begin{array}{l}\text { Paquemar, Martinique, } \\
\text { France }\end{array}$ & $\begin{array}{l}\text { by Pierre } \\
\text { Metzger, } 1983\end{array}$ & {$[227]$} \\
\hline & AC765 & Race L & Kossou, I vory Coast & $\begin{array}{l}\text { by Pierre } \\
\text { Metzger, } 1984\end{array}$ & [212] \\
\hline & AC767 & Racel & $\begin{array}{l}\text { Songkla Nakarin, } \\
\text { Thailand }\end{array}$ & $\begin{array}{l}\text { by Piere } \\
\text { Metzger, } 1985\end{array}$ & [228] \\
\hline & AC768 & Race L & $\begin{array}{l}\text { Yamoussoukro, Ivory } \\
\text { Coast }\end{array}$ & $\begin{array}{l}\text { by Pierre } \\
\text { Metzger, } 1984\end{array}$ & [228] \\
\hline
\end{tabular}




\subsubsection{DNA extraction}

On sampling days, $5 \mathrm{~mL}$ of fresh culture was harvested with sterilized membrane filters ( 0.2 $\mu \mathrm{m}$, Millipore) using a vacuum apparatus. The filters were cryopreserved in $-80^{\circ} \mathrm{C}$ until further processing. DNA was extracted from the cryopreserved filters that were cut into small pieces with a sterilescissor. Filter pieces were transferred to a $2 \mathrm{~mL}$ sterilized tube with zirconia/silica beads (Biospecs), and $1 \mathrm{~mL}$ S.T.A.R buffer (Roche, USA) was added. Cells werehomogenized for two rounds of 45 seconds, at the speed of 5500 rpm with Precellys (Bertin Technol ogies). Then DNA was extracted using the Maxwell 16 Tissue LEV Total RNA purification kit (Promega, USA) with aid of the Maxwell 16 instrument (Promega, USA). The purity and quantity of DNA was examined by electrophoresis on a 1\% agarose gel and measured with a Nanodrop (ND1000, Thermo Fisher Scientific Inc., Wilmington). The extracted DNA was stored at $-20^{\circ} \mathrm{C}$ until further use.

\subsubsection{S rR NA gene amplification and M iseq sequencing}

Amplicons from the V1-V2 region of 16S rRNA genes were generated by a two-step PCR strategy consisting of a forward primer (27F-DegS =5' GTTY GATY MTGGCTCAG 3' where $\mathrm{M}=\mathrm{A}$ or $\mathrm{C} ; \mathrm{R}=\mathrm{A}$ or $\mathrm{G} ; \mathrm{W}=\mathrm{A}$ or $\mathrm{T} ; \mathrm{Y}=\mathrm{C}$ or $\mathrm{T}$ ) and an equimolar mixture of reverseprimers (338R I = 5' GCWGCCTCCCGTAGGAGT 3' and II = ' ' GCWGCCACCCGTAGGTGT 3' where $\mathrm{M}=\mathrm{A}$ or $\mathrm{C} ; \mathrm{R}=\mathrm{A}$ or $\mathrm{G} ; \mathrm{W}=\mathrm{A}$ or $\mathrm{T} ; \mathrm{Y}=\mathrm{C}$ or $\mathrm{T}$ ). Eighteen bp Universal Tags 1 and 2 (Unitag1 = GAGCCGTAGCCAGTCTGC; Unitag2 = GCCGTGACCGTGACATCG) were appended at the 5' end of the forward and reverse primer, respectively [229-231]. The first PCR mix (50 $\mu \mathrm{L}$ ) contained $10 \mu \mathrm{L} 5 \times$ HF buffer (Thermo ScientificTM, the Netherlands), $1 \mu \mathrm{L}$ dNTP Mix (10 mM; Promega, Leiden, the Netherlands), $1 \mathrm{U}$ of Phusion ${ }^{\circledR}$ Hot Start II HighFidelity DNA polymerase (Thermo ScientificTM), $1 \mu \mathrm{M}$ of 27F-DegS forward primer, $1 \mu \mathrm{M}$ of $338 \mathrm{R}$ I and II reverse primers, $1 \mu \mathrm{L}$ template DNA and $32.5 \mu \mathrm{L}$ nuclease free water. 
Amplification included an initial denaturation at $98^{\circ} \mathrm{C}$ for $30 \mathrm{sec} ; 25 \mathrm{cycles}$ of denaturation at $98^{\circ} \mathrm{C}$ for $10 \mathrm{sec}$; annealing at $56^{\circ} \mathrm{C}$ for $20 \mathrm{sec}$ and elongation at $72^{\circ} \mathrm{C}$ for $20 \mathrm{sec}$; and a final extension at $72^{\circ} \mathrm{C}$ for $10 \mathrm{~min}$. The PCR product size was examined by $1 \%$ gel electrophoresis. The second PCR mix (100 $\mu \mathrm{L}$ ) contained $62 \mu \mathrm{L}$ nucleasefreewater, $5 \mu \mathrm{L}$ of PCR1 product, 20 $\mu \mathrm{L} 5 \times \mathrm{HF}$ buffer, $2 \mu \mathrm{L}$ dNTP Mix, $2 \mathrm{U}$ of Phusion ${ }^{\circledR}$ Hot StartII High-Fidelity DNA polymerase, $500 \mathrm{nM}$ of a forward and reverse primer equivalent to the Unitag1 and Unitag2 sequences respectively, each appended with an $8 \mathrm{nt}$ sample specific barcode. Amplification included an initial denaturation at $98^{\circ} \mathrm{C}$ for $30 \mathrm{sec} ; 5$ cycles of denaturation at $98^{\circ} \mathrm{C}$ for $10 \mathrm{sec}$, anneal ing at $52^{\circ} \mathrm{C}$ for $20 \mathrm{sec}$ and elongation at $72^{\circ} \mathrm{C}$ for $20 \mathrm{sec}$; and a final extension at $72^{\circ} \mathrm{C}$ for $10 \mathrm{~min}$. The concentration of PCR products was quantified with a Qubit Fluorometer (Life Technologies, Darmstadt, Germany) in combination with the dsDNA BR Assay kit (Invitrogen,

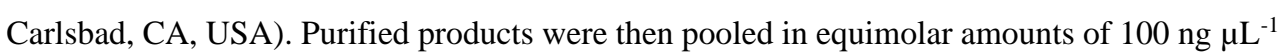
and sequenced on a MiSeq platform (GATC-Biotech, Konstanz, Germany).

\subsubsection{Processing M iSeq data}

Data was processed using the Quantitative Insights into Microbial Ecology (QIIME) 1.8.0. In short, paired-end libraries were filtered to contain only read pai rs perfectly matching barcodes. Low quality or ambiguous reads were removed and then chimeric reads were removed and checked. Sequences with less than $0.1 \%$ were discarded. Remai ining filtered sequences were assigned into Operational Taxonomy Units (OTUs) at 97\% threshold using an open reference method and a customized SILVA 16S rRNA gene reference [232]. Seven samples from day 4 were removed from the results due to contamination during the PCR steps: AC755, AC759, AC760, AC767, AC768, CCAP and UTEX572. The 16S rRNA gene dataset obtained in this study is deposited in the Sequence Read Archieve (SRA), NCBI with accession number SRP102970. 


\subsubsection{M icrobial community analysis}

For the interpretation of the microbial community data on family level, the Operational Taxonomic Unit (OTU) abundancetabl ewas converted to relative abundanceand visual ized as heatmaps using J Col orGrid [233]. Ordination analyses to estimate the relationship of the B. braunii strains based on dissimilarity of the microbial community compositions among the individual samples was performed for, a) all strains of B. braunii used in this study, b) all strains received from ALGOBANK-CAEN culture collection. For both analysis a standardized $97 \%$ OTU table (decostand function, method = hellinger) and the nMDS function metaMDS (distance $=$ Bray-Curtis) from the vegan package in $\mathrm{R}$ was used ( $\mathrm{R}$ version 3.0.2) $[234,235]$. Betadi spersion and a permutation test were performed to test homogeneity di spersion within a group of samples. Adonis from the vegan package in R (v.3.0.2) was used to test significant differences in bacterial community between strains. Hierarchical clustering analysis was performed using hclust function in $\mathrm{R}$ using method = average.

\subsection{Results}

Figure 3.1 shows the bacterial families with a relative abundance above $1 \%$ and a total of four bacterial phyla associated with $B$. braunii strains. The four phyla found associated with $B$. braunii are the Bacteroidetes, Germatimnadetes, Planctomycetes and Proteobacteria. Proteobacteria is the predominant bacterial phylumand representatives of this taxon are found in all 12 strains. Bacteroidetes is found in all strains with exception to strains AC761, AC768 and CCAP. Gemmatimonadetes is found only in the CAEN culture (with AC prefix) strains with exception to AC755. Planctomycetes is found in AC760, CCALA, K1489, Showa and UTEX strains. Three families are found across all $12 \mathrm{~B}$. braunii strains and all are Proteobacteria. 


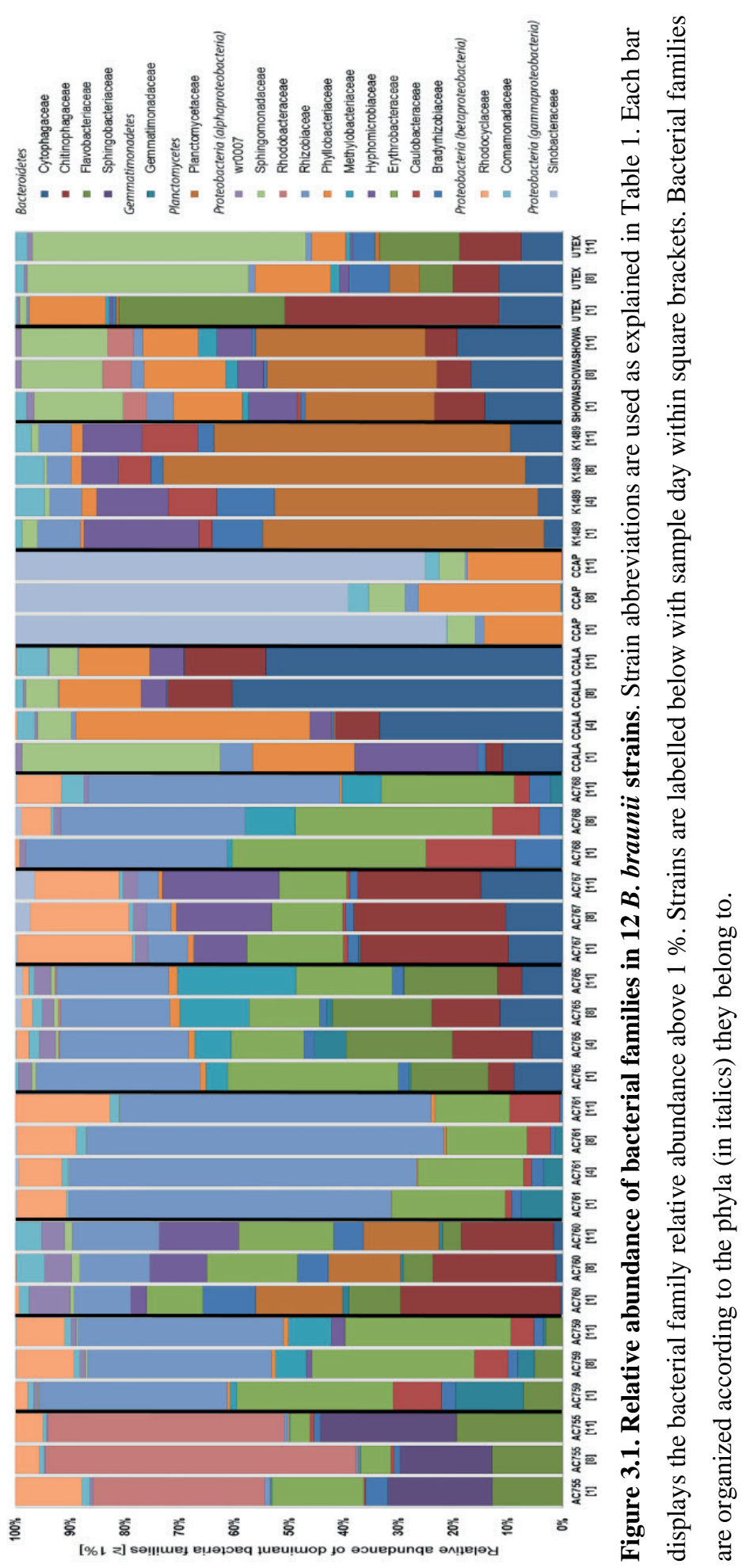


These are the Rhizobiaceae, Bradyrhizobiaceae and Comamnadaceae. Rhizobiaceae is represented by 1 to $59 \%$ of the bacterial reads. Bradyrhizobiaceae was found within the 1 to $8 \%$ range. Comamnadaceae was found between 1 and $5 \%$. Two families of bacteria are only found in the strains obtained from the CAEN culture collection: Erythrobacteraceae with bacterial reads ranging from 1 to $29 \%$ and Rhodocyclaceae with 1 to $18 \%$.

Some families of bacteria are particularly dominant in specific strains. Sinobacteraceae is dominant in CCAP with relative abundances ranging from 59 to $78 \%$. Planctomycetaceae is dominant in K1489 strain with relative abundances between 46 and $51 \%$. Rhizobiaceae is dominant in AC761 with relative abundances between 55 and $64 \%$. Other families of bacteria become dominant as the cultures become older. Rhodobacteraceae is present in AC755 strain with relative abundances ranging from $28 \%$ at day 1 to $40 \%$ at day 11 . Sphingomonadaceae is present in UTEX with $10 \%$ at day 1 and increases its presence to $47 \%$ at day 11 . Chytophagaceae is dominant in CCALA strain with relative abundance ranging from $10 \%$ at day 1 to $52 \%$ at day 11 .

Because we found three common families across all strains, we wanted to investigate in more detail the bacterial composition in these selected families and seeif we coul d identify an uni que microorganism present in all strains. Therefore we zoomed in and looked at the Operational Taxonomy Units (OTUs) distribution belonging to the three families: Rhizobiaceae, Bradyrhizobiaceae and Comamonadaceae. In addition, we picked the OTUs found only in the strains obtained from the CAEN culture collection which belong to two families: Erythrobacteraceae and Rhodocyclaceae. The most abundant OTUs were selected and a total of 28 OTUs were investigated. From Figure 3.2 it is clear that there is not an OTU that is found across all strains but rather each family comprises of several different OTUs. The second important observation is that CCAP strain has no representative OTUs for Bradyrhizobiaceae and Rhizobiaceae in the most abundant OTUs. The most represented family taxon is 
Rhizobiaceae with 12 OTUs. From the threefamilies found in the 12 strains, OTU 233 assigned to the genus Rhizobium has the highest OTU frequency abundance with $10 \%$ and is present in 7 out of 12 strains. The OTUs 143, 88 and 131 assigned to the genus Shinella are present in 9 out of 12 strains. The OTUs 477, 475 and 484 assigned to the genus Bosea cover 11 out of 12 strains. From the two families found only in the cultures originating from the CAEN culture collection, OTUs 333 and 539 are found in all seven CAEN strains with an assigned genus Porphyrobacter and Methyloversatilis, respectively.

The most abundant OTUs (as listed in Figure 3.2) were subjected to a Blast search against the NCBI database to infer their nearest neighbours (Table 3.2). OTUs 88, 115, 143 and 233 are similar in their nearest neighbours with four different Rhizobium spp. as candidates. Similar blast results are seen also for OTUs 566 and 567 with the nearest neighbours being Hydrogenophaga spp. The OTUs 819 and 832 with Dyadobacter spp. as nearest neighbour dominate CCALA bacterial community. Some OTUs show different species as closest neighbours such as OTUs 45 and 69 with Frigidibacter albus, Paracoccus sediminis and Nioel la nitratireducens as neighbours. The OTU 415 with high abundance in K 1489 belonging to Planctomycetaceae, has as closest neighbours uncultured bacterium and third closest neighbour uncultured Planctomyces spp. with the latter showing $87 \%$ identity. The OTU 333 present only in the strains from CAEN culture collection, has $100 \%$ identity with Sphingomonas as closest two neighbours, and third neighbour, al so with $100 \%$, identity being Porphyrobacter. 


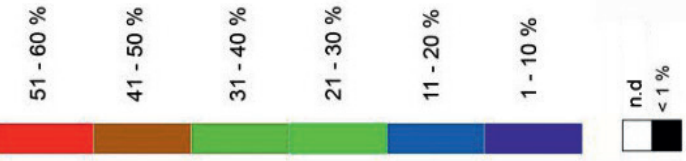

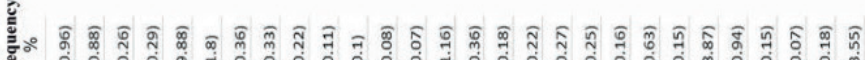

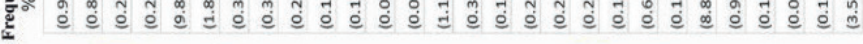

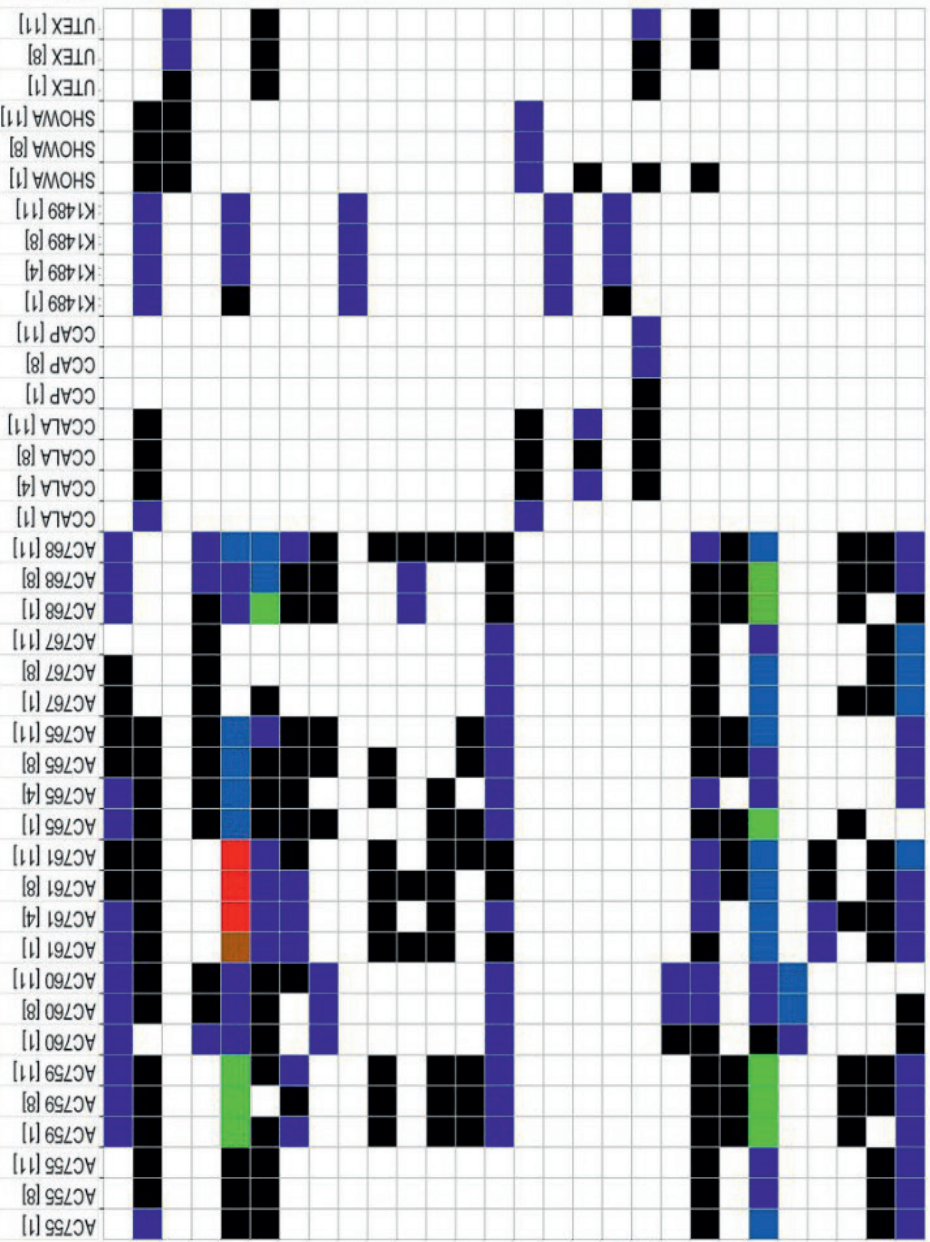

[l] gGLOH

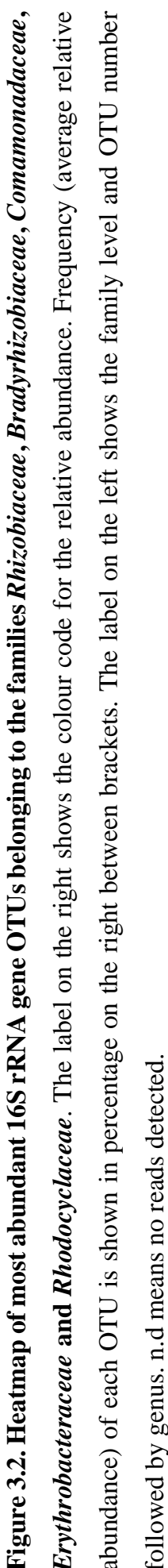


Table 3.2. NCBI database blast of OT Us for selected families. Closest first three neighbours with highest identity match and with a minimum of $85 \%$ coverage for each OTU. NCBI blast on the 11th February 2016, except the OTU 662 which the bl ast search from $30^{\text {th }}$ August 2016 and OTU 63 and 415 on February 2017.

\begin{tabular}{|c|c|c|c|c|c|c|}
\hline OTU & $\begin{array}{l}\text { nearest } \\
\text { neighbour1 }\end{array}$ & $\begin{array}{l}\text { G enbank } \\
\text { acc. }\end{array}$ & $\begin{array}{l}\text { nearest } \\
\text { neighbour2 }\end{array}$ & $\begin{array}{l}\text { Genbank } \\
\text { acc. }\end{array}$ & $\begin{array}{l}\text { nearest } \\
\text { neighbour3 }\end{array}$ & $\begin{array}{l}\text { G enbank } \\
\text { acc. }\end{array}$ \\
\hline 475 & $\begin{array}{l}\text { Hyphomicrobium } \\
\text { nitrativorans } \\
\text { (100) }\end{array}$ & NR_121713.1 & $\begin{array}{l}\text { Hyphomicrobium } \\
\text { nitrativorans (100) }\end{array}$ & NR_118448.1 & L Bosea lathyri (100) & NR_108515.1 \\
\hline 477 & $\begin{array}{l}\text { Bradyrhizobium } \\
\text { lupini (100) }\end{array}$ & NR_134836.1 & $\begin{array}{l}\text { Bradyrhizobiumlupini } \\
\text { (100) }\end{array}$ & NR_044869.2 & $\begin{array}{l}\text { Rhodopseudomonas } \\
\text { palustris (100) }\end{array}$ & ${ }^{S}$ NR_103926.1 \\
\hline 484 & $\begin{array}{l}\text { Bosea robiniae } \\
(100)\end{array}$ & NR_108516.1 & $\begin{array}{l}\text { Bradyrhizobiumlupini } \\
\text { (99) }\end{array}$ & NR_134836.1 & $\begin{array}{l}\text { Bradyrhizobium } \\
\text { ottawaense (99) }\end{array}$ & NR_133988.1 \\
\hline 502 & $\begin{array}{l}\text { Bradyrhizobium } \\
\text { daqingense (100) }\end{array}$ & $N R \_1$ & $\begin{array}{l}\text { Bradyrhizobium } \\
\text { lablabi (100) }\end{array}$ & $\mathrm{NR}_{-}$ & $\begin{array}{l}\text { Bejjerinckia } \\
\text { doebereinerae } \\
(100)\end{array}$ & NR_116304.1 \\
\hline 88 & $\begin{array}{l}\text { Rhizobium } \\
\text { rhizoryzae (100) }\end{array}$ & NR_133844.1 & $\begin{array}{l}\text { Rhizobiumflavum } \\
(100)\end{array}$ & NR_1338 & $\begin{array}{l}\text { Rhizobiumazibense } \\
(100)\end{array}$ & \\
\hline 115 & $\begin{array}{l}\text { Rhizobium } \\
\text { rhizoryzae (100) }\end{array}$ & & $\begin{array}{l}\text { Rhizobiumflavum } \\
\text { (100) }\end{array}$ & & $\begin{array}{l}\text { Rhizobiumazibense } \\
\text { (100) }\end{array}$ & NR_1 \\
\hline 143 & $\begin{array}{l}\text { Rhizobium } \\
\text { rhizoryzae (100) }\end{array}$ & NR_13 & $\begin{array}{l}\text { Rhizobiumflavum } \\
\text { (100) }\end{array}$ & NR_13 & $\begin{array}{l}\text { Rhizobiumazibense } \\
(100)\end{array}$ & NR_13 \\
\hline 233 & $\begin{array}{l}\text { Rhizobium } \\
\text { paranaense } \\
(100)\end{array}$ & NR_134152.1 & $\begin{array}{l}\text { Rhizobiumrhizoryzae } \\
\text { (100) }\end{array}$ & NR_133844.1 & $\begin{array}{l}\text { Rhizobiumfla } \\
\text { (100) }\end{array}$ & NR_133843.1 \\
\hline 555 & $\begin{array}{l}\text { Variovorax } \\
\text { guangxiensis } \\
(100)\end{array}$ & NR_134828.1 & $\begin{array}{l}\text { Vari } \\
(100\end{array}$ & NR_074654.1 & $\begin{array}{l}\text { Variovo } \\
1 \text { boronic } \\
(100)\end{array}$ & NR_114214.1 \\
\hline 566 & $\begin{array}{l}\text { Hydrogenophaga } \\
\text { flava (100) }\end{array}$ & NR_114133.1 & $\begin{array}{l}\text { Hydrogenophaga } \\
\text { bisanensis (100) }\end{array}$ & NR_044268.1 & $\begin{array}{l}\text { Hydrogenophaga } \\
\text { defluvii (100) }\end{array}$ & NR_029024.1 \\
\hline 567 & $\begin{array}{l}\text { Hydrogenophaga } \\
\text { flava (100) }\end{array}$ & $N R$ & $\begin{array}{l}\text { Hydrogenophaga } \\
\text { bisanensis (100) }\end{array}$ & NR_04 & $\begin{array}{l}\text { Hydrogenophaga } \\
\text { defluvii (100) }\end{array}$ & NR_029024.1 \\
\hline 333 & $\begin{array}{l}\text { Sphingomonas } \\
\text { gei (100) }\end{array}$ & 812.1 & $\begin{array}{l}\text { Sphingomonas } \\
\text { ginsengisoli (100) }\end{array}$ & 1 & $\begin{array}{l}\text { obacter } \\
\text { (100) }\end{array}$ & NR_114328.1 \\
\hline 539 & $\begin{array}{l}\text { Uncultured } \\
\text { bacterium (100) }\end{array}$ & KY 606782.1 & $\begin{array}{l}\text { Methy } \\
\text { discip }\end{array}$ & KY 284088.1 & $\begin{array}{l}\text { Meth } \\
\text { disci }\end{array}$ & KY284080.1 \\
\hline 63 & $\begin{array}{l}\text { Thioclava sp. } \\
\text { (100) }\end{array}$ & СР019437.1 & Rhodobacter sp. (100) & KY 608089.1 & $\begin{array}{l}\text { Uncultured } \\
\text { Rhodobacter sp. } \\
\text { (100) }\end{array}$ & KY 606875.1 \\
\hline 819 & $\begin{array}{l}\text { Dyadobacter } \\
\text { jiangsuensis } \\
\text { (100) }\end{array}$ & NR_134721.1 & $\begin{array}{l}\text { Dyadobacter } \\
\text { fermentans }(100)\end{array}$ & NR_074368.1 & $\begin{array}{l}\text { lobacter } \\
\text { ansis (88) }\end{array}$ & NR_109648.1 \\
\hline 832 & $\begin{array}{l}\text { Dyadobacter } \\
\text { jiangsuensis } \\
(100)\end{array}$ & NR_134721.1 & $\begin{array}{l}\text { Dyadobacter } \\
\text { fermentans (100) }\end{array}$ & NR_074368.1 & $\begin{array}{l}\text { acter } \\
\text { s (88) }\end{array}$ & NR_109648.1 \\
\hline 415 & $\begin{array}{l}\text { Uncultured } \\
\text { bacterium (100) }\end{array}$ & KT769749.1 & $\begin{array}{l}\text { Uncultured bact } \\
\text { (91) }\end{array}$ & KT724695.1 & $\begin{array}{l}\text { Uncultured } \\
\text { Planctomyces sp. } \\
\text { (87) }\end{array}$ & JX576019.1 \\
\hline 45 & $\begin{array}{l}\text { Frigidibacter } \\
\text { albus (100) }\end{array}$ & 31.1 & $\begin{array}{l}\text { Paracoccus sediminis } \\
\text { (96) }\end{array}$ & NR_134122.1 & $\begin{array}{l}1 \text { Nioella } \\
\text { nitratireducens (94) }\end{array}$ & $N R$ \\
\hline 69 & $\begin{array}{l}\text { Frigidibacter } \\
\text { albus (100) }\end{array}$ & & $\begin{array}{l}\text { Paracoccus sediminis } \\
(100)\end{array}$ & NR_13 & $\begin{array}{l}\text { Nioella } \\
\text { nitratireducens (97) }\end{array}$ & \\
\hline 302 & $\begin{array}{l}\text { Sphingorhabc } \\
\text { arenilitoris (1 }\end{array}$ & & $\begin{array}{l}\text { Sphingo } \\
(100)\end{array}$ & NR_1C & $\begin{array}{l}\text { Parasphingopyxis } \\
1 \text { lamellibrachiae } \\
\text { (100) }\end{array}$ & NR_113006.1 \\
\hline
\end{tabular}




\begin{tabular}{|c|c|c|c|c|}
\hline 310 & $\begin{array}{l}\text { Sphingomonas } \\
\text { yantingensis } \\
\text { (100) }\end{array}$ & NR_133866.1 $\begin{array}{l}\text { Sphingomonas } \\
\text { canadensis (100) }\end{array}$ & NR_108892.1 $\begin{array}{l}\text { Blastomonas } \\
\text { natatoria (100) }\end{array}$ & NR_113794.1 \\
\hline & $\begin{array}{l}\text { Blastomonas } \\
\text { natatoria (100) }\end{array}$ & NR_113794.1 $\begin{array}{c}\text { Sphingomonas } \\
\text { ursincola (100 }\end{array}$ & NR_040825.1 $\begin{array}{l}\text { Blastomonas } \\
\text { natatoria (100) }\end{array}$ & NR_040824.1 \\
\hline
\end{tabular}

Non-metric multidi mensional scaling ordi nation was performed for the 12 strains to determine the bacterial community dissimilarities (Figure 3.3A). B. braunii strains from theCAEN culture collection cl uster together when compared to theother strains indi cating thesestrains are similar to each other in bacterial community composition. This is supported by hierarchical cluster analysis showing CAEN strains in their own cluster (Supplementary Figure 3.1). The strains K1489, UTEX, CCAP, CCALA and Showa represent separate dusters. The homogeneity of dispersion within each strain with 1000 permutations show no significant difference $(F=0.323)$. Using adonis to test for bacterial community similarities between all strains, the results show that the bacterial communities are significantly different ( $D F=11$, Residuals $=28, R^{2}=0.921$, $P=0.001$ ). Figure $3.3 B$ zooms in to the $C A E N$ culture collection strains. Races $A, B$ and $L$ are subdivisions of B. braunii according to the type of hydrocarbons produced. No clustering by type of hydrocarbons produced was seen by the distribution of the race $B$ and race $L$ strains which are found mixed, namely race B AC759 and AC761 with race L AC765 and AC768. Similarly, the bacterial community between CAEN strains are significantly different (DF =6, Residuals $=16, \mathrm{R} 2=0.904, \mathrm{P}=0.001$ ). 


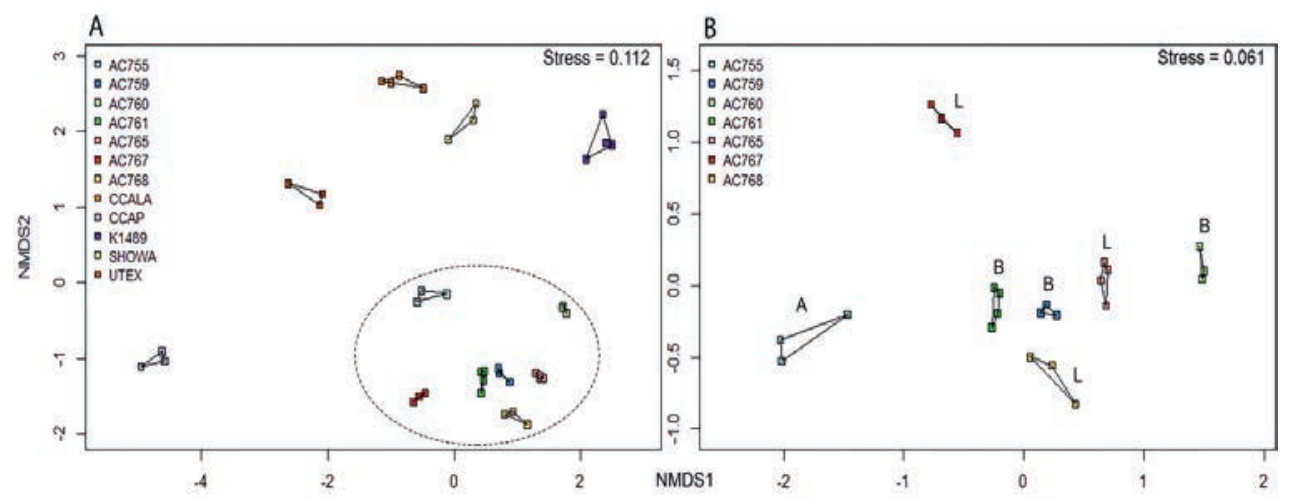

Figure 3.3. Non-metric multidimensional scaling (nMDS) ordination (based on BrayC urtis distance matrix) of 165 rR NA gene sequences of 12 B. braunii strains. A) ordination of all strains with CAEN cultures clustering together (within the ellipse dotted line); B) ordination of the CAEN culture collection strains only. Capital letters in plot B refer to therace subclassification based on thetype of hydrocarbons produced.

\subsection{Discussion}

It is evident that $B$. braunii possesses a highly diverse bacterial community as seen by the range of bacterial phylaand families presentinall thestrains used in this study (Figure 3.1 (for a more comprehensivelist see Supplementary Figure 3.2)).

From the bacterial community analysis (Figure 3.3A, B), it appears that each B. braunii strain has a specific bacterial community and no OTU is shared between all strains. The strains from the CAEN culture collection cluster together while B. braunii strains from other culture collections appear as separate groups. This implies that the culture collection from which the strain was obtained could potentially have an effect. With this study we are not able to really deduce the potential impact of the culture collection on the bacterial community because the experimental design was not set-up to do so. The presence of weak (within a culture collection) and strong (between culture collections) migration barriers may explain the bacterial profiles as obtained in our study and they may be a result of historical contingencies [236] rather than pointing towards highly specific interactions for a large number of OTUs. OTUs 539 and 333 
areonly found with the CAEN cultures and contributes towards thesestrains cl ustering in close proximity. OTU 333 is especially high in relative abundance and contributes to the distinctive clustering of the CAEN culture collection strains. The remaining strains also contain their specific OTUs that contribute towards their own clustering: OTU 819 and 832 with CCALA, OTU 310 with UTEX and K1489 with OTU 415. The bacterial community between three race $B$ and three race $L$ are mixed together (Figure 3.3B). Therefore, no correlation was found between bacterial community and the type of hydrocarbons produced between the two races. Similar observations were made in another study using six strains of B. braunii in which the authors did not find a corre ation between the bacteria and type of hydrocarbon produced [237].

Three bacterial families were found to be present with all twelve strains of B. braunii: Bradyrhizobiaceae, Rhizobiaceae, and Comamonadaceae. Two families were found abundantly only in the strains from the CAEN culture collection: Erythrobacteraceae and Rhodocyclaceae. TheOTUs 88, 115, 143 and 233 blast hits show theseare related to Rhizobium spp. (Table 3.2). Rhizobiumspp. areknown to formnodules in theroots of several plants within the family of legumes and are best known for nitrogen fixation. Nitrogen fixing bacteria were investigated in association with microalgae and it has been shown that they can enhance microal gæe growth [28]. Rhizobium spp. associated with B. braunii could have a similar role. Rivas et al. [80] al so found a Rhizobium sp. associated with B. braunii in particular UTEX LB572, and Kim \& al. [105] showed the presence of Rhizobium sp. with B. braunii 572. Sambles et al. [81] identified Rhizobiumsp. closely associated with B. braunii after submitting the cultures through a wash step and antibiotic treatment. Recent studies al so shows Rhizobium spp. present with Chlamydomonas reinhardtii, Chlorella vulgaris and Scenedesmus spp. [105]. Rhizobium spp. seem important to B. braunii strains as it appears in all 12 strains with more prominence in the CAEN cultures and K1489 with three to four OTUs (Figure 3.2). For the 
remaining strains CCALA, CCAP, Showa and UTEX, Rhizobiumspp. is represented only with one OTU.

OTU 475 from Bradyrhizobiaceae family shows $100 \%$ similarity with the species Hyphomicrobium nitrativorans as the two cl osest neighbours and is present in 10 out of $12 \mathrm{~B}$. braunii strains. H. nitrativorans is a known denitrifier isolated from a seawater treatment facility [238]. Denitrification is the process of reducing nitrate into a variety of gaseous compounds with the final being dinitrogen. Because denitrification mainly occurs in the absence of oxygen it is unlikely that this is happening within our cultures that are well oxygenated. The $3^{\text {rd }}$ d losest neighbour for OTU 475 is Bosea lathyri and is associated with root nodules legumes [239].

OTUs 555, 566 and 567 from Comamnadaceaefamily, appeared in seven out of twelvestrains. The three closest neighbours of OTU 555 were Variovorax spp. and for OTUs 566 and 567 these were Hydrogenophaga spp., Variovorax and Hydrogenophaga spp. are not known for being symbionts but may be able to support ecosystems by their ability to degrade toxic compounds and assist in nutrient recycling, therefore potentially producing benefits to other microorganisms [240, 241]. Comamonadaceae also appeared as one of the main bacteria families associated with cultivation of microal gae in bioreactors using a mix of fresh water and municipal water as part of a water treatment strategy [242].

Erythrobacteraceae and Rhodocyclaceae were only found in the strains from CAEN culture collection. OTU 333 (Erythrobacteraceae) first two closest neighbours are from Sphingomonas spp., and third closest neighbour is Porphyrobacter spp. isolated from water in a swimming pool. Most Porphyrobacter spp. isolated originate from aquatic environments [243] and are associated with fresh water sediments [244]. Porphyrobacter spp. have al so been associated with other microal gae such as Tetraselmis suecica [118]. OTU 539 (Rhodocyclaceae) second 
and third closest neighbour is Methyloversatilis discipulorum which is a bacteria found in biofilms formation in engineered freshwater installations [245]. It is not clear why OTU 333 and 539 are specifically found only in the strains originating from the CAEN culture collection, but it could bean introduced species during handl ing. Nonetheless, these two OTUsarepresent in high relativeabundance(Figure3.2), and woul d beinteresting to know if they havea positive or negative influence on the growth of the CAEN strains. It would be interesting to confirm such statement by attempting the removal of these OTUs and investigate the biomass growth.

Sinobacteraceae is dominant in CCAP (Figure 3.1). This family was proposed in 2008 with the characterization of a bacteria from a polluted soil in Chi [246]. A recent bacteria related to hydrocarbon degradation shows similarities with Sinobacteraceae [247]. OTU 63 is highly abundant in CCAP and could have a negative impact in the cultivation of CCAP strain by reducing its hydrocarbon content.

The Bactoroidetes family Cytophagaceae dominates the culture CCALA at later stages of growth (Figure 3.1). Cytophagaceae has also been found present in laboratory scale photobioreactor cultivation using wastewater for production of microal gae biomass [242]. The two OTUs that dominate the bacterial community in CCALA are OTU 819 and OTU 832. The Bl ast search on NCBI database approximates these two OTUs as Dyadobacter spp. which have al so been found co-habiting with Chlorella spp. [248].

Planctomycetaceae dominates the bacterial community in K1489 strain (Figure 3.1) with one OTU 415. This family can be found in freshwater bi films and al so strongly associated with macroalga [249, 250]. Species in this family could possibly be involved in metallic-oxide formation and be co-players in sulphatereduction with the latter also involving a sulphurreducing bacteria [251]. 
Rhodobacteraceae is present with up to $55 \%$ of bacterial relative abundance in AC755. Members of this family have been also isolated from other microalgae, namely Chlorella pyrenoidosa and Scenedesmus obliquus [252]. The OTUs 45 and 69 blast searches in NCBI database show the closest neighbours to be Frigidibacter albus, Paracoccus sediminis and Nioella nitratireducens (Table 3.2). All three neighbours were isolated from water environments [253, 254].

Sphingomonadaceae is mostly found in freshwater and marine sedi ments [255]. OTUs 302, 310 and 355 from this family were found in 6 out of 12 strains above $1 \%$ rel ative abundance. OTU 310 is only found in the UTEX strain with Sphingomonas spp. as the two closest neighbours. Sphingomonas spp. are shown to co-habit with other microal gae such as Chlorella sorokiniana and C. vulgaris [20, 218]. Sphingomonas spp. have been shown to be able to degrade polycyclic aromatic hydrocarbons [256] and could possi bly be degrading the hydrocarbons secreted by $B$. braunii as its carbon source.

Another characteristic of many bacteria is the ability to produce EPS such as species from the Rhi zobiaceae and Bradyrhizobiaceae family [257-259]. This characteristic could play a role on the colony aggregation of B. brauniii as EPS is known to be essential for biofilm formation [260]. Therefore it would be interesting in the future to study this possible relationship as B. braunii is a colony forming organism Such studies could involve the introduction of bacteria associated with col ony formation such as Terramonas ferruginea as it has been associated with inducing flocculation in C. vulgaris cultures [261].

With the present high microbial diversity, B. braunii shows qualities in resilience towards microbial activity, probably due to its colonial morphology and protective phycosphere made of hydrocarbons and EPS [262]. A number of microbes are potentially beneficial such as Rhizobiumspp. which have been shown to have a positive effect on the biomass productivities 
of B. braunii UTEX [80], and Hydrogenophaga with the ability to degrade toxic compounds [241]. Thereareal so microbes that may causedetrimental effects on hydrocarbon productivities of B. braunii such as Sphingomonas spp. (OTU 310) with its ability to degrade hydrocarbons [256]. The removal of such detrimental microbes could enhance cultivation allowing more nitrogen avail abl efor biomass production and increase hydrocarbon accumulation of B. braunii as well as EPS production at larger industrial scale.

\subsection{Conclusion}

B. braunii can host a diverse microbial community and it is likely that some form of interaction is taking place with the members from the Rhizobiaceae, Bradyrhizobiaceae and Comamonadaceae family, which all belong to the phylum Proteobacteria. There is not a specific bacterial community correlated to the different types of hydrocarbons produced by race $B$ and $L$ and mostly likely al so not race A. B. braunii has many strains and each seems to have its own species-specific bacterial community. With a diverse microbial community present, it is also likely that some bacteria are having antagonistic effects on B. braunii such as competition with nutrients and degradation of hydrocarbons. Botryococcus is a microal ga of high scientific interest and it is important to understand better the associated bacteria. Botryococcus-associated bacteria are hard to get rid of (Gouveia, J. unpublished data) and therefore it is important to start mass cultivation without those bacteria that are most harmful to the process.

\section{Acknowledgments}

This project is carried out with financial support from the European Community under the seventh framework programme (Project SPLASH, contract nr. 311956). The authors appreciate the contribution of Iago Teles from Wageningen University, in proofreading the manuscript 


\section{Supplementary Information}

Hierarchical Clustering average

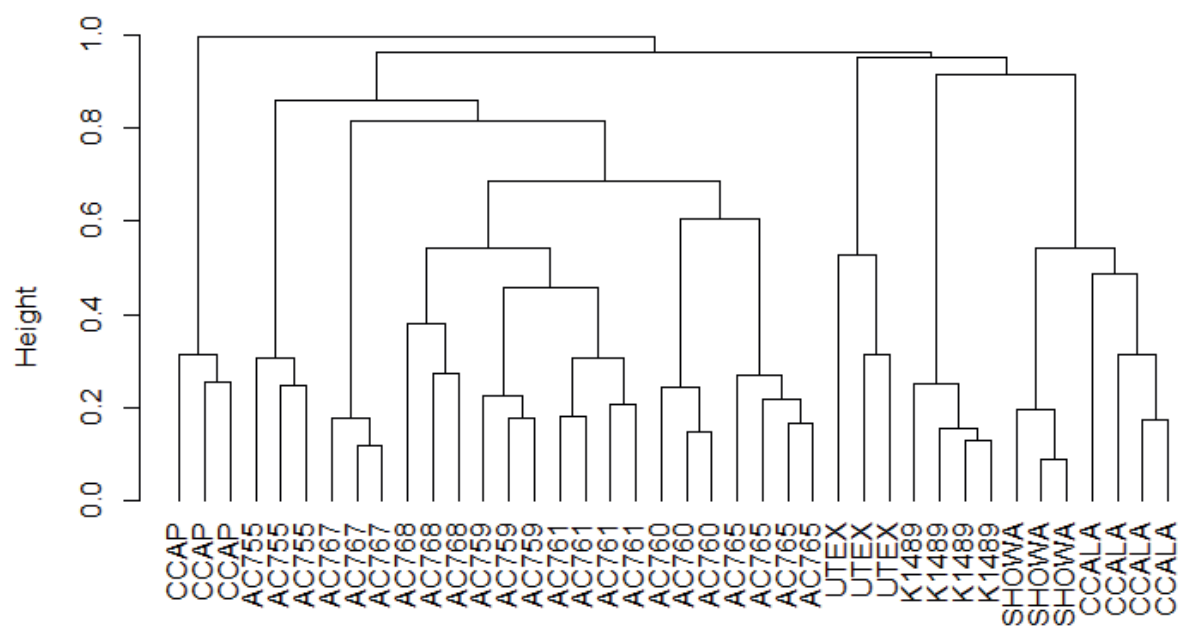

vegdist.deco.all hclust (", "average")

Supplementary Figure 3.1. Hierarchical clustering of B. braunii strains. Strains from CAEN culture collection (AC prefix) cluster together in comparison to the other strains. 

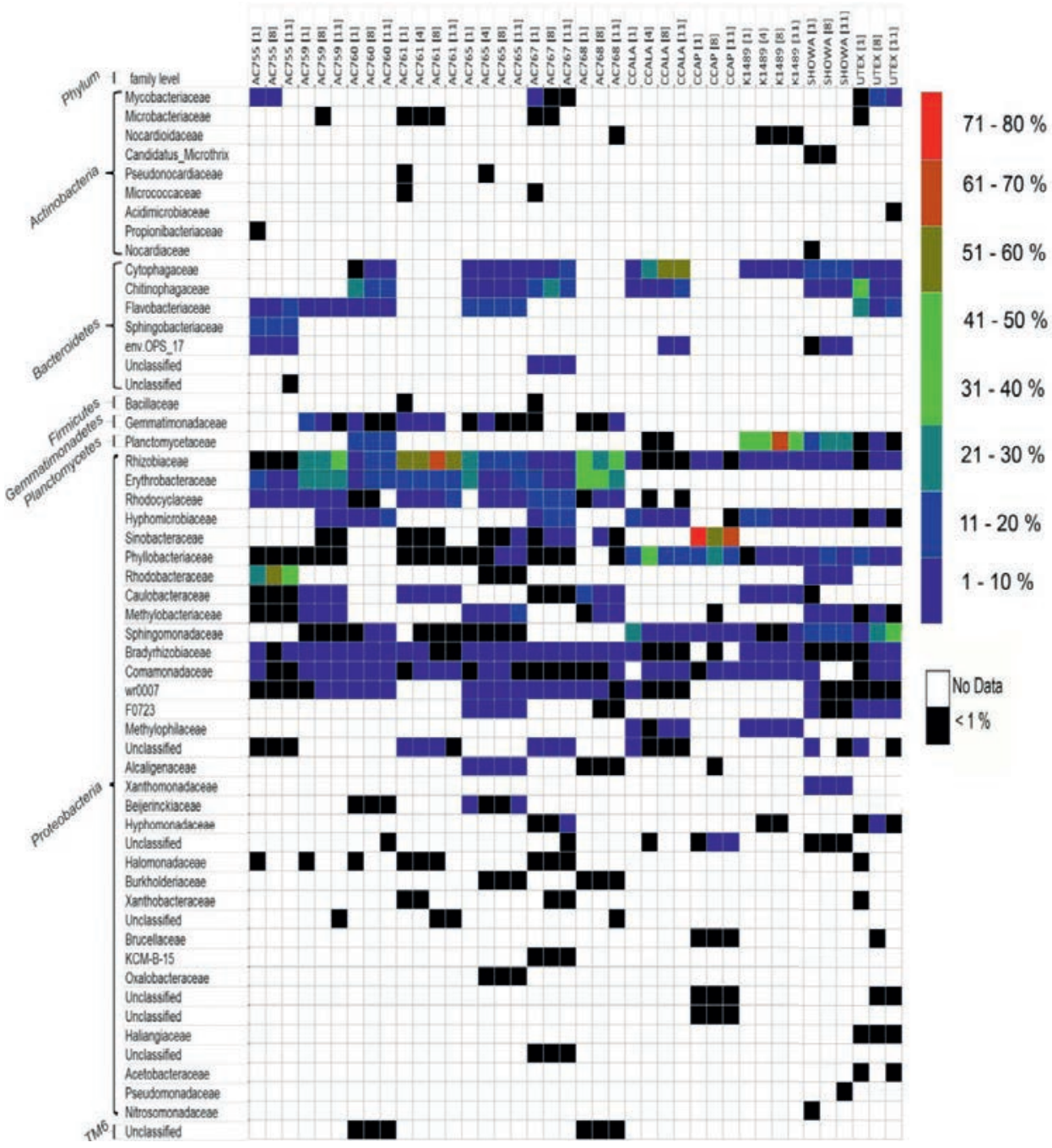

Supplementary Figure 3.2. Family taxa relative abundance heatmap of $\mathbf{1 2}$ B. braunii strains. On the left, is the family taxa classification. On the right, the colour coded label describes the rel ative abundance in percentage. 


\section{Chapter 4}

Bacterial diversity in different outdoor pilot plant photobioreactor types for production of the microalga Nannochloropsissp. C C A P211/78

JieLian, Georg Steinert, Jeroen de Vree, Sven Meijer, Christa Heryanto, RoukeBosma, RenéH. Wijffels, Maria Barbosa, Hauke Smidt, Detmer Sipkema 


\section{Abstract}

A range of microal gae production systems are scal ed up towards pi lot and demonstration pl ants. As large-scal e outdoor production cannot be done in complete contai nment, cul tures are (more) open for bacteria, which may affect the productivity and stability of the production process. We investigated the bacterial diversity in two indoor reactors and four pilot-scale outdoor reactors for production of Nannochloropsis sp. CCAP211/78 spanning four months of operation from July to October. Illumina sequencing of 16S rRNA gene amplicons demonstrated that a wide variety of bacteria were present in all reactor types, with predominance of Bacteroidetes and Alphaproteobacteria. Our results showed that bacterial communities were significantly different in all reactor types (except a horizontal tubular reactor and a vertical tubular reactor) and also between runs in each reactor. Bacteria common to the majority of samples ind uded one member each of the Saprospiraceae family and of the NS11-12_marine group (both Bacteroidetes). Hierarchical clustering analysis revealed two phases during the cultivation period separated by a major shift in bacterial community composition in the horizontal tubular reactor, the vertical tubular reactor and the raceway pond. The bacterial classes Al phaproteobacteria, Sphingobacteriia, Deltaproteobacteria and Flavobacteriia contributed most to the difference between the two phases, with a stark decrease of the Saprospiraceae and NS11-12_marine group that initially dominated the bacterial communities. Furthermore, we observed a less consistent pattern of bacterial taxa appearing in different reactors and runs, most of which belonging to the classes Deltaproteobacteria and Flavobacteriia. In addition, canonical correspondence analysis showed that the nitrate concentration in the reactor significantly corre ated with bacterial community composition in most reactor types except the plastic flat panel reactor, where al gal biomass productivity was the key factor associated with changes in bacterial community structure This study contributes to our understanding of bacterial diversity and composition in different types of outdoor reactors exposed to a range of 
dynamic biotic and abiotic factors. Differences in bacterial community composition between reactor types should be given more attention in order to improve the stability and success rate for large scale outdoor cultivation of microal gae.

Keywords: Nannochloropsis, outdoor reactors, al gae-bacterial interactions, bacterial community composition 


\subsection{Introduction}

Microal gae are one of the most promising feedstocks for production of food, feed, bi ofuels and other valuable chemicals [56, 263]. Algal cultivation does not necessarily compete for arable land and needs much less water to produce the same amount of bi ofuel compared to oil crops $[56,264]$. Nevertheless, although al gae have many appealing advantages as alternative cell factories, al gal bulk products are still far away from largescale application in industry due to high production costs [265].

Scal e up of al gae cult tivation is carried out in different systems, but most commonly in shal low open ponds or in enclosed plastic tubular photobioreactors [266]. Despite the fact that a good number of systems has been proposed and tested, the industry is far from settled on a single approach. The high performance of al gal strains in the laboratory can hardly be accomplished in largescale outdoor cultivation systems because of varying ambient conditions, including physicochemical and biological factors [267]. Both open and closed outdoor al gae production systems cannot easily be operated strictly axenically and are thus prone to microbial contamination. This is a substantial discrepancy compared to laboratory-based studies where whole reactors can be autoclaved. Therefore, in pilot-scale operation, bacteria present in photobioreactors cannot be ignored as is often the case for laboratory-based studies. However, relatively little is known about the bacteria present in al gal photobioreactors and about their effects on al gal cultivation $[153,268]$.

An increasing number of bacteria has been reported to be detrimental to microal gae and can cause mass algal cell destruction. Harmful impacts may be imposed through direct algalbacterial cell contact, such as for the lytic bacteria Saprospira sp. (SS98-5) [269], Pseudoalteromonas sp. ( 18/M01) [31] and Microbacterium sp. LB1 [32]. In addition, the synthesis of extracellular algicidal compounds may kill the algal host. For instance, 
Streptomyces malaysiensis 04-6 was shown to release compound NIG355 capable of killing nearly $80 \%$ of Phaeocystis globosa in $24 \mathrm{~h}$ [33]. Nevertheless, recent studies have reveal ed that mutual istic relationshi ps between al gae and bacteria may even occur more commonly than antagonistic interactions $[2,40]$. Associated bacteria benefit al gal growth in mainly three ways. First of all, bacteria are key players in decomposing and mineral izing al gal waste components, recycling carbon and phosphorus and making them again available for the al gae [137, 144]. Secondly, bacteria can benefit al gae through synthesizing a wide range of molecules ranging from vitamins [22, 26], phytohormones [16, 270], to siderophores [98, 271], which can stimulate algal growth. Lastly, some bacteria are able to kill algicidal bacteria by secreting antimicrobial compounds, such as tropodithietic acid in exchange for organic carbon [147].

Knowledge of bacterial communities in outdoor microal gae production systems is currently nearly non-existent. However, the impact of bacteria already presents in the microalgae inoculum, as well as temporal variation of bacterial communities due to variation of environmental parameters that are inevitably occurring in outdoor reactors are likely to be important for robust operation of these production systems. Therefore, we conducted a longitudinal study to investigatethe composition and dynamics of bacterial communities within two indoor microalgae inoculum-production systems (i.e., a sterile-operated flat panel bioreactor and a non-steri letubular indoor bi oreactor) and four outdoor pi lot-scal esystems (i.e, an open raceway pond, a horizontal tubular bioreactor, a vertical tubular bioreactor, and a plastic flat panel reactor) during the production of the microalga Nannochloropsis sp. CCAP211/78 (the al gal production data have been published by Vreeet al. [272]) to assess the impact of non-sterile outdoor photobioreactor operation. One hundred and twenty-eight samples were collected from indoor and outdoor bioreactors over a period of four months. Bacterial 16S rRNA gene fragments were amplified and sequenced to determine the composition of associated bacterial communities. 


\section{2. $M$ aterials and $M$ ethods}

\subsubsection{Algel cultivation and sampling procedures}

Nannochloropsis sp. CCAP211/78 was cultivated in $250 \mathrm{~mL}$ Erlenmeyer flasks, followed by cultivation in a flat panel reactor ( $\mathrm{FP}, 4.5 \mathrm{~L}$ ) and a horizontal tubular indoor reactor (TI, $280 \mathrm{~L}$ ) located in a greenhouse at AlgaePARC (Wageningen, the Netherlands). The bi omass harvested from TI was used to inocul ate three pil ot-scal e outdoor reactors within one week: a horizontal tubular reactor $(\mathrm{HT}, 560 \mathrm{~L})$, a vertical tubular reactor $(\mathrm{VT}, 1060 \mathrm{~L})$ and a raceway pond (RP, $4730 \mathrm{~L}$ ). An outdoor plastic flat panel reactor (PP, $60 \mathrm{~L}$ per panel) was inoculated with biomass directly harvested from the indoor FP. Samples were taken at AlgaePARC every Monday, Wednesday and Friday moming from J uly $3^{\text {rd }}$ - October $16^{\text {th }}, 2013$. Detail led sampleinformation can be found in Supplementary Figure S4.1. In addition, details of the production process of Nannochloropsis sp. CCAP211/78 [272] and a detailed description of outdoor reactors [273] were published previously. Liquid samples of $5 \mathrm{~mL}$ from each of the reactors were filtered through asterile polycarbonatefilter membrane $(0.2 \mu \mathrm{m}$, Millipore) with a vacuumpump. Filter membranes were then rolled up, placed in $2 \mathrm{ml}$ Eppendorf tubes and stored at $-80{ }^{\circ} \mathrm{C}$ until further processing. Data generated in this study were derived from two separate reactor runs performed during the above-mentioned period, with the first and second runs being designated TI1, HT1, VT1, RP1, PP1 and FP2, TI2, HT2, VT2, RP2, PP2, respectively.

\subsubsection{DNA extraction, $P C R$ amplification and sequencing}

To isolate total DNA, frozen filters were cut into small pieces with sterile scissors. DNA was extracted from these pieces using the FastDNA SPIN kit for soil (MP Biomedicals, USA) with the aid of a Precellys bead beater (Bertin Technologies, France) for two rounds of $45 \mathrm{~s}$ at a speed of 5500 rpm. DNA size and quantity were examined by el ectrophoresis on a 1\% agarose 
gel and measured spectrophotometrically with a Nanodrop (ND1000, Thermo Scientific, Wilmington, USA). The extracted DNA was stored at $-20^{\circ} \mathrm{C}$ until further use.

Amplicons from the V1-V2 region of bacterial 16S rRNA genes were generated using a twostep PCR strategy. Forward primer 27F-DegS (5'-GTTY GATYMTGGCTCAG-3'), and an equimolar mixture of reverse primers 338R I (5'-GCWGCCTCCCGTAGGAGT-3') and II (5'GCWGCCACCCGTAGGTGT-3') were appended at the $5^{\prime}$ end with 18 bp universal tags (Unitag1: GAGCCGTAGCCAGTCTGC and Unitag2: GCCGTGACCGTGACATCG for the forward and reverse primers, respectively). PCR was conducted in a $50 \mu 1$ reaction volume containing $1 \mu \mathrm{l}$ DNA template, $10 \mu \mathrm{l} 5 \times \mathrm{HF}$ buffer (Thermo Scientific, The Netherlands), $1 \mu \mathrm{l}$ dNTP Mix (10mM; Promega, Leiden, theNetherlands), $1 \mu \mathrm{M}$ of each primer, $1 \mathrm{U}$ of Phusion ${ }^{\circledR}$ Hot Start II High-Fidelity DNA polymerase (Thermo Scientific, The Netherlands) and $32.5 \mu \mathrm{l}$ nuclease free water (Qiagen, Germany). The PCR profile included the following steps: Predenaturation at $98^{\circ} \mathrm{C}$ for $30 \mathrm{~s}$, followed by 25 cycles of denaturation ( $10 \mathrm{~s}$ at $98^{\circ} \mathrm{C}$ ), annealing (20 s at $\left.56^{\circ} \mathrm{C}\right)$, extension $\left(20 \mathrm{~s}\right.$ at $\left.72^{\circ} \mathrm{C}\right)$, and a final elongation (10 min at $\left.72^{\circ} \mathrm{C}\right)$. The PCR product sizewas examined by $1 \%$ agarose gel el ectrophoresis. The second PCR was conducted in a $100 \mu \mathrm{l}$ reaction volume containing $5 \mu \mathrm{l}$ of the first PCR product, $20 \mu \mathrm{l} 5 \times \mathrm{HF}$ buffer (Thermo Scientific), $2 \mu \mathrm{l}$ dNTP Mix (10 mM; Promega), $500 \mathrm{nM}$ forward and reverse primer (equivalent to the Unitag1 and Unitag2 sequences, respectively) that were each appended with an 8 nt sample-specific barcode [231], 2 U of Phusion ${ }^{\circledR}$ Hot Start II High-Fidelity DNA polymerase (Thermo Scientific) and $62 \mu$ nuclease free water (Qiagen). The PCR conditions were predenaturation at $98^{\circ} \mathrm{C}$ for $30 \mathrm{~s}$, followed by 5 cycles of denaturation $\left(10 \mathrm{~s}\right.$ at $98^{\circ} \mathrm{C}$ ), anneal ing $\left(20 \mathrm{~s}\right.$ at $\left.52^{\circ} \mathrm{C}\right)$, extension $\left(20 \mathrm{~s}\right.$ at $\left.72^{\circ} \mathrm{C}\right)$, and a final el ongation $\left(10 \mathrm{~min}\right.$ at $\left.72^{\circ} \mathrm{C}\right)$. The PCR product was examined by gel electrophoresis and purified with the DNA HighPrep kit (Magbio Genomics, Rockville, MD, USA). The concentration of PCR products was quantified with a Qubit Fluorometer (Life Technologies, Darmstadt, Germany) in combination with the 
dsDNA BR Assay kit (Invitrogen, Carlsbad, CA, USA). Purified products were then pooled in equi molar amounts $\left(200 \mathrm{ng} \mathrm{\mu l}^{-1}\right)$ and sequenced on a MiSeq platform (GATC-Biotech, currently part of Eurofins Genomics Germany GmbH, Konstanz, Germany).

\subsubsection{Processing of MiSeq data}

Illumina sequencing data was processed using the NG-Tax pipeline [274]. In short, pai red-end reads of $2 \times 100$ nucl eotides were combined and filtered to retain only read pai rs with perfectly matching primers and barcodes. Demultiplexing, Operational Taxonomic Unit (OTU) picking, chimera removal and taxonomic assignment were performed within onesinglestep in NG-Tax. Filtered sequences were ranked per sample by abundance and unique OTUs (ata $100 \%$ identity leve) were added to an initial OTU table for that sample starting from the most abundant sequence until the abundance was lower than $0.1 \%$. The final OTU table was created by clustering the reads that were initially discarded to the OTUs from the initial OTU table with a threshold of 99\% similarity. Taxonomic assignment was done using the UCLUST al gorithm [275] and a customized SI LVA SSU Ref 111 database[232]. Samples with less than 1000 reads (Bacterial 16S rRNA gene reads plus chloroplast 16S rRNA gene reads) were removed, and all chloroplast 16S rRNA reads were removed from the dataset. The number of retained reads for each sample was cal culated again, and samples with less than 100 bacterial 16S rRNA gene reads were removed as well.

\subsubsection{Statistical analysis}

All statistical tests were performed in R (v.3.1.2) [235]. First, the OTU table was standardized by a square root transformation using the decostand function (method = "hellinger") from the vegan package [234]. Transformed data was subsequently used to calculate al pha-diversity indices (Shannon diversity and Richness). Pairwise comparison of al phardiversity between the different reactors within each run was cal culated using Wilcoxon rank sum test and Benjamini- 
Hochberg p-val ue adjustment as implemented in the "STATs" package [235, 276]. For further multivariate analyses the vegdist function from the vegan package was used to create a BrayCurtis dissimilarity matrix of thestandardised OTU table. Hierarchical clustering of all samples based on the Bray-Curtis dissimilarity matrix was performed using the "average" method. Then, anon-metric multidimensional (nMDS) scaling pl ot was generated using themetaMDS function based on pairwise Bray-Curtis di stances. Overal differences in bacterial communities between reactors were assessed statistically with PERMANOVA (adonis) from the vegan package. PERMANOVA was also performed to test whether bacterial communities between reactor types are significantly different. Detrended Correspondence Analysis (DCA) was performed and Canonical Correspondence Analysis (CCA) was the best constrained ordination model for the bacterial communities. Significance of the environmental factors was tested by the envit function with 999 MonteCarlo permutations. The overall significance of CCA and of each axis were tested by anal ysis of variance (ANOVA) permutation tests. Pearson's correlation analysis between each pair of parameters measured in this study was done using rcorr function in "Hmisc" package. The OTU heatmap was created with the "pheatmap" package

\subsection{Results}

\subsubsection{Bacterial community profiles}

Bacterial community composition dynamics in six different photobioreactors in which Nannochloropsis sp. CCAP211/78 was grown, was investigated with Illumina MiSeq amplicon sequencing of the V1-V2 region of bacterial 16S rRNA genes. After removing twenty-onelowqual ity samples, weretained 3,574,708 high-qual ity sequences with an average of 33,408 reads per sample. These sequences represented 1,217 operational taxonomic units (OTUs). A total of 2,703,376 reads ( $75.6 \%$ of all retained reads, 237 OTUs) were derived from Nannochloropsis chloroplasts. After removal of chloroplast OTUs from the dataset, 980 bacterial OTUs were 
used for bacterial diversity anal yses. This final dataset of 165 rRNA genereads fromall reactors represented 13 phyla, with only a small fraction of sequences that could not be classified at the phylum level (2.39\%) (Figure 4.1A). Bacteroidetes and Proteobacteria were on average the most predominant phyla in all reactors $(44.0 \% \pm 5.1 \%$ and $43.8 \% \pm 6.8 \%$, respectively). The raceway pond (RP) had the highest relative abundance of Actinobacteria (11.5\%) and Verrucomicrobia (7.5\%). The highest proportion of Planctomycetes was 3.7\% in the outdoor flat panel (PP), and Verrucomicrobia and Planctomycetes were present in all reactors except the indoor flat panel (FP). The other eight phyla together only contributed to a minor part of total bacterial reads in all reactors, which was approximately $1.2 \%$ in the vertical tubular reactor (VT) and less than $1 \%$ in other reactors. We then assessed the most abundant bacterial taxa across all samples at the family level (Figure 4.1B). The Rhodobacteraceae (phylum Proteobacteria) were highly predominant in all reactors and were the most abundant family in FP, RP and PP with relative abundances of 40.5, 22.6 and $19.5 \%$, respectively. The second most predominant family in FP was Flammeovirgaceae (phylum Bacteroi detes), constituting nearly $30 \%$ of the bacterial reads. However, theF lammeovirgaceae wereabsent or present at only low relative abundance in the other reactors. In contrast, two other families within the Bacteroidetes not detected in FP were present at high relative abundance in the other reactors: Flavobacteriaceae with relative abundances between $5.6 \%$ and $17.4 \%$, and Saprospiraceae between 3.9\% and 22.5\% (Figure 4.1B). Some bacterial families were only predominant in specific reactors. For instance, Microbacteriaceae (phylum Actinobacteria) and the NS1112_marine_group (phylum Bacteroidetes) were predominant in both TI and RP. 

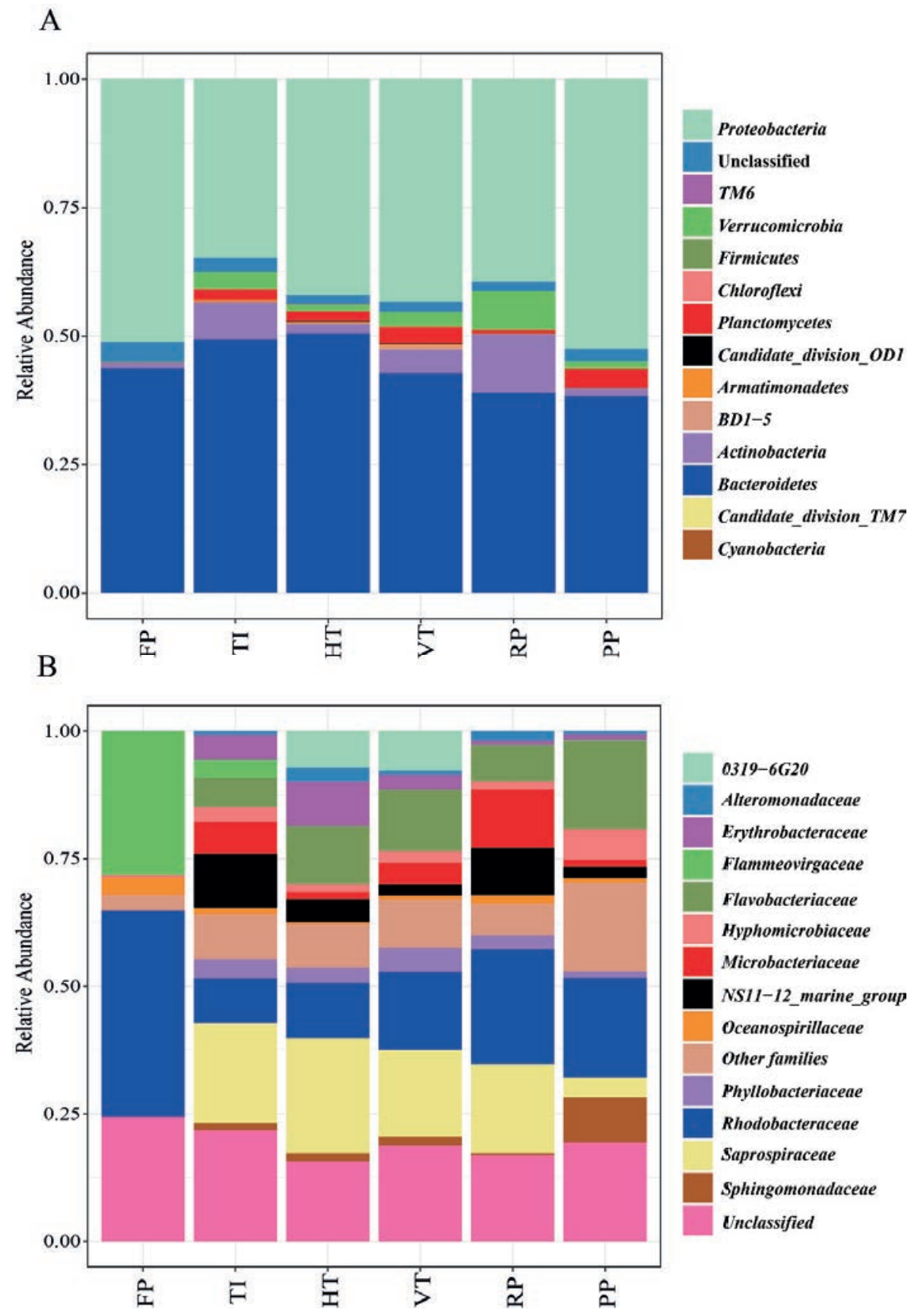

Figure 4.1. R elative abundance of (A) bacterial phyla and (B) families in different reactors. $\mathrm{FP}=$ Flat panel reactor, $\mathrm{TI}=$ Tubular indoor reactor, $\mathrm{HT}=$ Horizontal tubular reactor, VT = Vertical tubular reactor, $\mathrm{RP}=$ Raceway pond, $\mathrm{PP}=$ Plastic flat panel reactor. 
At the OTU level, members of the genera Rhodobacter (OTU538) and Ekhidna (OTU1117) had the highest relative abundance in FP (Figure S4.4). OTUs from unidentified genera from the Saprospiraceae (OTU1261) and the NS11-12_marine_group (OTU1092) predominated all other reactors. Other OTUs had a more incidental occurrence and were present at high relative abundance only in certain reactors or individual runs, such as OTU249 (Devosia) and OTU288 (Paracoccus) in PP, OTU398 (Erythrobacter) in HT, and OTU863 (Microbacteriaceae) in RP (Figure S4.4).

\subsubsection{Bacterial diversity in indoor and outdoor reactors}

The bacterial communities present in the autoclaved indoor reactor FP al ready were characterized by a considerable al phardiversity (Figure 4.2). Generally in the larger nonsteri lely operated indoor reactor (TI) and outdoor reactors (HT, VT, PP, RP) Shannon diversity and OTU richness were not significantly different fromFP. In addition, Shannon diversity and OTU richness were not significantly different between different outdoor reactor types (Figure 4.2, Table S4.1). Both al phardiversity indices were significantly higher in VT and PP for the second run in the year (run2) than for the first run (run1).

A

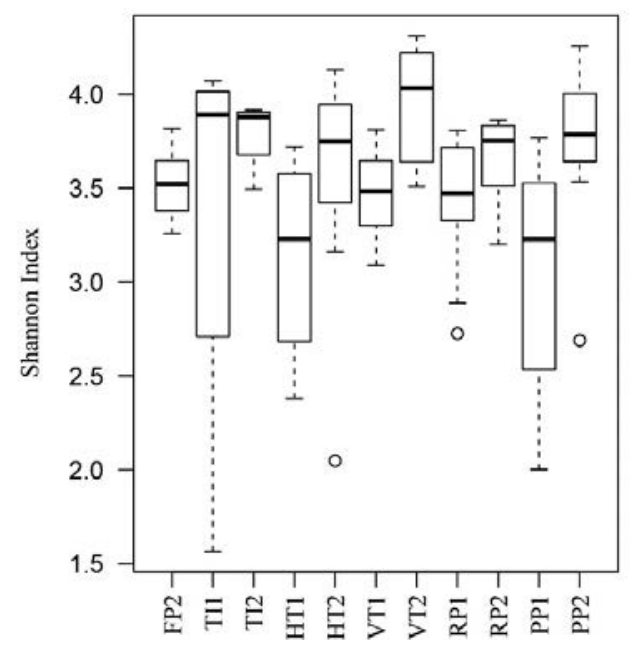

B

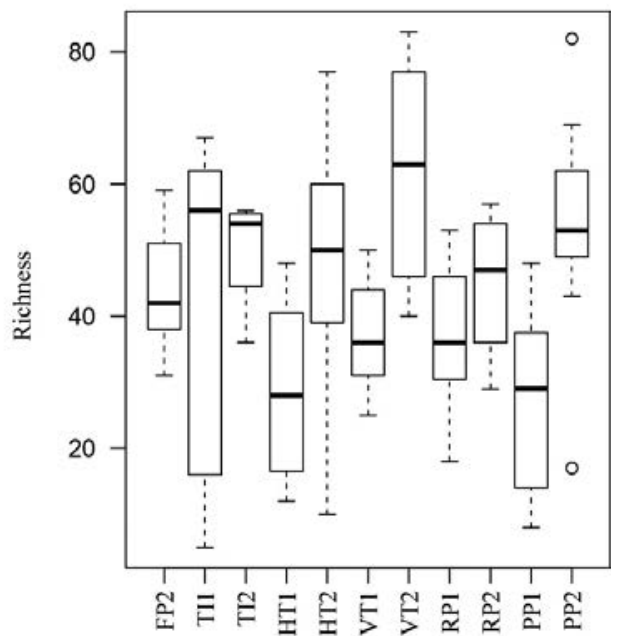


Figure 4.2. Box-plot of (A) Shannon diversity indices and (B) Observed OTU richness for each of the reactors for the two runs. Upper and lower lines correspond to the maximum and minimum of the distribution. The upper and lower limits of theboxes are third and first quartile. Horizontal black thick lines are the median val ues. Outliers are displayed as open circles.

The reactor type had a significant impact on the beta-diversity of the bacterial communities present in the reactors (Adonis test, $p=0.001$ ). Pairwise comparisons of bacterial communities between reactor types reveal ed that bacterial communities in all reactors significantly differed from each other except HT and VT (Table S4.2A). Bacterial communities within the same reactor type were different in different runs (Table S4.2B) for all reactor types.

\subsubsection{Temporal fluctuations of bacterial communities}

Although bacterial communities in $\mathrm{TI}$ and PP reactors were initially si milar to those in FP from which they were inocul ated, the communities changed as the cul tivation continued (Figure4.3). Likewise, theother three outdoor reactor types (HT, VT, RP) initially clustered closeto TI from which they were inocul ated, but at a later stage becamemore dissimilar to the community in $\mathrm{TI}$ with especially rapid community changes near the end of a run in HT, VT and RP (Figure 4.3). Hierarchical clustering of bacterial community composition clearly showed temporal differences in profiles in HT, VT and RP1 where samples early in the runs were clustered in group 2 and all samples later in the runs in group 3 (Figure S4.2). No different phases were identified in RP2 as only five samples passed sequencing qual ity thresholds.

The twenty-one OTUs that contributed most to the dissimilarity between bacterial community profiles in the starting phase and end phase of the runs in HT, VT and RP1 (group 2 and 3 in FigureS4.2) wereidentified. In total, thesetwenty-oneOTUs contributed more than $28 \%$ to the between-group dissimilarity. OTU1261 (family Saprospiraceae) had highest contribution (3.67\%) to the dissimilarity between the two phases of cultivation and decreased dramatically in HT, VT as well as in RP1 during the run. Other predominant OTUs that nearly disappeare 


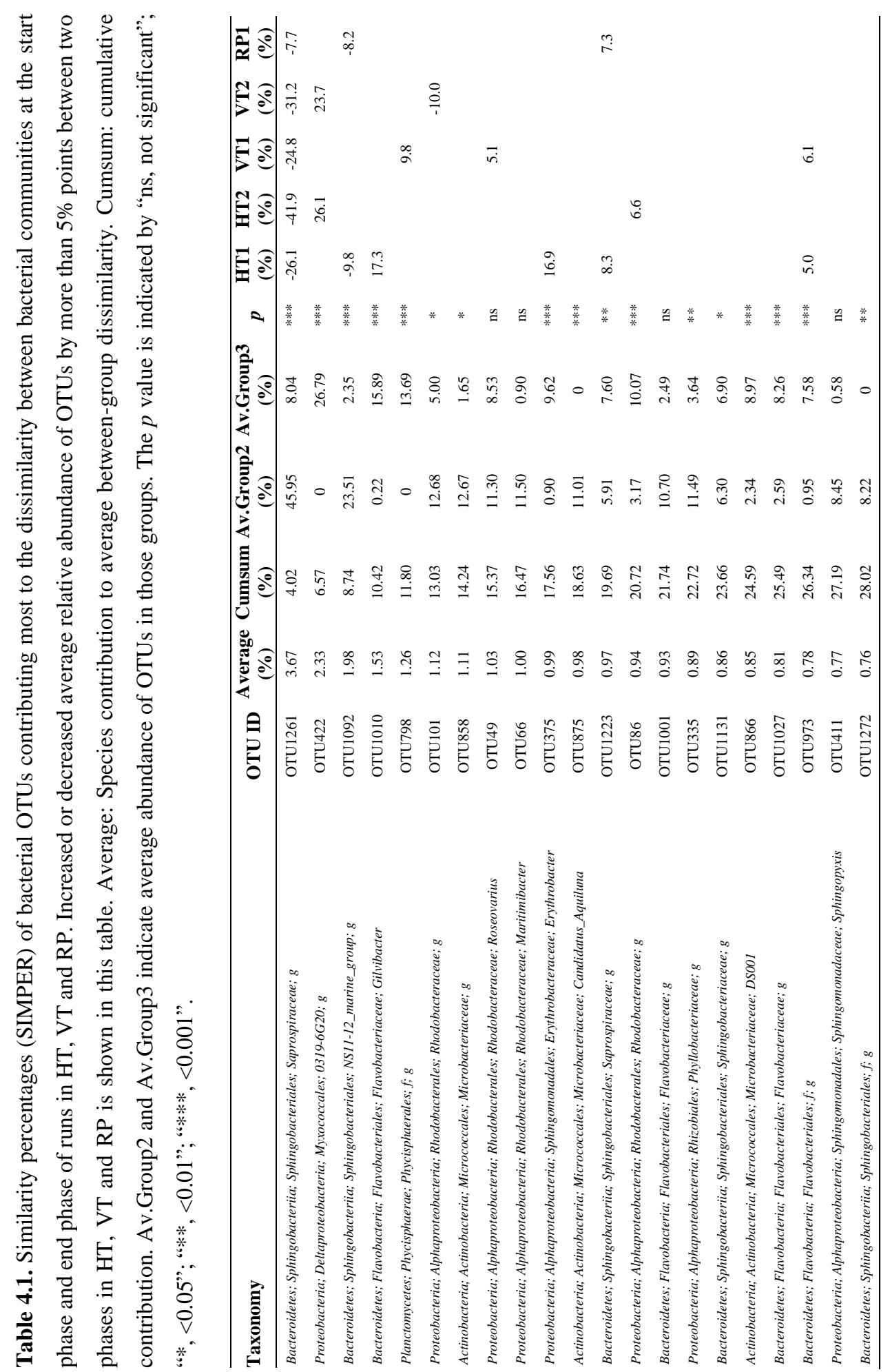


in the end phase were OTU1092 (NS11-12_marine_group) in HT1 and RP1 and OTU101 (Rhodobacteraceae) in VT2. Eight OTUs were strongly increased in the late phase of the runs. These mostly varied by reactor type and run but many belonged to the classes Al phaproteobacteria and Flavobacteriia (Table 4.1).

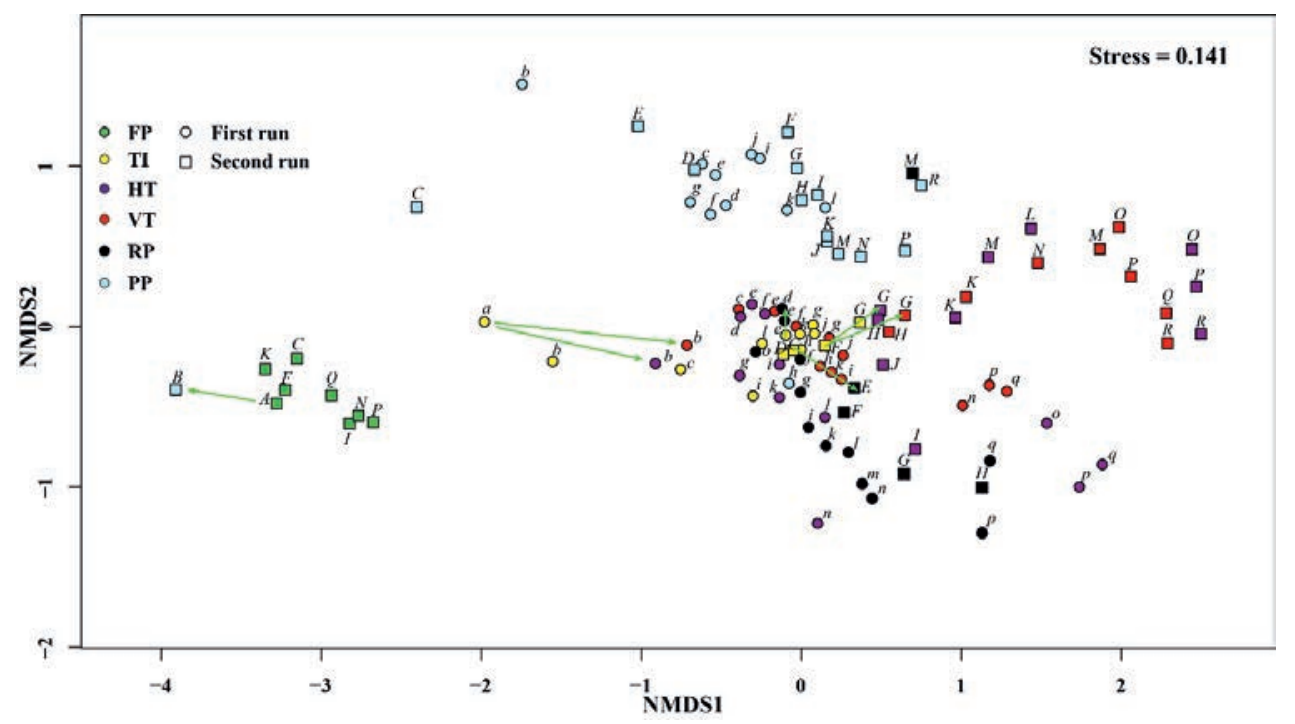

Figure 4.3. Non-metric multidimensional scaling (nMDS) of Bray-Curtis distances based on normali sed rel ative abundance of OTUs in bacterial communities in six reactor types (different colours). Each reactor was run twice (except FP), and samples from the first run are indicated by circles and the second run by squares. Inoculation is indicated by green arrows. First run samples are sequentially labelled with lower case letters (a-q), and second run samples are sequentially labelled with upper case letters (A-R). Same letters indicate that samples were taken at the same day. FP = Flat panel reactor, $\mathrm{TI}=$ Tubular indoor reactor, $\mathrm{HT}=$ Horizontal tubular reactor, $\mathrm{VT}=$ Vertical tubular reactor, $\mathrm{PP}=$ Plastic flat panel reactor, $\mathrm{RP}=$ Raceway pond.

\subsubsection{Environmental dhivers of Nannochloropsis-associated bacterial community development}

To identify themain driver(s) underlying temporal changes in bacterial community composition in different reactors as well as differences in bacterial community composition between 
different reactor types, the correlation of temperature (Temp), $\mathrm{pH}$, nitrate concentration ( $\mathrm{NO}_{3}^{-}$), photon flux density (PFD), and algal biomass productivity (PRO, defined as volumetric productivity: $\mathrm{g} \mathrm{L}^{-1} \mathrm{~d}^{-1}$ ) with bacterial community structure was investigated. Overall, only approximately $4.8 \%$ of the compositional variation could be explained by the first axis and $3.5 \%$ by thesecond axis of the CCA using the parameters eval uated in this study (Figure4.4A). The bacterial community in PP correlated best with PRO and Temp, while $\mathrm{NO}_{3}{ }^{-}, \mathrm{PFD}$ and $\mathrm{pH}$ correlated best with bacterial community composition in all samples of FP and part of the samples in TI, HT, VT and RP (Figure 4.4A). A nother part of the HT and VT samples were correlated with lower values of Temp, PFD and PRO. From the parameters we measured, Temp, PFD and PRO were positively correl ated with each other (Figure 4.4B). By contrast, $\mathrm{NO}_{3}{ }^{-}$was negatively correlated with PRO and PFD. This trend also corresponded with the observation that the first run in the outdoor reactors was characterized by higher PRO than the second run, which likely resulted from higher Temp and PFD in the first run (Figure S4.5). 
A

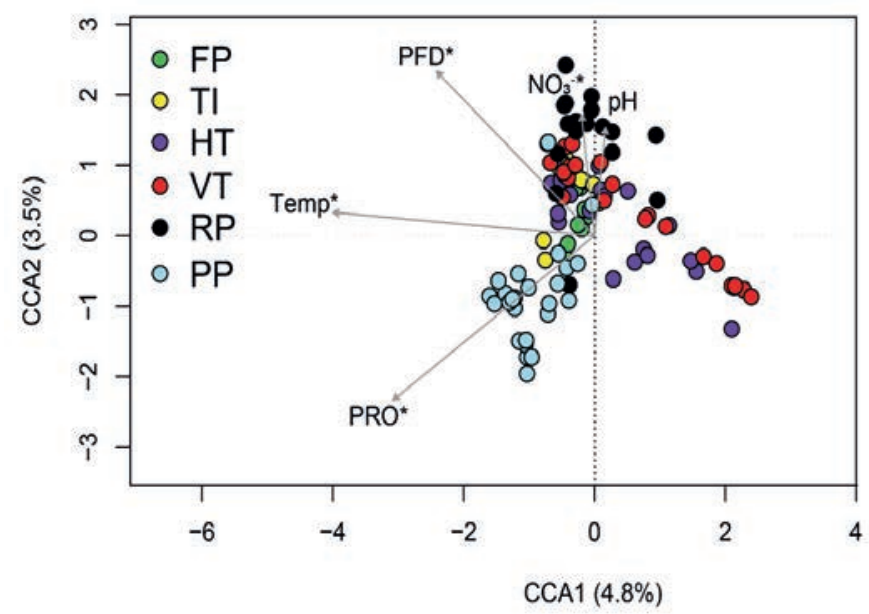

B

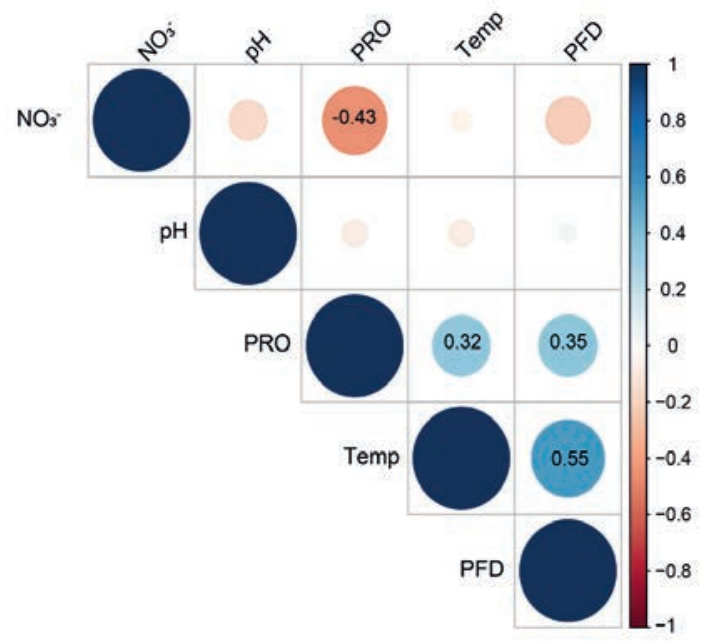

Figure 4.4. (A) Canonical correspondance analysis (CCA) showing correlation between bacterial communities (response variables) and environmental factors (explanatory variables). The percentage of variation in the bacterial community explained by each axis is indicated in parentheses after the axis label. The environmental factors with * significantly contribute to explaining the observed variation in bacterial community composition ( $p<0.05$ ). (B) Pearson correlation anal ysis between environmental factors. Only correl ation coefficients with $p<0.05$ are indicated. The factors included are Temp (temperature), $\mathrm{pH}, \mathrm{NO}_{3}{ }^{-}$(nitrate concentration), PFD (photon flux density), PRO (al gal biomass productivity). 


\subsection{Discussion}

Bacteria in association with microalgae have rarely been investigated in large microalgae culture systems and the studies that did, onl y assessed onetype of outdoor reactor. For instance, bacterial communities were analysed before in a $300 \mathrm{~L}$ outdoor flat panel reactor with Tetraselmis suecica [118], in a 550 L outdoor tank with Nannochl oropsis sal ina [91], in a 200 L polyethylene flat panel reactor with Nannochloropsis salina [69] and in a $1600 \mathrm{~L}$ enclosed membrane reactor with Desmodesmus and Scenedesmus for treatment of domestic waste water [162].

\subsubsection{Differences between reactors}

We compared for the first time the bacterial communities of four pilot-scale outdoor photobioreactors operated under identical climatological conditions for the production of Nannochloropsis sp. CCAP211/78. We found bacterial communities were significantly different between FT, $\mathrm{TI}$ and theoutdoor reactors (Figure 4.1A and TableS4.2). This result was in accordance with a previous study that showed that the bacterial community of Nannochl oropsis sal ina differed between small indoor reactors (Volume: $5 \mathrm{~mL}-4 \mathrm{~L}$ ), medium indoor reactors (Volume: 20-60 L) and a large outdoor reactor (Volume: 200 L) [69]. Fulbright et al. [69] also reported that OTU richness increased as the size of the reactors increased. However, neither OTU richness nor Shannon index was significantly different between reactor types inthisstudy (Figure4.2, TableS4.2A). Thisfinding reveals sthat Nannochloropsis cultures in FP were al ready colonised by diverse bacteria before being harvested to inoculate other reactors. Weobserved a cl oseassociation between i nocul um samples in onereactor and receiver samples in theother reactor (Figure4.3), which corroborates that theinitial bacterial community composition in each reactor is largely determined by the bacterial community in precultures from which the subsequent reactors was inoculated. 
Despite differences in bacterial community composition between reactor types, the most abundant bacterial phyla in all reactors were similar, with predominance of Proteobacteria (predominantly Alphaproteobacteria) and Bacteroidetes (Figure 4.1). In previous studies, Alphaproteobacteria and Bacteroidetes were shown to be the most abundant phyla in Nannochl oropsiscultures [69, 87, 277]. Several bacterial familiesfound in this study aresimilar to those found in the cultures of N. salina, which include members of the families Saprospiraceae, Phyllobacteriaceae, Hyphomonadaceae, Rhodobacteraceae and Alteromonadaceae [69, 278]. Theoccurrence of thesametaxa associated with Nannochloropsis species in different environments and locations suggests that these bacteria may have specific interactions with Nannochl oropsis [87, 279]. For example, members of the Phyllobacteriaceae have been shown to enhance the growth of algae through vitamin supplementation [22] and nitrogen fixation [105].

At the OTU level, the FP bacterial community was predominated by a few highly abundant OTUs, whereas more diverse OTUs were found in the larger reactors (Figure S4.4). Three predominant representatives in FP (Rhodobacter_OTU538, Ekhidna_OTU1117 and Bal neola_OTU835) have previously been found either in cultures of Nannochloropsis ocul ata [92], Ectocarpus sp. [103] or Emiliania huxleyi [280]. Y et their roles in algal cultures havenot been characterized. Themost abundant taxon (OTU1261) in TI and all outdoor reactors bel ongs to the Saprospiraceae (Figure S4.4). The best hit returned by a Blast search against the NCBI $\mathrm{nr} / \mathrm{nt}$ database is Phaeodactylibacter xiamenensis ( $100 \%$ identity), which was isol ated from a culture of themarinediatom Phaeodactylumtricornutum[281]. Although two Saprospiraceaerelated OTUs were al so observed in the inflowing seawater (Table S4.4), these were different from the most abundant OTU (OTU1261) and represented only minor fractions of the bacteria found in the different reactors. I naddition, OTU1261 is not closel y related to thelytic bacterium Saprospira sp. (92\% identity) that was reported to kill and lyse the cells of the diatom 
Chaetoceros ceratosporum [269]. A bacterium belonging to the Saprospiraceae family was previously found to be most abundant on average (comprising $34.7 \% \pm 14.3 \%$ of bacterial communities) inlarge-scalecul tures of Nannochloropsis salina in aclosed polyethylenegrowth panel ( $0.05 \mathrm{~m}$ wide $\times 0.28 \mathrm{~m}$ high $\times 17.3 \mathrm{~m}$ long) located outdoor in a water basin [69]. Although no correlation was observed between relative abundance of Saprospiraceae and N. salina growth performance [69], its ubiquitous predominance in all mass culture systems both in a previous study and this study suggests that there are important interactions between members of this family and Nannochloropsis or at least a commensal relationship. Another OTU common to TI and outdoor reactor samples was classified as a member of the NS1112_marinegroup (Bacteroidetes) that has been mainly detected in marine environments [282]. However, as the unresolved taxonomy indicates, we still know little of their ecological roles. Some genera with random occurrence in certain reactors or runs, such as Devosia (OTU249), Paracoccus (OTU288) and Erythrobacter (OTU398) (Figure S4), have been frequently found to associate with either seaweeds [283-285] or microal gae [286]. Devosia sp. was inferred to play a role in nitrogen fixation as an epiphytic bacterium associated with the macroal ga Cladophora glomerata [287], and may have a similar interaction with Nannochloropsis. Paracoccus as well as Erythrobacter were reported to be diatom-associated and found to be resistant to polyunsaturated al dehydes released by diatom cells upon disruptions by grazers, suggesting co-evol ution of resistanceto toxic molecul es in diatoms and their associated bacteria [96].

Thel ongitudi nal sampling strategy hel ped us examinetheinfluence of biotic and abi otic factors on the structure of Nannochloropsis sp. CCAP211/78-associated bacterial communities. Temperature, salinity and nutrient concentration (nitrate) are the most important factors structuring bacterial communities in aquatic environments, such as in estuaries and coastal seawater [288-290]. Salinity was not measured in this study because the fluctuation in sal inity 
is negligible in our experimental setup. To this end, it should be noted that sal inity fluctuation of RP due to evaporation or rain was adjusted by daily addition of fresh water or sodium chloride. Temperature and nitrate can directly affect bacterial growth, but also influence al gal growth [291, 292], which would in turm affect bacterial growth. Similarly, light intensity and $\mathrm{pH}$ can affect the growth of both algae and bacteria [293, 294]. Correspondence canonical analysis reveal ed that nitrate is a primary factor that drives variation in bacterial community composition in all reactor types except PP. Nitrate is a key chemical that influences microbial communities through its effects on nutrient utilization and growth [295, 296]. Many bacteria can utilize nitrateand even compete with al gae when nitrateconcentration is low [96, 297, 298]. Besides, nitrate was actively consumed by Nannochloropsis, which was demonstrated by the negative correlation between al gae biomass productivity and nitrateconcentrations (Figure 4B). These results indicate that the bacterial community is at least partly structured by the avai lability of nitrate but al so by the growth of al gae. On the other hand, the distinct bacterial community composition in PP could be explained by the highest biomass productivity of Nannochloropsis. It is likely that al gal physiology and metabolites released by microal gae could substantially contribute to the distinctness of bacterial communities [272]. It should benoted that the biggest part of bacterial community variation cannot be explai ned by the monitored factors included in the CCA (Figure 4.4A). The omission of some important environmental factors, such as phosphorus concentration and dissol ved organic matter, coul d bea reason. Theseenvi ronmental factors were previously shown to affect microbial community composition in marine waters [299, 300] and should be measured in future studies. In addition, stochastic effects related to microorganisms entering the reactors from the outside could contribute to the different changes of bacterial community composition in different systems. For instance, bacteria may enter reactors through the addition of seawater for the daily dilution of algal biomass, which is 
supported by the observation that a range of bacteria are shared between seawater samples and microal gal cultures (TableS4.3).

\subsubsection{Differences between runs}

Bacterial community composition was significantly different between runs. Presumably, one factor governing this difference relates directly to inoculation. Specifically the bacterial community of theinoculum used for the firstrun was different from theinoculumfor the second run (Figure 4.3). More importantly, since the first run spanned the period fromJ uly till August and the second run spanned the period fromA ugust till October, temperature and light intensity differed between both runs, which may directly or indirectly change the bacterial community. These discrepancies between two runs might al so be linked to the observation that both al pha diversity indices were seemingly higher for the second run than for the first run for all outdoor reactor types. In marine environments, the maximum OTU richness and evenness were found in a temperature range from $15^{\circ} \mathrm{C}$ to $20^{\circ} \mathrm{C}$, with lower diversity both above and bel ow those temperatures [301]. All our outdoor reactors were operated at an average temperature $>20^{\circ} \mathrm{C}$ (except $\mathrm{HT} 2$ ) and the temperature was at least $2^{\circ} \mathrm{C}$ higher during the first run than during the second run (Figure S4.5). Therefore, the higher temperature in the first run may have led to the reduction of both al pha-diversity indices. Furthermore, the higher al gal biomass productivity of thefirst run might haveresul ted in higher concentrations of extracellular organic compounds, which favour the growth and dominance of fast growing copiotrophic bacteria and thus lowering OTU richness and diversity. In addition, this observation can be supported by independent studies that have found a decrease of OTU richness and/or Shannon diversity during algal blooms [302-304].

\subsubsection{Bacterial community dynamics within runs}


Bacterial community composition al so varied within runs in all reactor types from the start of monitoring to theend (Figure4.3). TheFP reactor showed least variation, whereas this variation was more apparent in outdoor reactors. Presumably, this variation was caused by theinherently more variable environmental conditions (temperature, for instance) that were not as well controlled as in the indoor reactors. We identified a substantial number of the OTUs that increased pronouncedly in relative abundance near the end of the cultivation in outdoor runs in HT, VT and RP. These OTUs were annotated as members of the Flavobacteriaceae (2 OTUs) and Rhodobacteraceae (3 OTUs). These two families were also shown to be dominant in the stationary phase of batch cultures of Nannochloropsis salina [279], as well as in al gal blooms [305] and in a range of al gal production systems in general [117, 162, 306]. Bacteria belonging to the Flavobacteriaceae are fast-growing specialists observed during algae blooms and specialize in the degradation of al gal-derived complex organic matter [304, 307]. Members of the Rhodobacteraceae are often most abundant in bacterial communities that are closely associated with marine al gae, including natural phytoplankton blooms and al gal cultures [308, 309]. The frequent occurrence of Flavobacteriaceae and Rhodobacteraceae from independent studies emphasizes the specialized fitness of these taxa for thriving in al gal cultures [279]. Three OTUs showed a strong decrease in relative abundance at theend of cultivation incl uding the most preval ent OTU (Saprospi raceae_OTU1261). It has been shown that the growth phase and physiological state of algal cultures could serve as selective factors affecting bacterial composition and governing bacterial community structure [306]. As the growth of Nannochloropsis sp. CCAP211/78 in outdoor reactors at the end phase of cultivation is often associated with foul ing and contamination as indicated by Vree at al. [272], the observed shift of the predominant bacterial taxa in relative abundance near the end phase could potentially be a first indicator of culture instability [310]. Nevertheless, mechanistic insights are needed to 
understand the observed correlations of certain bacteria with the growth performance of Nannochloropsis sp. CCAP211/78.

\subsection{Conclusions}

165 rRNA geneamplicon sequencing enabled us to gain detailed insights into composition and dynamics of bacterial communities of Nannochloropsis sp. CCAP211/78 cultures grown under arange of environmental conditions and different pi lot-scal ephotobioreactor types. We showed changes in bacterial community composition during the successional scaling up process of algal cultivation from a small indoor reactor to large outdoor reactors. Each reactor type had a significantly different bacterial community composition except HT and VT. Bacterial community composition also significantly differed between runs of each reactor type. The inoculum source played a critical role in determining the initial bacterial community composition of each reactor type, whereas the physio-chemical factors affected later development of bacterial community composition. Nitrate concentration was the main abiotic factor that could be identified in this study regul ating di versity and composition of the bacterial community in all reactors except PP where al gal biomass productivity had a significant impact on shaping community structure. Although interactions between the bacterial community and biotic and abiotic factors across different reactors were explored in our study, a large fraction of the observed variation in community structure could not be explained by the variables we measured. Weal so identified a number of bacterial species with large changes in their relative abundance between the start and end of the cultivation of Nannochloropsis sp. CCAP211/78 and they may serve as a potential indicator of microal gal culture stability 


\section{Supplementary Information}

A

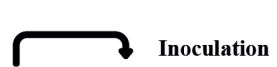

First run samples Second run samples

\begin{tabular}{|c|c|c|c|c|c|c|c|}
\hline Sampling Date & FP & TI & HT & VT & RP & PP & Labels \\
\hline \multicolumn{8}{|l|}{ 1-Jul-2013 } \\
\hline 3-Jul-2013 & & & & $\sqrt{5}$ & & & $a$ \\
\hline 5-Jul-2013 & & & & & & & $b$ \\
\hline 8-Jul-2013 & & & & & & & c \\
\hline 10-Jul-2013 & & & & & & & d \\
\hline 12-Jul-2013 & & & & & & & e \\
\hline 15-Jul-2013 & & & & & & & $f$ \\
\hline 17-Jul-2013 & & & & & & & $\mathrm{g}$ \\
\hline 19-Jul-2013 & & & & & & & $\mathrm{h}$ \\
\hline 22-Jul-2013 & & & & & & & $\mathrm{i}$ \\
\hline 24-Jul-2013 & & & & & & & j \\
\hline 26-Jul-2013 & & & & & & & $\mathrm{k}$ \\
\hline 29-Jul-2013 & & & & & & & 1 \\
\hline 31-Jul-2013 & & & & & & & $\mathrm{m}$ \\
\hline 2-Aug-2013 & & & & & & & $\mathrm{n}$ \\
\hline 5-Aug-2013 & & & & & & & 0 \\
\hline 7-Aug-2013 & & & & & & & $p$ \\
\hline 9-Aug-2013 & & & & & & & $q$ \\
\hline \multicolumn{8}{|l|}{ 12-Aug-2013 } \\
\hline \multicolumn{8}{|l|}{ 14-Aug-2013 } \\
\hline 16-Aug-2013 & & & & & & & $\mathrm{A}$ \\
\hline \multicolumn{8}{|l|}{ 19-Aug-2013 } \\
\hline 21-Aug-2013 & & & & & & & $B$ \\
\hline 23-Aug-2013 & & & & & & & $\mathrm{C}$ \\
\hline 26-Aug-2013 & & & & & & & $\mathrm{D}$ \\
\hline 28-Aug-2013 & & & & & & & $\mathrm{E}$ \\
\hline 30-Aug-2013 & & & & & & & $\mathrm{F}$ \\
\hline 2-Sep-2013 & & & & & & & $\mathrm{G}$ \\
\hline 4-Sep-2013 & & & & & & & $\mathrm{H}$ \\
\hline 6-Sep-2013 & & & & & & & 1 \\
\hline 9-Sep-2013 & & & & & & & $\mathrm{J}$ \\
\hline 12-Sep-2013 & & & & & & & $\mathrm{K}$ \\
\hline 14-Sep-2013 & & & & & & & $\mathrm{L}$ \\
\hline 16-Sep-2013 & & & & & & & $M$ \\
\hline 19-Sep-2013 & & & & & & & $\mathrm{N}$ \\
\hline 23-Sep-2013 & & & & & & & $\mathrm{O}$ \\
\hline 26-Sep-2013 & & & & & & & $\mathrm{P}$ \\
\hline 30-Sep-2013 & & & & & & & $\mathrm{Q}$ \\
\hline 3-Oct-2013 & & & & & & & $\mathrm{R}$ \\
\hline
\end{tabular}


B
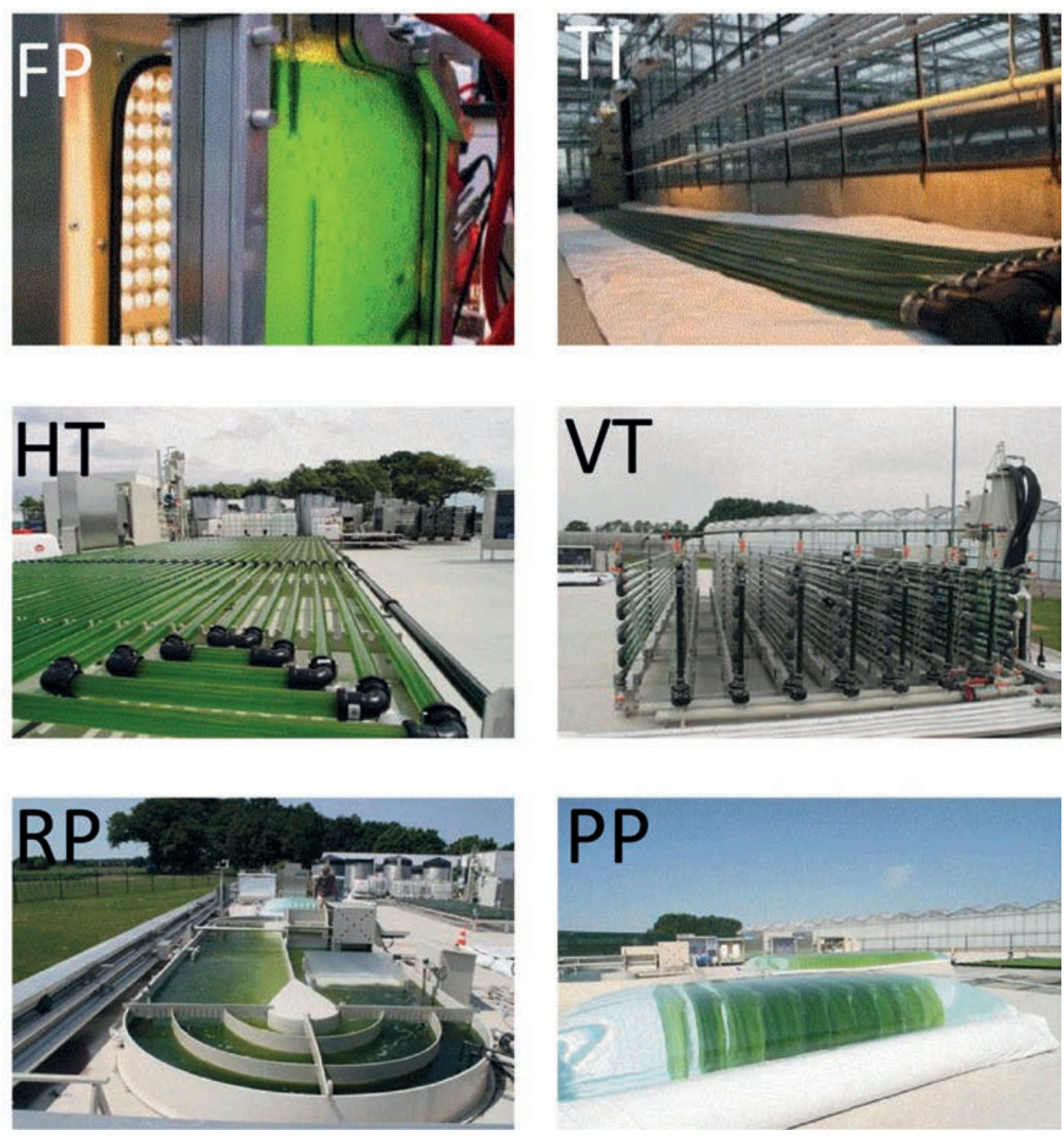

Figure S4.1. (A) Sampling and inoculating information for six reactors of two separate runs. (B) Overview of cultivation systems in this study. FP $=$ Flat panel reactor, $\mathrm{TI}=$ Tubular indoor reactor, $\mathrm{HT}=$ Horizontal tubular reactor, $\mathrm{VT}=$ Vertical tubular reactor, $\mathrm{RP}=$ Raceway pond, $\mathrm{PP}=$ Plastic flat panel reactor. Pictures were taken at AlgaePARC, Wageningen, the Netherlands. 


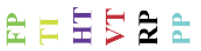

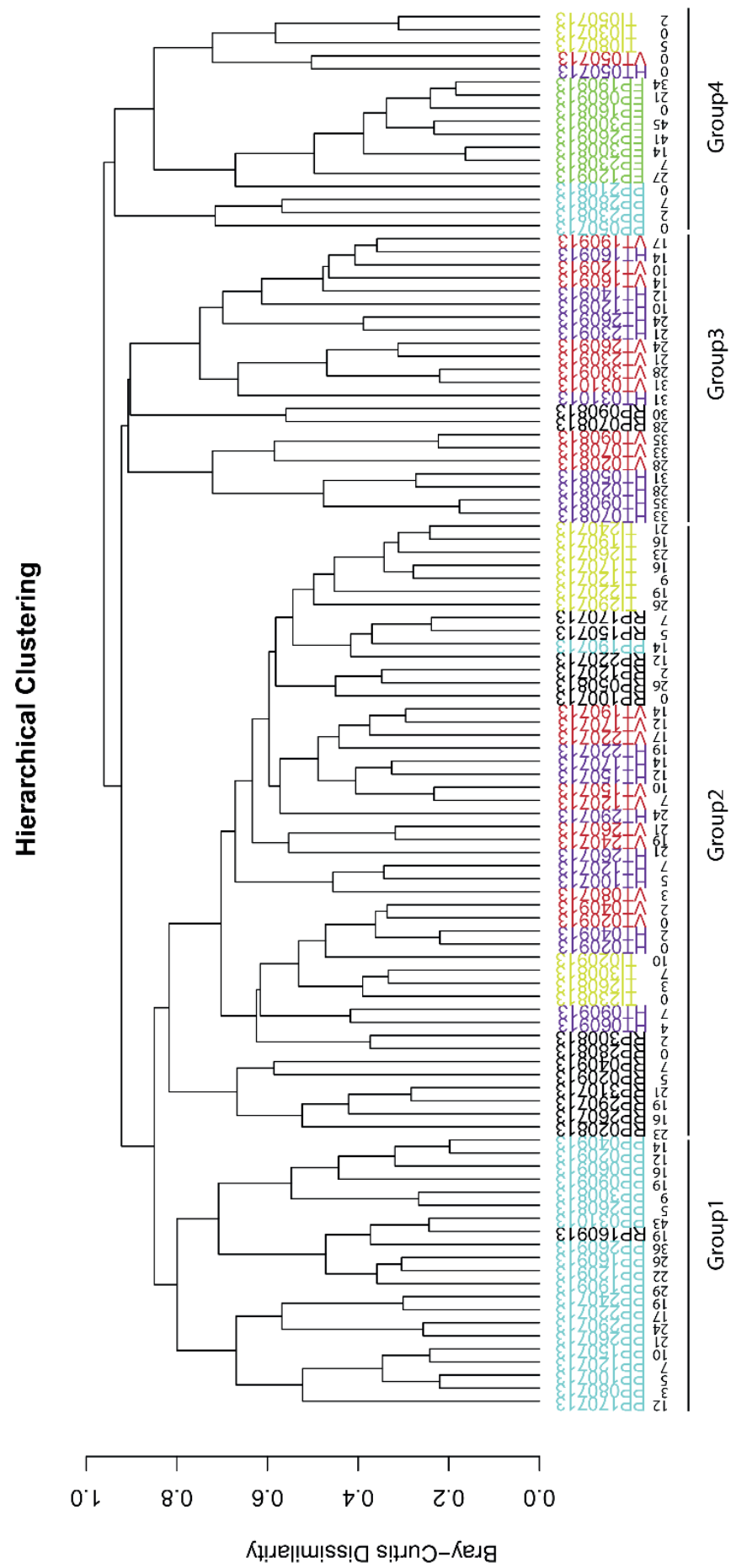

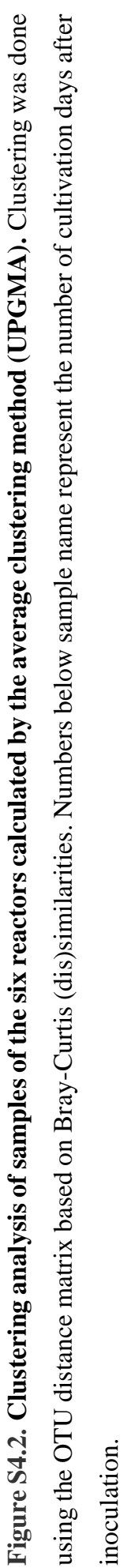




\begin{tabular}{|c|c|c|c|c|c|c|}
\hline Sampling Date & FP & $\mathrm{TI}$ & $\mathrm{HT}$ & VT & RP & PP \\
\hline \multicolumn{7}{|l|}{ 1-Jul-2013 } \\
\hline \multicolumn{7}{|l|}{ 3-Jul-2013 } \\
\hline \multicolumn{7}{|l|}{ 5-Jul-2013 } \\
\hline \multicolumn{7}{|l|}{ 8-Jul-2013 } \\
\hline \multicolumn{7}{|l|}{ 10-Jul-2013 } \\
\hline \multicolumn{7}{|l|}{ 12-Jul-2013 } \\
\hline 15-Jul-2013 & & $\mathrm{x}$ & & & & \\
\hline \multicolumn{7}{|l|}{ 17-Jul-2013 } \\
\hline 19-Jul-2013 & & & $x$ & & $\mathrm{x}$ & \\
\hline \multicolumn{7}{|l|}{ 22-Jul-2013 } \\
\hline 24-Jul-2013 & & & $x$ & & $x$ & \\
\hline \multicolumn{7}{|l|}{ 26-Jul-2013 } \\
\hline 29-Jul-2013 & & & & $x$ & & \\
\hline 31-Jul-2013 & & & $x$ & $x$ & & \\
\hline \multicolumn{7}{|l|}{ 2-Aug-2013 } \\
\hline \multicolumn{7}{|l|}{ 5-Aug-2013 } \\
\hline \multicolumn{7}{|l|}{ 7-Aug-2013 } \\
\hline \multicolumn{7}{|l|}{ 9-Aug-2013 } \\
\hline \multicolumn{7}{|l|}{ 12-Aug-2013 } \\
\hline \multicolumn{7}{|l|}{ 14-Aug-2013 } \\
\hline \multicolumn{7}{|l|}{ 16-Aug-2013 } \\
\hline \multicolumn{7}{|l|}{ 19-Aug-2013 } \\
\hline \multicolumn{7}{|l|}{ 21-Aug-2013 } \\
\hline \multicolumn{7}{|l|}{ 23-Aug-2013 } \\
\hline 26-Aug-2013 & & & & & $x$ & \\
\hline \multicolumn{7}{|l|}{ 28-Aug-2013 } \\
\hline \multicolumn{7}{|l|}{ 30-Aug-2013 } \\
\hline \multicolumn{7}{|l|}{ 2-Sep-2013 } \\
\hline 4-Sep-2013 & & $x$ & & & & \\
\hline 6-Sep-2013 & & & & $x$ & $\mathrm{x}$ & \\
\hline 9-Sep-2013 & & & & $x$ & $\mathrm{x}$ & \\
\hline 12-Sep-2013 & & & & & $x$ & \\
\hline 14-Sep-2013 & & & & & & \\
\hline 16-Sep-2013 & & & & & & \\
\hline 19-Sep-2013 & & & & & & \\
\hline 23-Sep-2013 & & & & & & \\
\hline 26-Sep-2013 & & & & & & \\
\hline 30-Sep-2013 & & & $x$ & & & $x$ \\
\hline 3-Oct-2013 & & & & & & \\
\hline
\end{tabular}

\begin{tabular}{|l|l|}
\hline $\mathbf{x}$ & Inoculation \\
\hline & Low quality samples \\
\hline & Group1 \\
\hline & Group2 \\
\hline & Group3 \\
\hline & Group4 \\
\hline
\end{tabular}

Figure S4.3. Samples marked with different colours according to the clustering analysis in FigureS2. Low-qual ity samples indicated with $x$ were removed before analysis. 


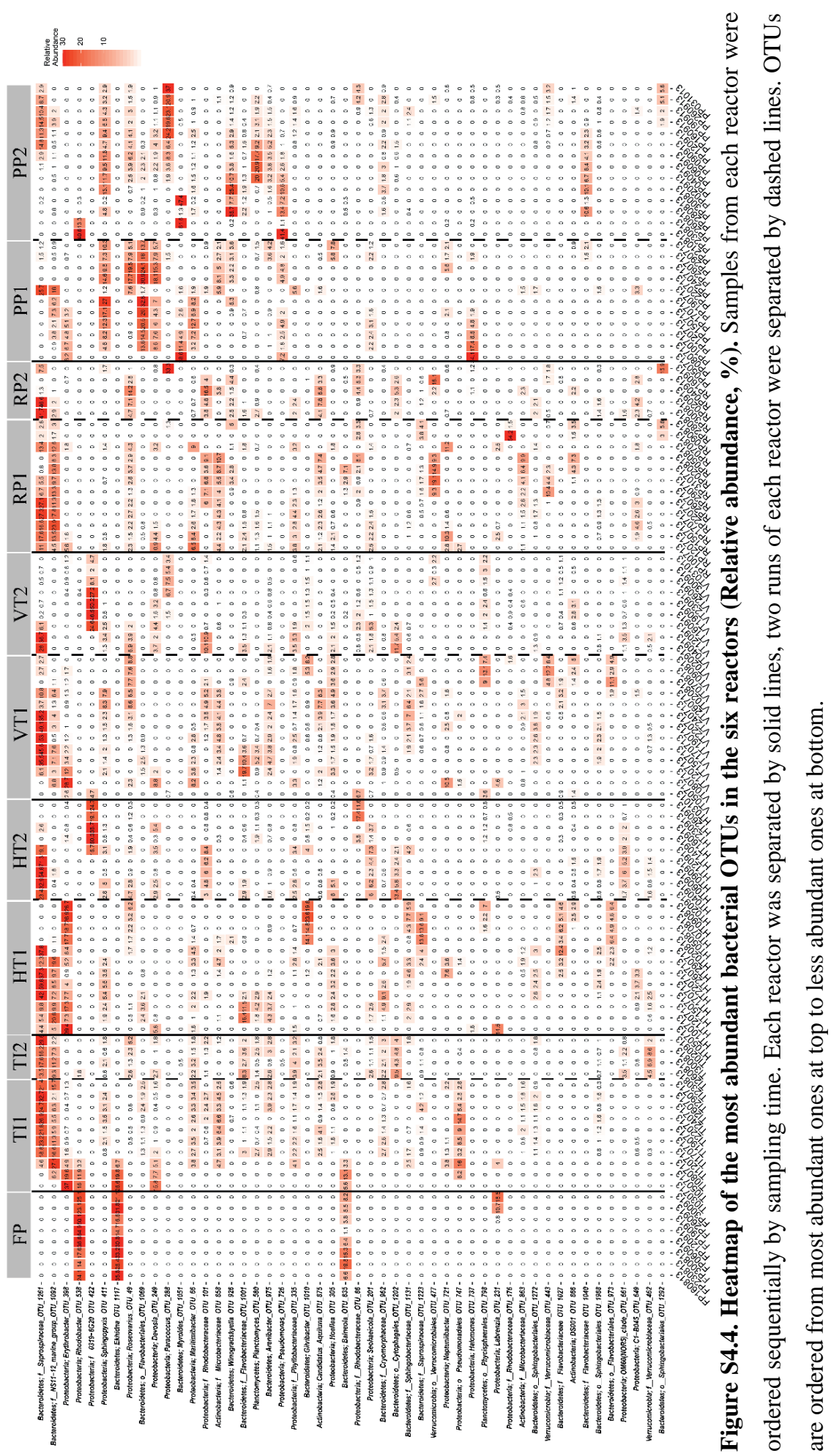



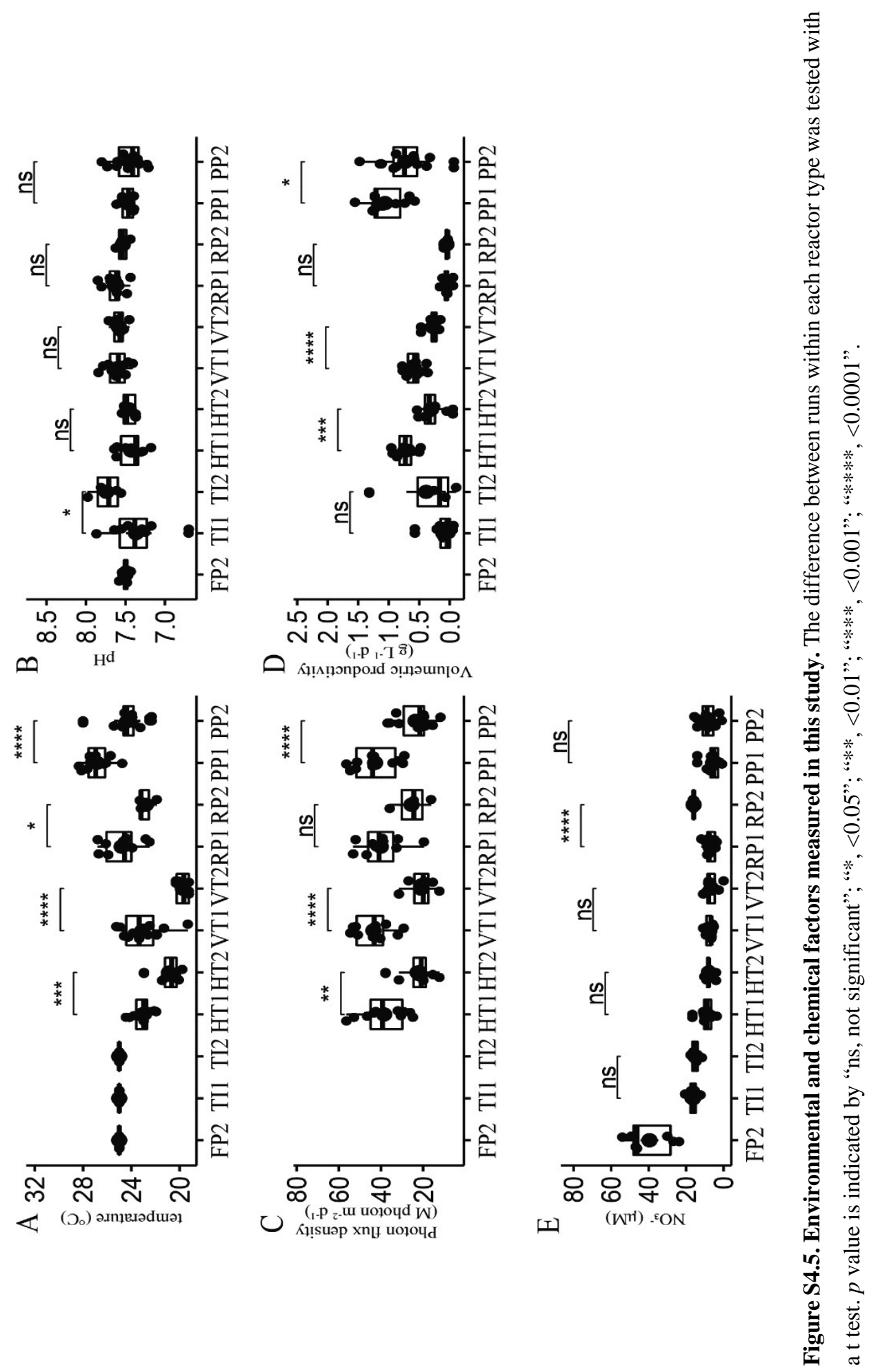
Table S4.1. Pair-wise comparison of Shannon index (A) and richness (B) for different runs in each reactor cal culated according to the Wilcoxon test ( $p$ adjustment method: BenjaminiHochberg), Bold val ues indicate $p \varangle 0.05$.

\begin{tabular}{lcccccccccc}
\hline \multicolumn{2}{c}{ (A) Shannon Index } & & & & & & & & \\
& FP2 & TI1 & TI2 & HT1 & HT2 & VT 1 & VT2 & RP1 & RP2 & PP1 \\
\hline TI1 & 0.4604 & & & & & & & & & \\
TI2 & 0.2000 & 0.9774 & & & & & & & & \\
HT 1 & 0.2230 & 0.2488 & 0.0659 & & & & & & & \\
HT 2 & 0.3868 & 0.9774 & 0.8416 & 0.0809 & & & & & & \\
VT 1 & 0.8112 & 0.3681 & 0.1020 & 0.2230 & 0.2331 & & & & & \\
VT2 & $\mathbf{0 . 0 3 7 9}$ & 0.2230 & 0.3101 & $\mathbf{0 . 0 0 8 4}$ & 0.2230 & $\mathbf{0 . 0 1 4 4}$ & & & & \\
RP1 & 0.8416 & 0.3681 & 0.0809 & 0.1823 & 0.3101 & 0.9774 & $\mathbf{0 . 0 3 3 8}$ & & & \\
RP2 & 0.4604 & 0.7426 & 0.3101 & 0.1182 & 0.8447 & 0.3101 & 0.2230 & 0.3101 & & \\
PP1 & 0.2230 & 0.2214 & 0.0627 & 0.9774 & 0.1020 & 0.2448 & $\mathbf{0 . 0 1 1 0}$ & 0.2230 & 0.1988 & \\
PP2 & 0.0731 & 0.8442 & 0.9774 & $\mathbf{0 . 0 0 6 2}$ & 0.7640 & $\mathbf{0 . 0 2 8 0}$ & 0.4199 & 0.0659 & 0.4596 & $\mathbf{0 . 0 0 6 2}$ \\
\hline
\end{tabular}

\begin{tabular}{lcccccccccc}
\hline \multicolumn{3}{l}{ (B) O bserved 0T Us } & & & & & & & & \\
& FP2 & TI1 & TI2 & H T 1 & H T2 & VT 1 & VT2 & RP1 & RP2 & PP1 \\
\hline TI1 & 0.6734 & & & & & & & & & \\
TI2 & 0.3790 & 0.8120 & & & & & & & & \\
HT 1 & 0.0733 & 0.2577 & 0.0785 & & & & & & & \\
HT 2 & 0.5545 & 0.9107 & 1.0000 & 0.0822 & & & & & & \\
VT 1 & 0.2577 & 0.3484 & 0.1175 & 0.2466 & 0.1210 & & & & & \\
VT 2 & 0.1175 & 0.2265 & 0.3196 & $\mathbf{0 . 0 1 2 8}$ & 0.2905 & $\mathbf{0 . 0 1 8 0}$ & & & & \\
RP1 & 0.4326 & 0.3388 & 0.1175 & 0.1712 & 0.1959 & 0.8984 & $\mathbf{0 . 0 3 1 7}$ & & & \\
RP2 & 0.9590 & 0.6734 & 0.7149 & 0.1175 & 0.7149 & 0.2905 & 0.2095 & 0.3196 & & \\
PP1 & 0.0785 & 0.1959 & 0.0785 & 0.9107 & 0.0785 & 0.2916 & $\mathbf{0 . 0 1 2 8}$ & 0.2265 & 0.1403 & \\
PP2 & 0.1210 & 0.6734 & 0.9107 & $\mathbf{0 . 0 0 9 1}$ & 0.6734 & $\mathbf{0 . 0 1 2 8}$ & 0.4838 & $\mathbf{0 . 0 3 1 7}$ & 0.3559 & $\mathbf{0 . 0 0 9 1}$ \\
\hline
\end{tabular}


Chapter 4

Table 54.2. Pairwise comparison of bacterial communities based on Bray-Curtis (dissimilarity at OTU level in different reactor types (PE RM ANOVA) (A) between pairs of reactors and (B) between different runs within each reactor. Bold val yes indicate $p<0.05$.

\begin{tabular}{lccccc}
\hline (A) & & & & & \\
\cline { 2 - 5 } & FP & TI & HT & VT & RP \\
\hline FP & & & & & \\
TI & 0.001 & & & & \\
HT & 0.001 & 0.001 & & & \\
VT & 0.001 & 0.002 & 0.177 & & \\
RP & 0.001 & 0.001 & 0.001 & 0.001 & \\
PP & 0.001 & 0.001 & 0.001 & 0.002 & 0.001 \\
\hline
\end{tabular}

\begin{tabular}{lr}
\hline (B) & \\
\hline TI1-TI2 & 0.007 \\
HT 1-HT2 & 0.001 \\
VT 1-VT2 & 0.001 \\
RP1-RP2 & 0.04 \\
PP1-PP2 & 0.001 \\
\hline
\end{tabular}

86 


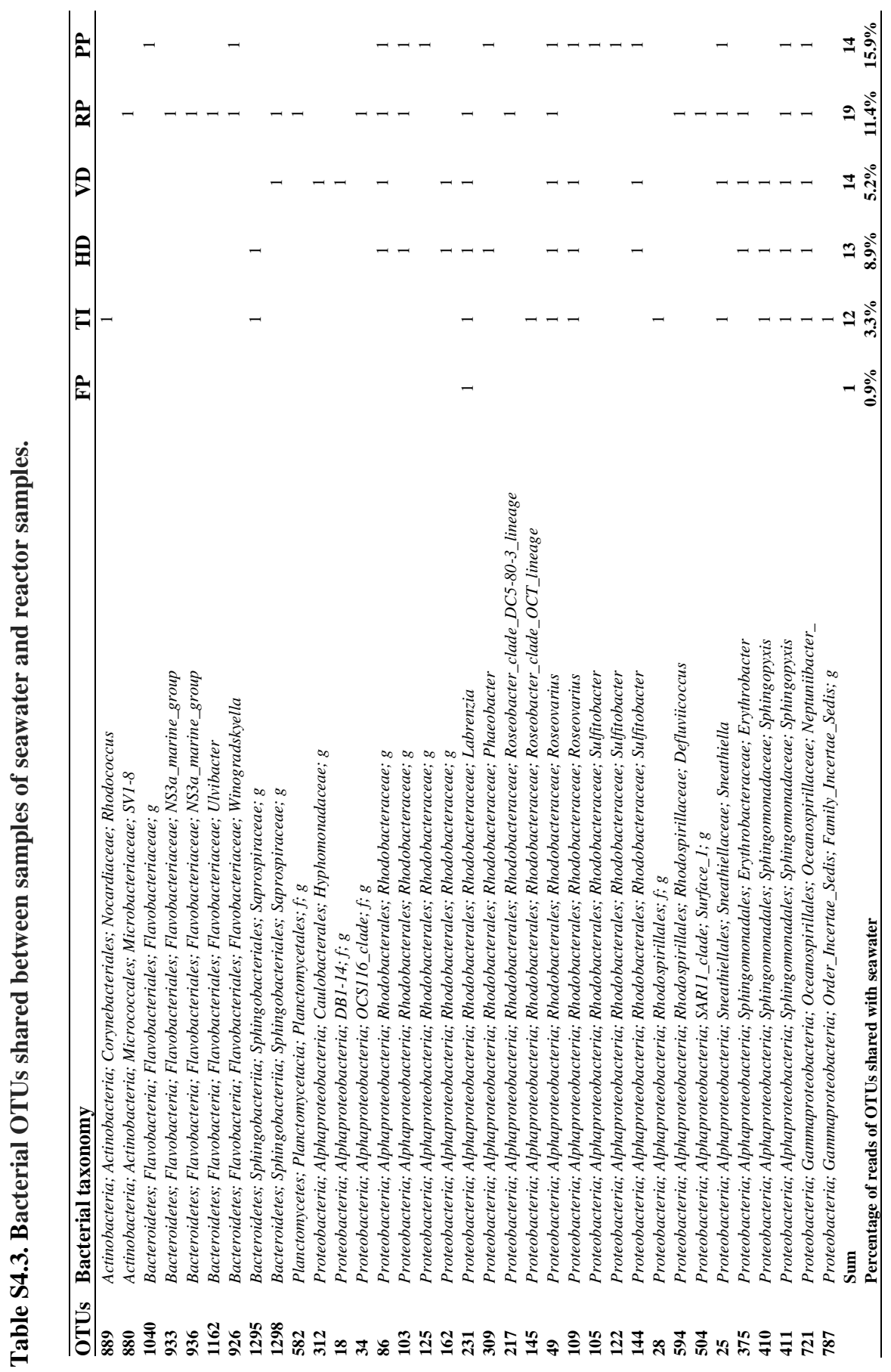





\section{Chapter 5}

Different co-occurring bacteria enhance or decrease the growth of the microalga Nannochloropsissp. C C A P211/78

Jie Lian, Patrick Schimmel, SeleneSanchez-Garcia, ReneH. Wijffels, Hauke Smidt, Detmer Sipkema

Manuscript in preparation 


\section{Summary}

Marine photosynthetic microal gae are ubiquitously associated with bacteria in nature. However, the influence of these bacteria on al gal cultures in bioreactors is still largely unknown. In this study, eighteen different bacterial strains were isolated from cultures of Nannochloropsis sp. CCAP211/78 in two outdoor pil ot-scale tubular photobioreactors. The majority of isol ates was affiliated with the classes Al phaproteobacteria and Flavobacteriia. To assess the impact of the eighteen strains on the growth of Nannochloropsis sp. CCAP211/78, 24-well plates coupled with custom-made LED boxes were used to simultaneously compare replicate axenic microalgal cultures with addition of individual bacterial isolates. Co-culturing of Nannochloropsis sp. CCAP211/78 with these strains demonstrated distinct responses, which shows that the technique we developed is an efficient method for screening the influence of harmful/beneficial bacteria. One strain of Maritalea porphyrae (DMSP31) and one strain of Labrenzia aggregata (YP26) significantly enhanced microal gal growth with a $14 \%$ and $12 \%$ increase of the chlorophyll concentration, respectively, whereas flavobacterial strain YP206 greatly inhibited the growth of the microalga with $28 \%$ reduction of the chlorophyll concentration. Our study suggests that al gal production systems represent a "natural" source to isolate and study microorganisms that can either benefit or harm algal cultures. Thus, the addition of specific bacteria may be used to maximise production of microal gae biomass.

Keywords: Algae-bacteria interaction, al gal bi otechnology, bacterial isolation, co-cultivation 


\subsection{Background}

Microal gae show great potential in producing numerous sustainable bioproducts as al tematives to fossil feedstocks [56, 57, 311]. A long-neglected aspect in al gal biomass production is the role of bacteria that are co-occurring in al gae cultivation systems [29, 312]. Algal cultures are axenic in only a few applications, whereas all microal gae mass production systems inevitably contain a number of non-target organisms (contaminants), incl uding bacteria[70, 266]. Bacteria are introduced in al gae cul tivation systems as al gae stocks used as starter cultures are often not axenic $[118,312,313]$. On the other hand, bacterial contaminants may enter cultivation systems through multiple operation processes, such as the supplementation of unsterilized medium or simply as ai rborne invaders in open al gal cul tures.

Microalgae-bacteria interactions are prevalent in natural aquatic environments, where microalgae release exudates into the phycosphere, the region immediately surrounding individual cells. Chemotaxis drives mul tiple bacteria to the phycosphere[314], and metabolites are readily exchanged between al gae and bacteria [2]. Although the phycosphere represents only a tiny area that can be as small as $1 \mu$ msurrounding the al gal cell, it represents the hotspot for most of the algal-bacterial interactions that can profoundly affect the productivity and stability of aquatic ecosystems $[2,96]$.

Recent research on al gal-bacterial interactions has usuall ly been centred around the competitive or antagonistic aspects, which often involve competition for nutrients [277, 315, 316] or al gicidal activities [2, 317]. For instance, in a microcosm experiment it was found that bacteria were more efficient than al gae in the uptake of phosphorus [315]. The advantage for bacteria is especially evident under phosphorus-limiting conditions [318]. Apart from competing for nutrients with al gae, some bacteria are known to inhi bit al gal cell division [319] or cause al gal cell lysis via secretion of al gicidal compounds [33, 35, 46]. 
In contrast to early views that bacteria mostly affect microalgae negatively, it has been demonstrated that mutual istic rel ationships between microal gae and bacteria areal so preval ent, or even more common than antagonistic interactions [2, 71]. Proof has been found from frequent observations that the absence of bacteria in algal cultures negatively affects algal physiology and growth [221, 320]. In exchange for dissolved organic matter from microal gae, bacteria fix nitrogen [141, 321] and synthesize a wide range of molecules, including vitamins $[22,24]$, the growth-promoting hormone indole-3-acetic acid [16, 270] and the siderophore vibrioferrin [271, 322]. Such division of labour and close cooperation enable the holobiont to better adapt to and grow in changing aquatic environments, which has al so triggered a growing interest for applications in industrial settings [323-325].

Contrary to extensive tests of effects of environmental and chemical factors (insolation, temperature, $\mathrm{pH}$, nutrients, etc.) on al gal growth in industrial photobioreactors, only a few studies have considered the effects of biotic factors such as associated bacteria. In order to assess the effects of co-occurring bacteria on microalgae in algal cultivation systems, we isolated and characterized bacteria from two pilot-scale outdoor tubular photobioreactors. Subsequently, a 24-well plate-based co-cultivation device was used to eval uate al gal growth with addition of the isolated bacterial strains to axenic microal gae. Effects of bacteria on microal gæe were further tested on a double layer agar plateto verify al gal-bacterial interactions.

\subsection{Experimental Procedures}

\subsubsection{Algal altivation}

Nannochl oropsis sp. CCAP211/78 cul tures used for bacterial isolation were obtained fromone horizontal and one vertical tubular photobioreactor at AlgaePARC, Wageningen, the Netherlands. Nannochloropsis sp. CCAP 211/78 was cultivated in seawater (Eastern Schel dt, the Netherlands) enriched with a nutrient stock solution resulting in the following final 
concentrations (in mM); $\mathrm{NaNO}_{3}, 25 ; \mathrm{KH}_{2} \mathrm{PO}_{4}, 1.7 ; \mathrm{Na} 2 \mathrm{EDTA}, 0.56$; $\mathrm{Fe} 2 \mathrm{SO} 4 \cdot 7 \mathrm{H}_{2} \mathrm{O}, 0.11$; $\mathrm{MnCl}_{2} \cdot 2 \mathrm{H}_{2} \mathrm{O}, 0.01 ; \mathrm{ZnSO}_{4} \cdot 7 \mathrm{H}_{2} \mathrm{O}, 2.3 \cdot 10^{-3} ; \mathrm{Co}\left(\mathrm{NO}_{3}\right)_{2} \cdot 6 \mathrm{H}_{2} \mathrm{O}, 0.24 \cdot 10^{-3} ; \mathrm{CuSO}_{4} \cdot 5 \mathrm{H}_{2} \mathrm{O}, 0.1 \cdot 10^{-3}$; $\mathrm{Na}_{2} \mathrm{MoO}_{4} \cdot 2 \mathrm{H}_{2} \mathrm{O}, 1.1 \cdot 10^{-3}$. For the cultivation in outdoor photobioreactors, seawater was chemically sterilized by using sodium hypochlorite. Active chlorite was deactivated by filtration over activated carbon, followed by filtration across a filter with a pore size of $1 \mu \mathrm{m}$ Subsequently, the nutrient stock solution was added through a sterile filter $(0.45 \mu \mathrm{m})$. The detailed description of the cultivation process was given by de Vree, Bosma[265].

For the co-cultivation experiment, the non-axenic pre-cultures of Nannochloropsis sp. CCAP211/78 (100 mL liquid volume in $250 \mathrm{~mL}$ Erlenmeyer flasks) were maintained in autoclaved seawater supplemented with HEPES (20 mM) and NazEDTA (5 mM). The nutrient stock solution with the same final concentrations as above was added to theautoclaved seawater through a syringe filter $(0.2 \mu \mathrm{m})$. Werefer to this medium as enriched seawater medium(ESW medium). The Erlenmeyer flask cultures of Nannochloropsis were capped with aeraseal sterile film (Alphalabs) and placed in an orbital shaker incubator (Sanyo), shaken at 120 rpm, illuminated with continuous light of $50 \mu \mathrm{mol}$ photons $\mathrm{m}^{-2} \mathrm{~s}^{-1}$ at $25^{\circ} \mathrm{C}$, and the headspace was enriched with $2 \% \mathrm{CO}_{2}$.

\subsubsection{Generation of axenic algal cultures}

Axenic cultures of Nannochl oropsis sp. CCAP211/78 were prepared using a treatment with an antibiotics cocktail consisting of Streptomycin $(50 \mu \mathrm{g} / \mathrm{mL})$, Gentamycin $(67 \mu \mathrm{g} / \mathrm{mL})$, Ciprofloxacin $(20 \mu \mathrm{g} / \mathrm{mL})$, Ampicillin $(100 \mu \mathrm{g} / \mathrm{mL})$ and Chloramphenicol $(2.2 \mu \mathrm{g} / \mathrm{mL})$. Specifically, $2 \mathrm{~mL}$ exponentially growing non-axenic Nannochloropsis sp. CCAP211/78 were taken from a $250 \mathrm{~mL}$ flask, washed twice in $2 \mathrm{~mL}$ sterile ESW medium and concentrated by centrifugation at $8000 \mathrm{~g}$ for $3 \mathrm{~min}$ and transferred into a six-well microplate. After adding the abovementioned antibiotics cocktail, the plate was incubated at $25^{\circ} \mathrm{C}$ and illuminated with a 
16/8 $\mathrm{h}$ light/dark cycle with a light intensity of $50 \mu \mathrm{mol}$ photons $\mathrm{m}^{-2} \mathrm{~s}^{-1}$. Every two days, the cultures in the well platewere washed as mentioned before, fresh anti biotics sol ution was added and the cultures were incubated as described above. This procedure was repeated four more times.

Axenicity of Nannochloropsis sp. CCAP211/78 was confirmed via inocul ating ESW-YP agar (sterile ESW supplemented with $1 \mathrm{~g} / \mathrm{L}$ of yeast extract, $1 \mathrm{~g} / \mathrm{L}$ of peptone and $15 \mathrm{~g} / \mathrm{L}$ of agar) with $100 \mu \mathrm{L}$ of antibiotics-treated al gal cultures. Furthermore, al gal cultures wereincubated for 10 min with $1 \mu \mathrm{g} / \mathrm{ml} \mathrm{4',6-diamidin-2-phenylindol} \mathrm{(DAPI,} \mathrm{dissolved} \mathrm{in} \mathrm{phosphate} \mathrm{buffer).}$ Stained samples were inspected with a fluorescence microscope (Olympus). The obtained axenic Nannochloropsis sp. culture was maintained in $250 \mathrm{~mL}$ flasks in the orbital shaker incubator (Sanyo) according to the same method as described for the non-axenic culture.

\subsubsection{DNA isolation and 165 rRNA geneprofiling of bacteria}

Four samples of $5 \mathrm{~mL}$ from two outdoor photobioreactors were vacuum-filtered onto a cellul ose nitratemembranefilter $(0.2 \mu \mathrm{m}$, Millipore). To isol ate the genomic DNA, filters werecut in half using sterilescissors and DNA was extracted from half a filter using theFastDNA SPIN kit for soil (MP Biomedicals) with the aid of a Precellys bead beater (Bertin Technologies) with two rounds of bead beating for $45 \mathrm{~s}$ at speed of $5500 \mathrm{rpm}$

Amplicons of the 165 ribosomal RNA (rRNA) gene were generated from the extracted DNA with a two-step PCR reaction carried out in a BIOKÉ SensoQuest Labcycler 48. During the first step of $16 \mathrm{~S}$ rRNA gene PCR, a geneamplicon of approximately 311 bp comprising the V1 and V2 regions was generated using degenerate primers 27F-Degs [326] and a mixture of 338R-I and 338R-II [327]. Theforward primer was used with Unitag1 attached to the 5' end of the primer and Unitag2 was attached to the 5 ' end of the reverse primer to facilitate the second step of the PCR (Supplementary Table S5.1). The first PCR reaction ( $50 \mu \mathrm{l}$ ) contained $10 \mu \mathrm{l} 5 \times$ 
HF buffer (Thermo Scientific, theNetherlands), $1 \mu$ dNTP Mix (10 mM; Promega, Leiden, the Netherlands), $1 \mathrm{U}$ of Phusion ${ }^{\circledR}$ Hot StartII High-Fidelity DNA polymerase(Thermo Scientific), $500 \mathrm{nM}$ of Unitag1-27F-DegS forward primer, $500 \mathrm{nM}$ of Unitag2-338R I and II reverse primer and $1 \mu$ template DNA. The PCR was performed using the following conditions: an initial denaturation at $98^{\circ} \mathrm{C}$ for $30 \mathrm{~s}$, foll lowed by 25 cycles of denaturation at $98^{\circ} \mathrm{C}$ for $10 \mathrm{~s}$, anneal ing at $56^{\circ} \mathrm{C}$ for $20 \mathrm{~s}$, elongation at $72^{\circ} \mathrm{C}$ for $20 \mathrm{~s}$, and a final extension at $72^{\circ} \mathrm{C}$ for $10 \mathrm{~min}$. Subsequently, the first PCR product was used as template in a second PCR in order to add sample-specific barcodes (8 nucleotides). The second PCR reaction (100 $\mu \mathrm{l})$ contained $20 \mu \mathrm{l}$ $5 \times$ HF buffer, $2 \mu$ lNTP Mix, $2 U$ of Phusion Hot Start II High-Fidelity DNA polymerase (Thermo Scientific), $500 \mathrm{nM}$ of a forward and reverse primer equivalent to the Unitagl and Unitag2 sequences, respectively, that were each appended with an $8 \mathrm{nt}$ sample specific barcode (TableS5.1) [328]. The second PCR was performed using the following conditions: an initial denaturation at $98^{\circ} \mathrm{C}$ for $30 \mathrm{~s}$, followed by 5 cycles of denaturation at $98^{\circ} \mathrm{C}$ for $10 \mathrm{~s}$, anneal ing at $52^{\circ} \mathrm{C}$ for $20 \mathrm{~s}$, elongation at $72^{\circ} \mathrm{C}$ for $20 \mathrm{~s}$, and a final extension at $72^{\circ} \mathrm{C}$ for $10 \mathrm{~min}$. The barcoded PCR products from the second PCR were purified using the High-Prep PCR purification kit (MOBIO) according to the manufacturer's protocols. The concentration of purified DNA was measured using a Qubit 2.0 Fluorometer, according to manufacturer's instructions for the Qubit dsDNA BR assay (INVITROGEN). Then, the second step PCR products were pooled in an equimolar concentration and again purified using the High Prep PCR purification Kit. The purified PCR products (final concentration: $200 \mathrm{ng} / \mathrm{\mu l}$ ) were sequenced at GATC Biotech Europe (Konstanz, Germany, now part of Eurofins Genomics Germany GmbH) using the Ill umina MiSeq GenomeSequencer platform Nucleotidesequences of all samples were deposited at NCBI GenBank under Bio Project ID number PRJ NA488170 with accession number: SRR7760408. 
Illumina sequencing data was processed and analyzed using the NG-Tax pipeline [329] as previously described by Dat et al. [330]. Briefly, paired-end libraries were combined, and only read pairs with matching primers and barcodes were retained. Both forward and reverse reads were trimmed to $100 \mathrm{bp}$ and concatenated to yield sequences of $200 \mathrm{bp}$ that were used for subsequent sequence data processing. Demultiplexing, OTU picking, chimera removal and taxonomic assignment were performed within one single step. Reads were ranked per sample by abundance, and sequences (at a 100\% identity level) were added to an initial OTU table starting from the most abundant sequence until the abundance was lower than $0.1 \%$ per sample. The final OTU table was created by clustering the reads that were initially discarded (as they represented OTUs $\varangle 0.1 \%$ of the relative abundance) with the OTUs from the initial OTU table allowing a singlemismatch. Taxonomic assignment was done utilizing the UCLUST al gorithm al gorithm[331] and theSILVA 111_SSU Ref database [332, 333].

\subsubsection{Bacterial isolation andidentification}

Cryopreserved ( $15 \%$ glycerol) algal cultures from two outdoor reactors (horizontal tubular bioreactor and vertical tubular bioreactor) at AlgaePARC and stored at $-80{ }^{\circ} \mathrm{C}$ were used as inoculum for bacterial isolation. The description of bioreactors and algal cultivation process was given by de Vree, Bosma [265]. Aliquots of cryopreserved cultures were diluted ( $10^{4} \mathrm{fold}$ ) and plated on ESW agar ( $1.5 \%$ agar) supplemented with one of the foll lowing carbon sources: $2 \mathrm{~g} / \mathrm{L}$ glucose (ESW-GLU); $2 \mathrm{~g} / \mathrm{L}$ propionate(ESW-PRO); $2 \mathrm{~g} / \mathrm{L}$ casamino acids (ESW-CAS); $2 \mathrm{~g} / \mathrm{L}$ Nannochloropsis extract (ESW-ALG; $2 \mathrm{~g}$ freeze-dried Nannochloropsis cells from AlgaePARC suspended in $10 \mathrm{~mL}$ ESW, French-pressed twice at $110 \mathrm{MPa}$ and centrifuged at $8000 \mathrm{~g}$ for $5 \mathrm{~min}$. Subsequently, all the resulting supernatant was filter-sterilised $(0.2 \mu \mathrm{m})$ and added to $1 \mathrm{~L}$ of autoclaved ESW medium); $2 \mathrm{~g} / \mathrm{L}$ succinate (ESW-SUC); $1 \mathrm{~g} / \mathrm{L}$ yeast extract and $1 \mathrm{~g} / \mathrm{L}$ peptone (ESW-YP); $2 \mathrm{~g} / \mathrm{L}$ palmitate (ESW-PAL) or $0.6 \mathrm{mM}$ dimethylsul foniopropionate (ChemCruz, Dallas, TX) (ESW-DMSP). Plates weremaintai ned in 
the dark at room temperature. Singl e col onies were picked and streaked until pure cultures were obtained. All the pure bacterial strains were maintained in ESW-YP medium For bacterial identification, the 16S rRNA gene was amplified with universal primers 27F and 1492R (Table S5.1). The PCR reaction ( $50 \mu \mathrm{l}$ ) contained $10 \mu \mathrm{l} 5 \times \mathrm{HF}$ buffer (Thermo Scientific), $1 \mu \mathrm{l}$ dNTP Mix (10 mM; Promega), $1 \mathrm{U}$ of Phusion ${ }^{\circledR}$ Hot Start II High-Fidelity DNA polymerase(Thermo Scientific), $1 \mu \mathrm{M}$ of $27 \mathrm{~F}$ primer, $1 \mu \mathrm{M}$ of $1492 \mathrm{R}$ primer and $1 \mu \mathrm{l}$ bacterial culture. The PCR protocol consisted of a predenaturation step ( 10 min at $98{ }^{\circ} \mathrm{C}$ ) followed by 30 cycles of denaturation $\left(30 \mathrm{~s}\right.$ at $\left.98^{\circ} \mathrm{C}\right)$, annealing $\left(40 \mathrm{~s}\right.$ at $\left.60^{\circ} \mathrm{C}\right)$ and elongation steps $\left(1.5 \mathrm{~min}\right.$ at $72{ }^{\circ} \mathrm{C}$ ) with a final elongation step at $72^{\circ} \mathrm{C}$ for $10 \mathrm{~min}$. The purified amplicons (High-Prep PCR purification kit, MOBIO) were Sanger sequenced with primer 806R (Table S5.1) by GATC Biotech Europe (Konstanz, Germany). The sequences were clustered into contigs with a cut off of $99 \%$ similarity using ContigExpress (Invitrogen). One representative isolate from each contig was selected (Table 5.1) and analysed with the BLASTn tool from NCBI (http://www.ncbi.nlm.nih.gov/) to determine its phylogenetic affiliation. All sequences of selected isolates were deposited at NCBI GenBank under accession numbers as listed in Table 5.1.

\subsubsection{Co-culturing of algae with bacteria in microplates}

For co-cultivation in 24-well microplates, both exponentially growing axenic and non-axenic cultures of Nannochl oropsis sp. CCAP211/78 grown in flasks were di luted with ESW medium supplemented with $5 \mathrm{mM} \mathrm{NaHCO}_{3}$ to a fluorescence intensity of -5000 (Excitation: $450 \mathrm{~nm}$, Emission: $685 \mathrm{~nm}$ ). Single bacterial strains, separately grown in ESW-YP broth, werewashed twice in sterile ESW medium and concentrated by centrifugation (8000 $\mathrm{g}$ for $5 \mathrm{~min}$ ), then resuspended in ESW medium and diluted to an OD600 of 0.2. Subsequently, $1 \mathrm{~mL}$ of axenic Nannochloropsis and $50 \mu \mathrm{L}$ of bacterial strain suspension were inoculated in 24-well plates. The control cultures (either $1 \mathrm{~mL}$ of axenic Nannochloropsis sp. CCAP211/78 or $1 \mathrm{~mL}$ of non- 
axenic Nannochloropsis sp. CCAP211/78) were supplemented with $50 \mu \mathrm{L}$ ESW medium instead of diluted bacteria. All treatments incl uded threereplicates and were randomly all ocated into different wells of the microplate. The microplates were incubated in a custom-made LED box with one LED for each well and continuously illuminated at a light intensity of $71.1 \pm 6.2$ $\mu$ mol photons $\mathrm{m}^{-2} \mathrm{~s}^{-1}$ (Figure 5.1). TheLED box was then placed in a shaking incubator (Innova, New Brunswick), agitated at $180 \mathrm{rpm} / \mathrm{min}$ and incubated at a temperature of $23 \pm 1^{\circ} \mathrm{C}$. Fluorescence intensity (Excitation: $450 \mathrm{~nm}$, Emission: $685 \mathrm{~nm}$ ) of co-cul tures was measured at the same time every day with a plate reader in the endpoint mode (BioTek Synergy). Fluorescence intensity was measured from the bottom at $8 \mathrm{~mm}$ read height and $100 \mathrm{~ms}$ delays after plate movement. We determined that the relative fluorescence intensity was linearly correlated to cell counts of Nannochloropsis (Beckman-Coulter, Multisizer3) (Pearson's $r=$ 0.98, $p<0.0001$ ) (FigureS5.1). Datafrom different treatments was compared using at-test and the p val ue was adj usted with the "Holm" method [334].
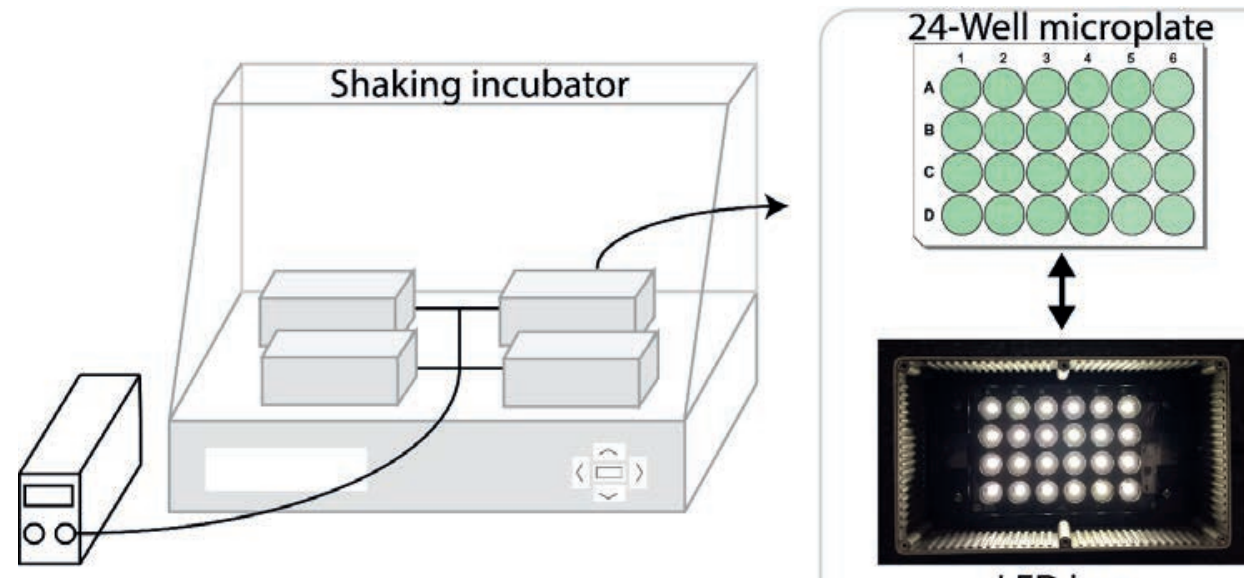

LED box

Figure 5.1. Diagram illustrating the 24-well plate coupled with LE D box for co-cultivation in a shaking incubator. 


\subsubsection{Co-culturing of algae with bacteria on agar plates}

For mixed cultivation of al gae and bacteria on agar plates, an ESW plate (2\% agar, diameter Petri dish $94 \mathrm{~mm}$ diameter) was overlaid with $5 \mathrm{~mL}$ 0.5\% ESW agar (top agar) containing axenic Nannochloropsis cells $\left(-10^{5} \mathrm{~mL}^{-1}\right)$. After solidification of the top agar, $15 \mu \mathrm{L}$ of bacterial culture was dropped onto the surface of the top agar. The plates were incubated for one week at a light intensity of $50 \mu \mathrm{mol}$ photons $\mathrm{m}^{-2} \mathrm{~s}^{-1}$ with a $16: 8 \mathrm{~h}$ light/dark cycle at $25^{\circ} \mathrm{C}$.

\subsection{R esults}

\subsubsection{Bacterial isolation and identification}

Eighteen bacterial strains were isolated from four outdoor photobioreactor cultures of Nannochloropsis sp. CCAP211/78, of which three were obtained from a horizontal tubular photobioreactor and one from a vertical tubular photobioreactor, respectively, at AlgaePARC. Of the 18 isolates, 11 bel ong to the class Al phaproteobacteria and five to the Flavobacteriia. In addition, single isolates were obtained from the classes Cytophagia and Saprospiria (Table 5.1). At thefamily level, isol ates weremainly classified into threefamilies: Hyphomicrobiaceae, Rhodobacteraceae and Flavobacteriaceae. When Sanger-sequenced 16S rRNA genes of the bacterial strains were compared to the 138 operational taxonomic units (OTUs) present in the four original bi oreactor cultures, 14 out of 18 bacterial strains had an identical match with OTUs encountered in the reactors, while four isolates had not (Table 5.1).

\section{Table 5.1. B acterial strains isolated from Nannochloropsis cultures.}

\begin{tabular}{|c|c|c|c|c|c|c|c|c|}
\hline Strain & $\begin{array}{l}\text { Accession } \\
\text { Number } \\
\text { (bacterial } \\
\text { isolate) }\end{array}$ & Class & Family & B last result* & $\begin{array}{l}\text { Identity } \\
\text { [\% ] }\end{array}$ & $\begin{array}{l}\text { Accession } \\
\text { Number } \\
\text { (Genbank } \\
\text { best hit) }\end{array}$ & $\begin{array}{l}\text { OTUs in } \\
\text { bioreactors** }\end{array}$ & $\begin{array}{l}\text { Identity } \\
\text { [\% ] }\end{array}$ \\
\hline GLU107 & MH843917 & Alphaproteobacteria & Erythrobacteraceae & Porphyrobacter sanguineus & 100 & LC349792 & OTU247 & 100 \\
\hline PRO103 & MH843918 & Al phaproteobacteria & Hyphomicrobiaceae & Algimonas arctica & 98 & NR_137369 & OTU321 & 100 \\
\hline DMSP31 & MH843919 & Al phaproteobacteria & Hyphomicrobiaceae & Maritalea porphyrae & 99 & AB583776 & OTU327 & 100 \\
\hline DMSP20 & MH843920 & Al phaproteobacteria & Hyphomicrobiaceae & Maritalea sp. & 99 & AB758563 & OTU331 & 100 \\
\hline PRO34 & MH843921 & Al phaproteobacteria & Hyphomicrobiaceae & Maritalea sp. & 96 & KP301112 & OTU343 & 100 \\
\hline
\end{tabular}




\begin{tabular}{lllllllll} 
YP210 & MH843922 & Alphaproteobacteria & Phyllobacteriaceae & Pseudohoeflea suaedae & 100 & LT600545 & OTU490 & 100 \\
YP18 & MH843923 & Alphaproteobacteria & Rhodobacteraceae & Celeribacter sp. & 100 & MF045112 & OTU582 & 100 \\
YP26 & MH843924 & Alphaproteobacteria & Rhodobacteraceae & Labrenzia aggregata & 100 & MG273739 & OTU247 & 100 \\
YP29 & MH843925 & Alphaproteobacteria & Rhodobacteraceae & Roseovarius mucosus & 99 & CP020474 & OTU585/709 & 100 \\
YP202 & MH843926 & Alphaproteobacteria & Rhodobacteraceae & Sulfitobacter sp. & 99 & KY272045 & OTU143/289 & 100 \\
PAL103 & MH843927 & Alphaproteobacteria & Sphingomnadaceae & Sphingorhabdus sp. & 99 & KT325114 & OTU259 & 98 \\
DMSP2-Y & MH843928 & Cytophagia & Cytophagaceae & Enticicia sp. & 99 & KP265953 & OTU574 & 100 \\
YP206 & MH843929 & Flavobacteriia & Flavobacteriaceae & Aquaticitalealipolytica & 99 & NR_149769 & OTU532/533 94 \\
ALG110 & MH843930 & Flavobacteriia & Flavobacteriaceae & Arenibacter sp. & 98 & JX529985 & OTU582 & 100 \\
PAL10 & MH843931 & Flavobacteriia & Flavobacteriaceae & Cellulophaga lytica & 100 & MG456766 & OTU519 & 96 \\
PAL110 & MH843932 & Flavobacteriia & Flavobacteriaceae & Maribacter sp. & 99 & KT731371 & OTU525 & 96 \\
SUC105 & MH843933 & Flavobacteriia & Flavobacteriaceae & Muricauda sp. & 99 & KJ188010 & OTU512 & 100 \\
PRO13 & MH843934 & Saprospiria & Saprospiraceae & Phaeodactylibacter xiamenensis & 99 & NR_134132 & OTU579 & 100 \\
\hline Th
\end{tabular}

*The best hit (highest percent identity) in Genbank.

**The best hit of photobioreactor OTUs.

The cultivable bacteria isolated in this study accounted for approximately $11 \%$ of the total OTUs (14 of 124) present in the original photobioreactor samples, which represented nearly $7 \%$ of the total number of reads $(11,820$ of 152,260$)$ in the bioreactor samples. Thus, a substantial fraction of bacteria in al gal cultures remained uncultured. We observed 16 OTUs with high relativeabundance $(\geq 5 \%$ ) in our al gal cultures (TableS5.2), of which four (OTU533, 579, 327, 331) were successfully cultured. It is noticeable that al though Gammaproteobacteria was one of themost abundant classes in two of four bi oreactor cul tures based on cul tivation-independent assessment of bacterial diversity, no strains belonging to this class were recovered (TableS5.2 and FigureS5.2).

\subsubsection{Effect of bacterial isolates on the growth of algae}

To examine potential interactions between Nannochloropsis and the bacterial isolates, the bacterial isolates were re-introduced to axenic microalgae. All the cultures except the ones supplemented with strain YP206 had a similar growth pattern, that is, after rapid growth for nearly five days the stationary phase was reached, which continued until the end of the experiment at day 11 (FigureS5.3). No significant differencewasfound in relativefluorescence 
between axenic and non-axenic control cultures of Nannochloropsis. Addition of bacteria to the axenic Nannochloropsis sp. cultures mostly resulted in a slight decrease of the maximal fluorescent intensity reached at the stationary phase (Figure 5.2). For strain YP206 (Flavobacteriia), Nannochloropsis growth was strongly inhibited, leading to a reduction of more than $28 \%$ in fluorescence intensity. In contrast, two bacterial strains (DMSP31, Y P26) resulted in significantly better growth of the algae and the intensity of algal fluorescence increased by 12 - 14\% compared to the axenic control (Figure 5.2).

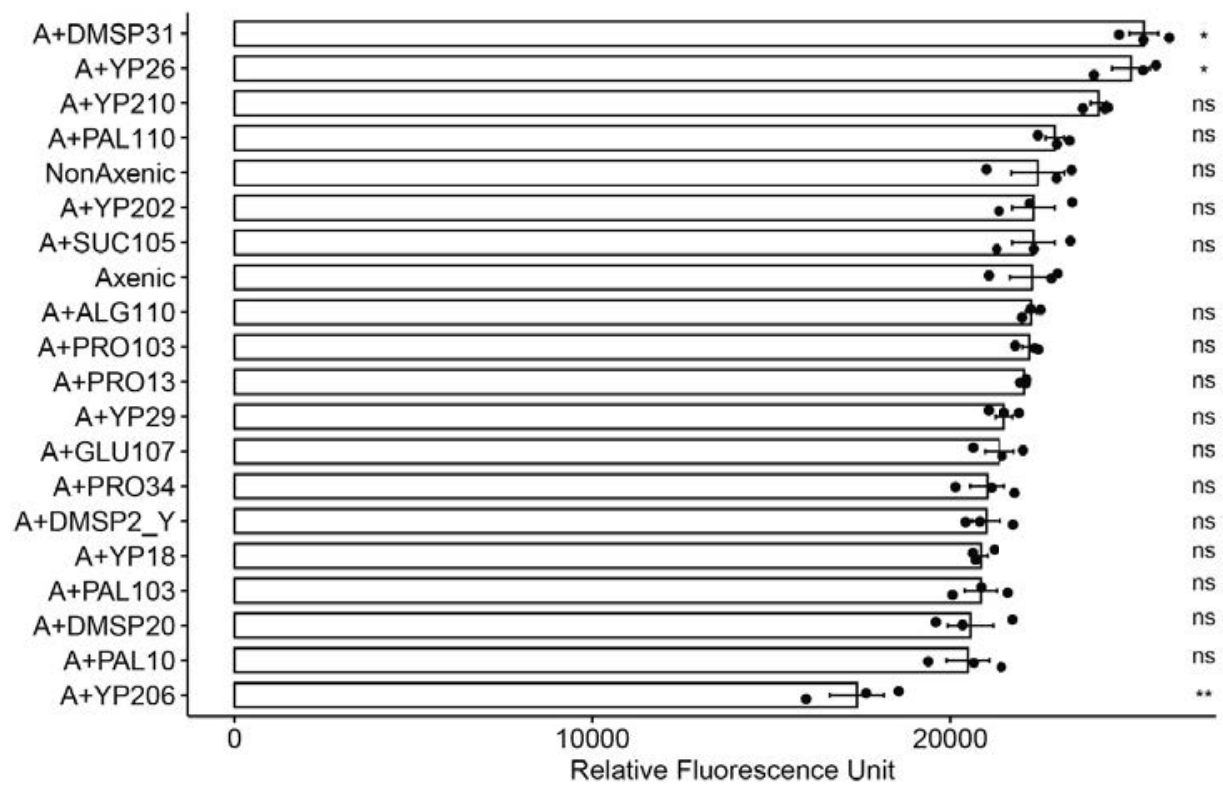

Figure 5.2. R elative Fluorescence ( algal biomass) of Nannochloropsis sp. C CAP211/78 co-cultured with individual bacterial strains. Relative Fluorescence Unit (RFU) for Nannochloropsis sp. CCAP211/78 was calculated as maximal fluorescent intensity and compared to RFU of the axenic culture. Error bars represent standard deviation. Results of the statistical analysis are indicated by NS (p.adjust $>0.05$ ), * (p.adjust $<=0.05$ ), and ** (p.adjust $<=0.01$ ), respectively. The statistical results of pair-wise comparison against non-axenic culture (not shown) are the same as for the comparison to the axenic culture.

To further confirm the effect of the addition of bacteria on al gal growth we observed in liquid cultures weadded individual fresh cultures of the bacterial strains to thetop-agar that contained 
axenic Nannochloropsiscell s on double layer agar plates. When co-cul tured with Y P26, growth of Nannochloropsis was strongly stimulated, indicated by the greenest algal lawns after oneweek of incubation (Figure 5.3). Interestingly, two other bacteria (ALG110, PRO34) slightly enhanced the al gal growth on solid medium (Figure 5.3), whereas this beneficial effect was absent in liquid culture. Two agar-degrading bacteria (PAL10 and PAL110) formed much bigger colonies than other strains, and thus promoted the al gal growth on a much bigger surface on the solid medium (Figure 5.3).

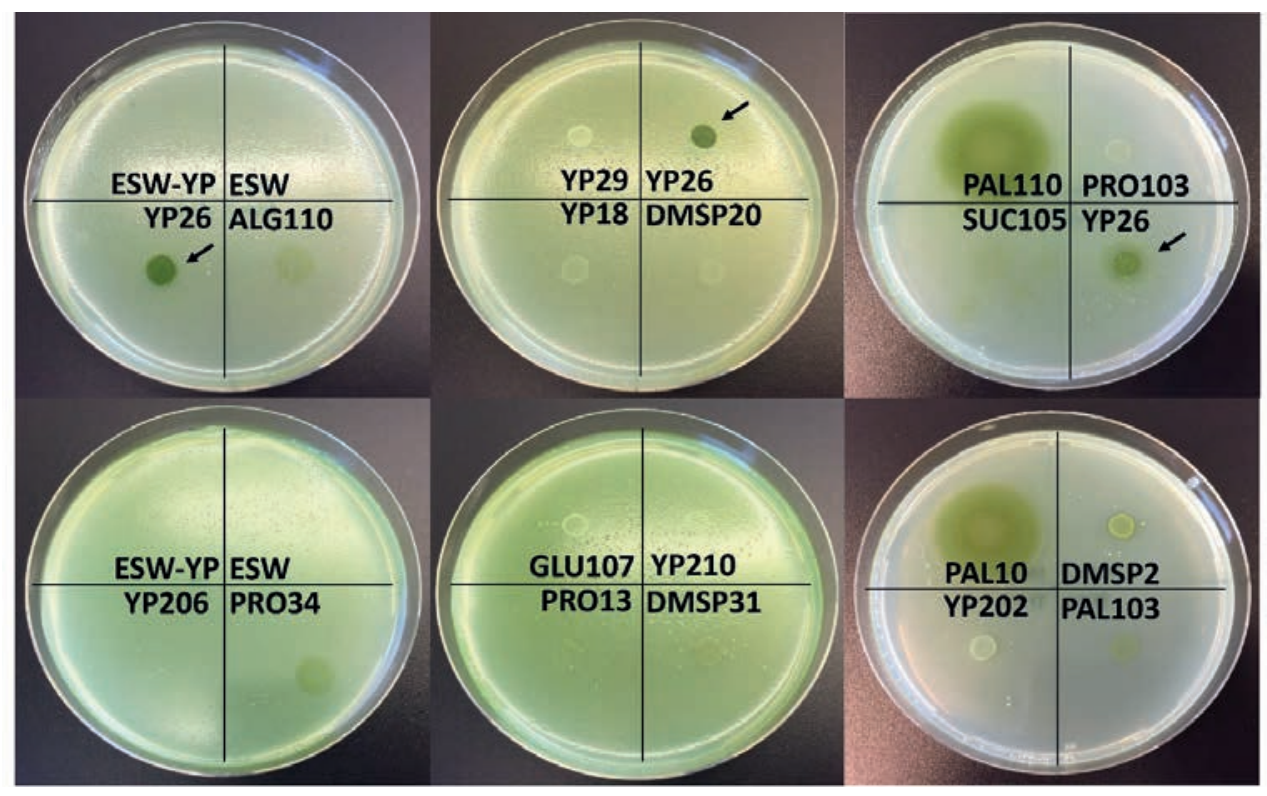

Figure 5.3. C 0-cultivation of Nannochloropsis sp. CCAP211/78 and bacterial strains on double-layer agar plates after seven days. ESW (Enriched natural seawater medium) and ESW-YP (ESW medium with peptone and yeast extract) were used as controls. The label led names referred to the added bacteria. Y P26 was added on three different plates as replicates indicated by arrows.

\subsection{Discussion}

Bacterial isolation was carried out from four samples taken from two outdoor photobioreactors of AlgaePARC where bacterial strains were present in microalgae cultures that were not 
supplemented with external organic carbon. Therefore, we suspected that heterotrophic cooccurring bacteria depended on the organic carbon released by microal gae, which suggests at least a commensal relationship between Nannochloropsis and bacteria. In total, 18 bacterial strains were isolated from the outdoor photobioreactor samples. These 18 isolates constituted approximately ten percent of the whole bacterial community, whereas nearly $90 \%$ remained uncultured under the conditions applied in our experiment. Hence it cannot be excluded that even more potent candidates with respect to an al gae growth-promoting effect remain to be discovered from the yet uncultured fraction. The bacteria in our culture collection were mostly classified as Alphaproteobacteria and Flavobacteriia (Figure S5.2). It has also been corroborated by gl obal surveys that phytoplankton-associated bacterial communities are often restricted to only a few bacterial classes including Al phaproteobacteria (Rhodobacteraceae), Gammaproteobacteria (Alteromonadaceae) and Flavobacteriia (Flavobacteraceae) [96, 304, 335, 336]. These apparenty widespread patterns imply that thel ifestyle of some bacteria within these groups is substantially related to that of al gae. Likewise al gae can either benefit or suffer from the bacterial partners [2]. Bacteria reported to be beneficial to microal gae are mostly Al phaproteobacteria, and al gal growth-promoting bacteria bel onging to Al phaproteobacteria are quite diverse, including members of Rhizobium [105], Brevundimonas [121], Mesorhizobium loti [22], and Hyphomonas [122]. Within Al phaproteobacteria, bacteria from the family Rhodobacteraceae are frequently associated with al gae, of which the most studied ones are Phaeobacter gallaeciensis [46], Dinoroseobacter shibae [337], Sulfitobacter sp. [16] and Ruegeria pomeroyi [17].

Labrenzia aggregata (Y P26) was the only isolate in our experiment that exhibited significant growth enhancement both in liquid and solid media (Figure 5.2, Figure 5.3 and Figure S5.3). Members of the genus Labrenzia have been isol ated from a widerange of habitats and found to be frequently associated with other marine organisms [338]. These organisms include 
invertebrates such as molluscs, corals and sponges, and a wide variety of photosynthetic partners including seaweeds, diatoms, dinoflagellates, green and red algae [339]. Labrenzia aggregata has also been isolated previously from Nannochloropsis oculata and Nannochloropsis gaditana [340]. A recent study revealed that Labrenzia sp. increased the biomass accumulation of the marine microal gal sochrysis gal bana by $72 \%$ and the growth rate by $18 \%$ [341]. On the other hand, it has been reported that a bacterial isolate (KD531) with $100 \%$ similarity to the partial 16S rRNA gene of our Labrenzia aggregata isolate had an al gicidal effect on Chlorella vulgaris [342]. The addition of bacterial lysate of KD531 to Chlorella vulgaris cultures caused nearly $20 \%$ reduction in bi omass dry weight and nearly $60 \%$ reduction in lipid content. The contradiction between these and our observations may be due to strainspecific differences between isolates of L. aggregata, and/or different interactions of the bacterium with different al gal hosts. Prior research has shown that some bacteria that are mutualistic to their native algal partner can be parasitic to foreign al gae, which hints at coadaption and evolution of al gae and their associated microbiome [119]. In addition, we added live bacteria rather than a bacterial lysate, which may lead to a different effect. Nannochloropsis sp. also appeared to grow faster and denser on a solid growth medium in the presence of Labrenzia aggregata. To our knowledge, this is the first time that one bacterium has been shown to strongly promote the growth of microal gae on solid agar. Agar plates have been the most commonly used method to study al gal-bacterial interactions [27, 34]. For example, the vitamin B 12-dependent microal ga Lobomonas rostrata could grow on agar plates only when vitamin $B_{12}$ or a vitamin $B_{12}$-Synthesizing bacterium (Mesorhizobium loti) was added [27]. Therefore, it is tempting to specul ate that the growth promotion observed here for Labrenzia aggregata could be related to inorganic nutrient exchange or al gal acqui sition of growth factors released by bacteria. 
Although the growth increase of Nannochloropsis in the presence of Maritalea porphyrae (DMSP31) was significant in liquid cul tures, this beneficial effect disappeared on theagar plate. This discrepancy between two screening methods corroborated that al gae-bacteria interactions are complex and may vary under different culture conditions. Therefore, prel iminary screening results should be confirmed by other methods such as flask cultures or bi oreactors before claims regarding beneficial effects of bacteria on large-scal eal gal growth can be made. It is interesting to note that Maritalea porphyrae (DMSP31) and Pseudohoeflea suaedae (YP210), the latter of which caused a numerical, but non-significant increase in al gal growth in the plate assay, have been previously isolated from the thalli of the red al ga Pyropia yezoensis [343] and root of the hal ophyte Suaeda maritima [344], respectively. However, experimental evidence showed that these bacteria exhibited no apparent morphogenesis effects on the red al ga [345], and therefore thenature of asymbiotic relationship-if any- with the phototroph remains unknown. The genus Pseudohoeflea (reclassification of Hoeflea) to which Y P210 belongs, has not yet been well characterized [346], however, it has been speculated that the genus Pseudohoeflea may resemble somemembers of the marine Roseobacter clade in phytopl ankton col onization by the production of secondary metabolites that inhibit the growth of competing bacteria (antibiotics) and promote growth of phytoplankton (auxins) [46, 346].

Three out of five Flavobacteriia strains (ALG110, SUC105, PAL110) showed no significant effect on the growth of Nannochloropsis cultures, despite the fact that members of the Flavobacteriia have repeatedl y been reported to have antagonistic relationships with al gae. For instance, Kordia algicida was shown to excrete an extracellular protease to lyse al gal cells to acquire their dissolved organic carbon [317], and Croceibacter atlanticus was observed to release an uni dentified molecule to arrest diatom cel division and increase secretion of organic carbon [319]. On the other hand, the greatest reduction in chlorophyll content in the stationary phase compared to the controls was observed in the presence of strain YP206 from the 
Flavobacteriaceae family (Table 5.1 and Figure 5.2). The closest relative of strain Y P206 is Aquaticital ea lipolytica (99\% identity of the 16S rRNA gene) that was isolated from Antarctic seawater and known to hydrolyse lipids [347]. However, when Y P206 was co-cul tured on agar plates with Nannochloropsis, the growth inhibition observed in liquid culture was not observed (Figure 5.2 and Figure 5.3). Although mechanistic insight requires future research, one can speculate that the incubation time (seven days) used in the agar plate experiments described here was too short or that the al gal density was still too low on the agar plate for the bacterial inhibition to take place, as some al gicidal bacteria have been shown to only kill senesced algal cells in the stationary phase or decline phase [46, 337]. This has previously been explained by competition for limiting nutrients such as nitrogen [348] and phosphorus [315, 349]. However, that is not likely to be the case for our experiments as nitrogen and phosphorus concentrations added would support much higher algae concentrations than those present in the stationary phase, and for nitrogen it was confirmed in the stationary phase that it was not depleted (data not shown). Alternatively, release of toxic compounds by bacteria could contribute to the inhibitory effects observed at stationary phase [350, 351]. Many bacteria belonging to the family Flavobacteriaceae are able to glideon solid surfaces and decompose agar [352]. PAL10 and PAL110 displayed these features and formed larger and concave colonies on the agar surface (Figure 5.3). Although both strains showed no significant effects on al gal growth in liquid co-culture, they slightly enhanced the growth of Nannochloropsis sp. in the agar-plate assay (Figure 5.3). A possible explanation for the growth promotion on solid media could be that Nannochl oropsis cells consumed the by-products from theagar degradation by the bacteria. For instance, Cellul ophaga lytica has previously been shown to synthesize different kinds of agarases [353], and the enzymatic hydrolysis of agar yields monomeric sugars, such as Dgal actose, 3,6-anhydro-L-gal actose, and L-gal actose-6-sul fate [354]. Research has shown that 
supplementation with gal actose increases the growth rate of Nannochl oropsis salina by nearly $10 \%[355]$.

PRO13 (Saprospiria) and DMSP2-Y (Cytophagia) were the only two isol ates not belonging to Al phaproteobacteria or Flavobacteriia. Both PRO13 and DMSP2-Y had no significant effect on the growth of Nannochloropsis sp. A previous study has found that the family Saprospiraceae was the most prevalent taxon, and also the most abundant one in industrial cultures of Nannochl oropsis salina [69]. The 16S rRNA gene of strain PRO13 was identical to OTU579 found in the outdoor photobioreactors, particularly in sample HD0105 where this bacterium made up nearly $25 \%$ of the whole bacterial community (TableS5.2). In spite of this strikingly high relative abundance, co-culturing with strain PRO13 had no significant effect on the growth of Nannochloropsis sp. neither in liquid co-cul tures nor on agar plates (Figure 5.2 and Figure 5.3). Similarly, the study by Fulbright, Robbins-Pianka [69] reported that there was no correlation between the abundance of Saprospiraceae and growth of N. salina. However, the preval ence of this bacterium suggests it may have other functions in al gal cultures, and the Iytic capability of members of this bacterial family may relate to degrading cell debris for nutrient recycling [69]. DMSP2-Y is closely related to Emticicia sp., and species from the genus Emticicia have been recorded to live with Chlorella vulgaris [248] and the macroalga Cladophora glomerata [287]. Emticicia sp. was found to slightly reduce the growth rate of axenic Chlorella vulgaris in co-cultivation, but the co-culture reveal ed prolonged stationary phase[356].

\subsection{Conclusion}

In this study, we isol ated 18 bacterial strains from two outdoor photobi oreactors for cultivation of microalgae. Two strains assigned to Maritalea porphyrae and Labrenzia aggregata, respectively, significantly promoted growth of Nannochloropsis sp. CCAP211/78 in liquid 
cultures in well plates ( $14 \%$ and $12 \%$ increase of chlorophyll in stationary phase compared to the controls, respectively), and the Labrenzia aggregata strain al so notably increased growth of theal ga on agar plates. In addition, one strain most closel y related to Aquaticitalea li polytica significantly reduced thechl orophyll content with $28 \%$ compared to the axenic and non-axenic controls. Our results suggest that some bacteria from al gal production systems may have a pronounced impact on al gal growth under control led laboratory conditions, an effect that should beverified for larger-scal eal gaecultures. Our results indi cated that in thepractice of improving the production of microal gae, the bacterial community in al gal inocul a should beconsidered. If harmful bacteria are present, the inoculum should be replaced by an inocul um where these bacteria are absent to increase the cultivation success. Perhaps even moreinteresting, beneficial bacterial strai ns may besupplemented as a new means to improve al gal productivity and culture stability.

\section{Acknowledgements}

Jie Lian would like to thank the China Scholarship Council for financial support (Grant Number: 201406310023). 


\section{Supplementary Information}

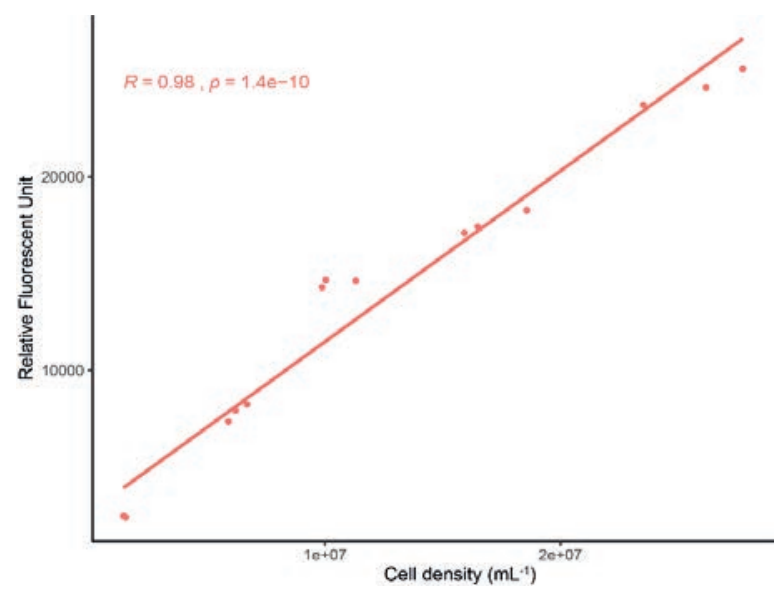

Figure S5.1. Linear correlation between the cell density of Nannochl oropsis sp. CCAP211/78 as determined by direct cell counting and the corresponding relative fluorescence. Samples shown here were taken from a pilot experiment that was carried out in a microplate under the same conditions as for the co-cultivation experiments.

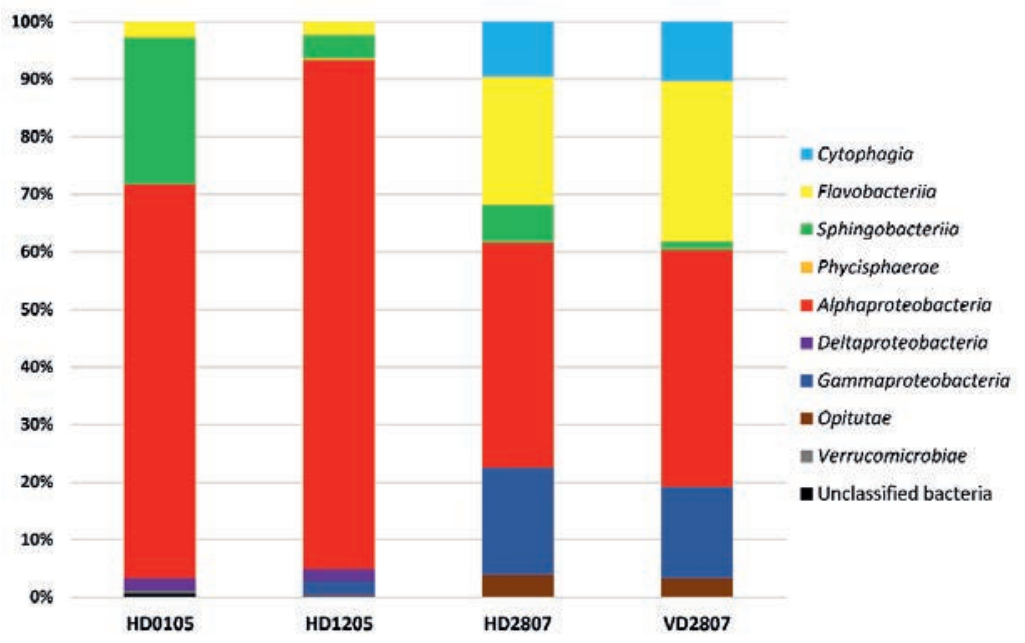

Figure S5.2. Relative abundance of bacteria (class leve) in samples from different photobioreactors. HD and VD refer to horizontal tubular bioreactor and vertical tubular bioreactor, respectively. The number in the sampl ename refers to the sampling time point (daymonth) in 2015. The total number of bacterial 16S rRNA gene reads for each sample was HD0105 (16,033), HD1205 (132,458), HD2807 (9,672) and VD2807 (4,762), respectively. 


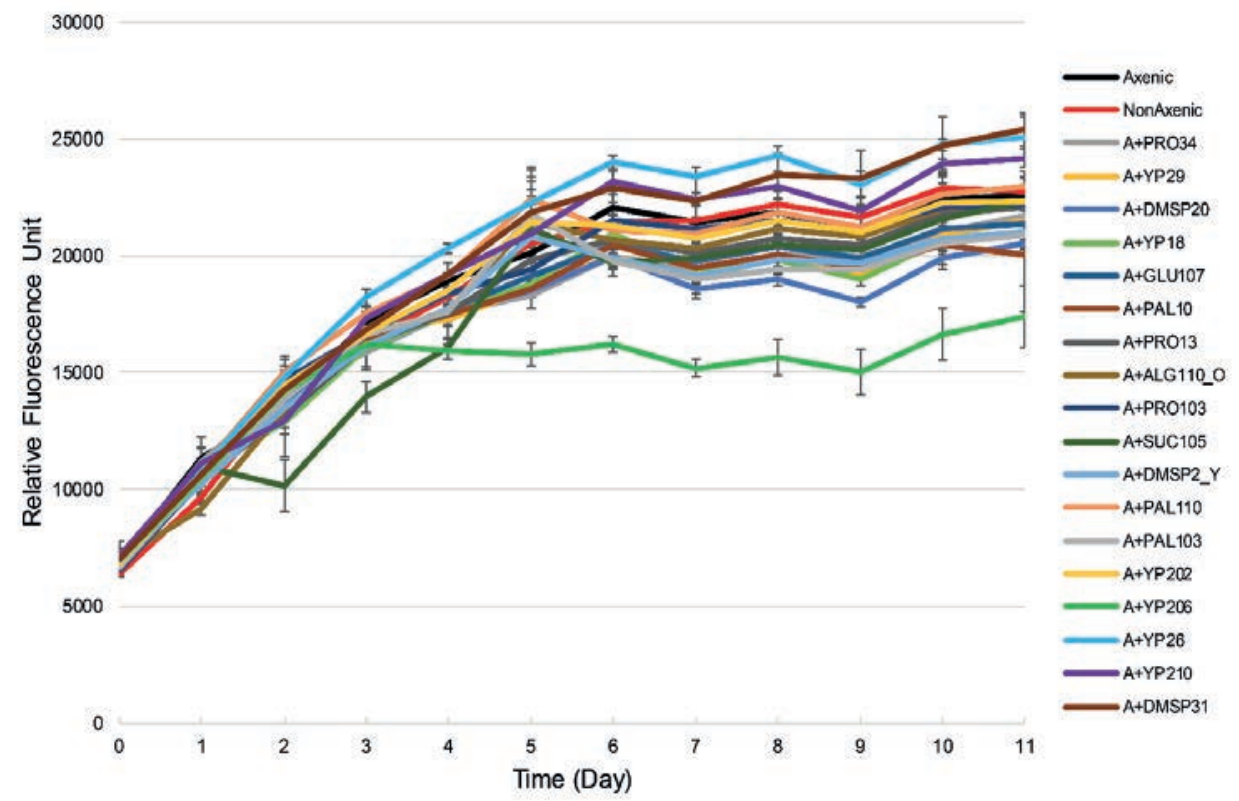

Figure S5.3. Co-culturing of Nannochloropsis sp. CCAP211/78 with individual bacterial strains. For each group, rel ative fluorescence was cal cul ated as the mean of triplicate samples.

Table S5.1. Oligonucleotides used in this study.

\begin{tabular}{llr}
\hline Primer Name & Oligonucleotide sequence (5'-3') & Reference \\
\hline 27F-DegS-Fwd & GTTYGATYMTGGCTCAG & {$[229]$} \\
338R-I-rev & GCWGCCTCCCGTAGGAGT & {$[230]$} \\
338R-II-rev & GCWGCCACCCGTAGGTGT & {$[230]$} \\
Unitag1 & GAGCCGTAGCCAGTCTGC & {$[231]$} \\
Unitag2 & GCCGTGACCGTGACATCG & {$[231]$} \\
27F & AGAGTTGATCMTGGCTCAG & {$[357]$} \\
1492R & CGGYTACCTTGTACGACTT & {$[357]$} \\
806R & GGACTACNVGGGTWTCTAAT & {$[358]$} \\
\hline
\end{tabular}




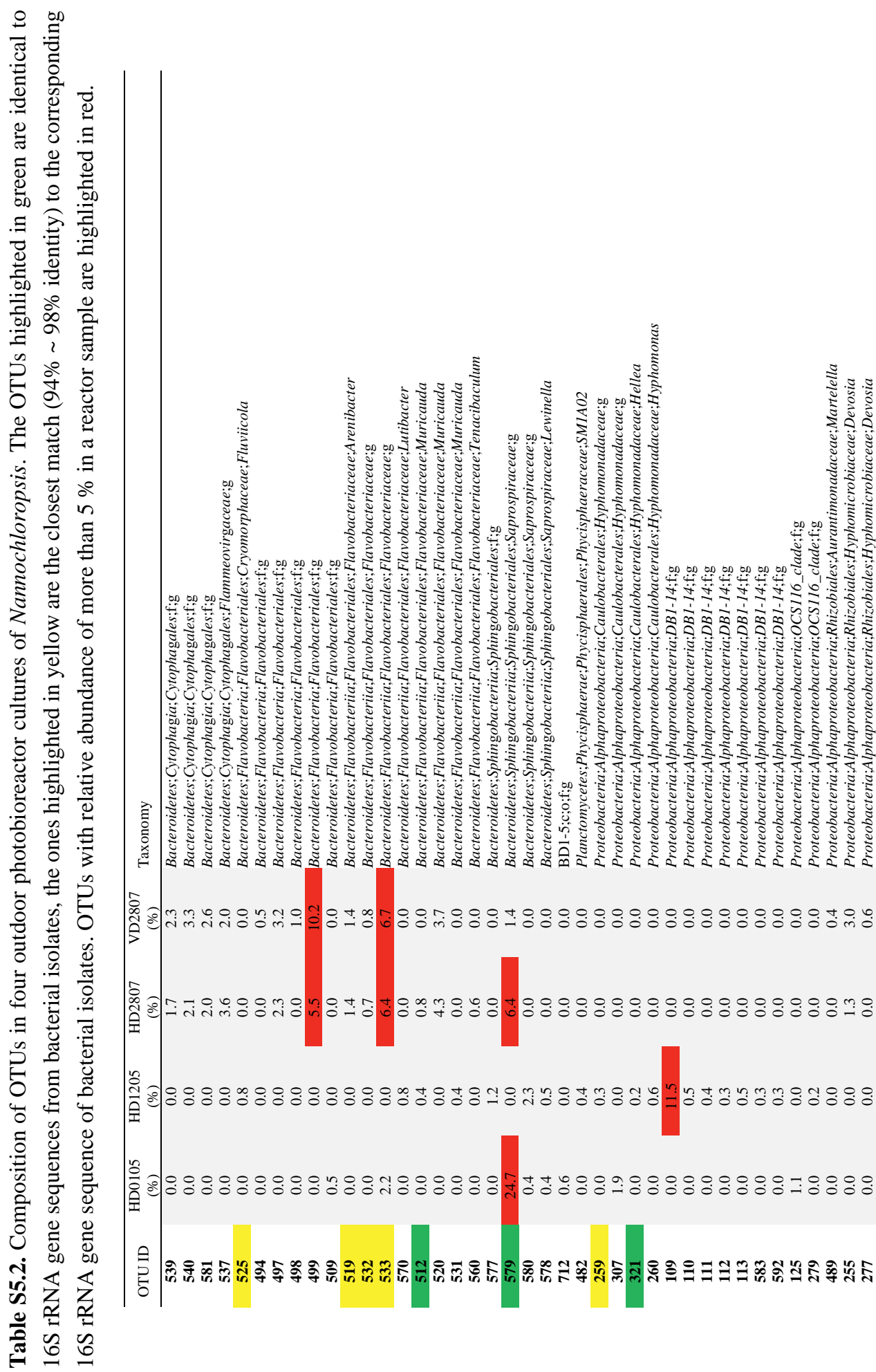




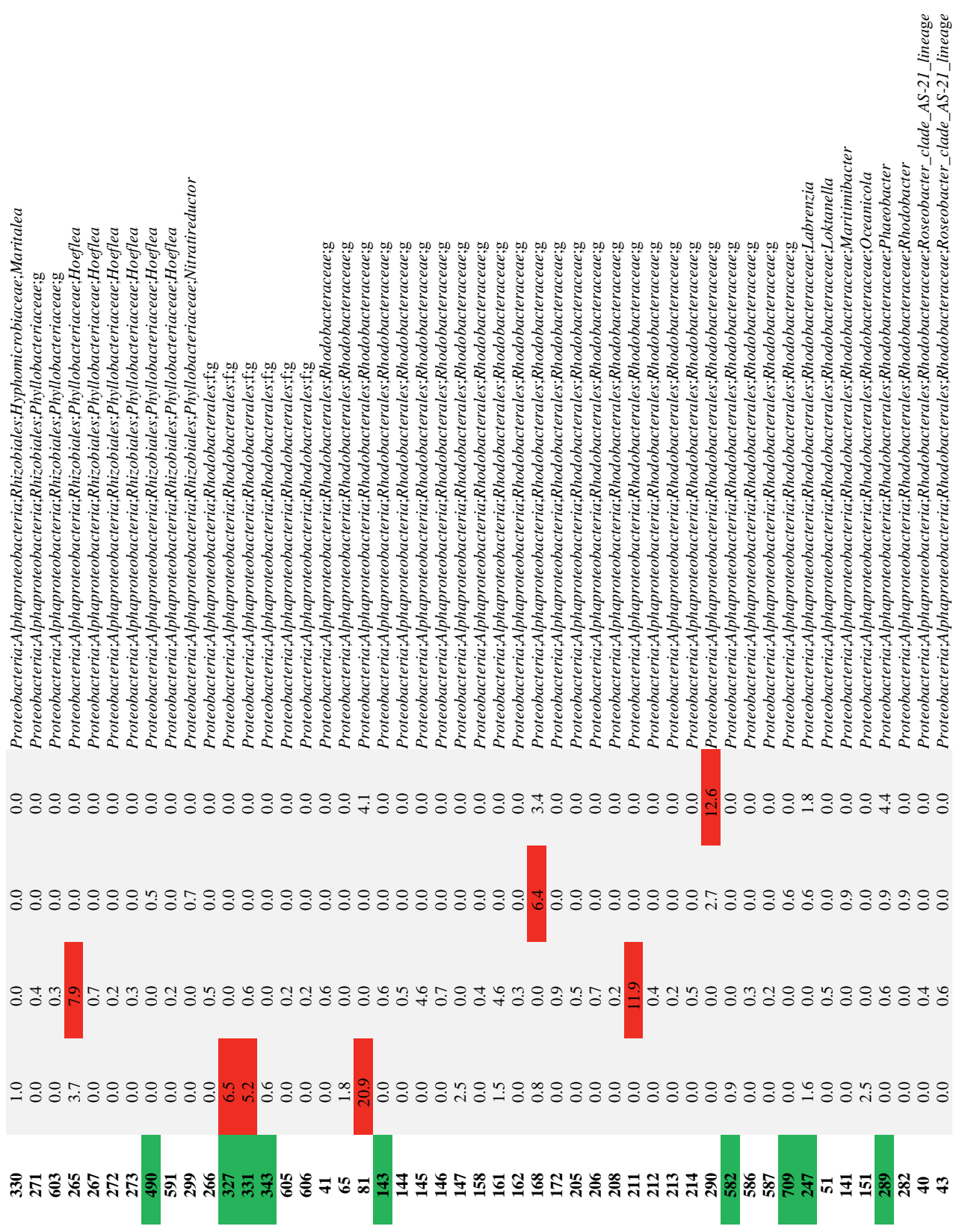




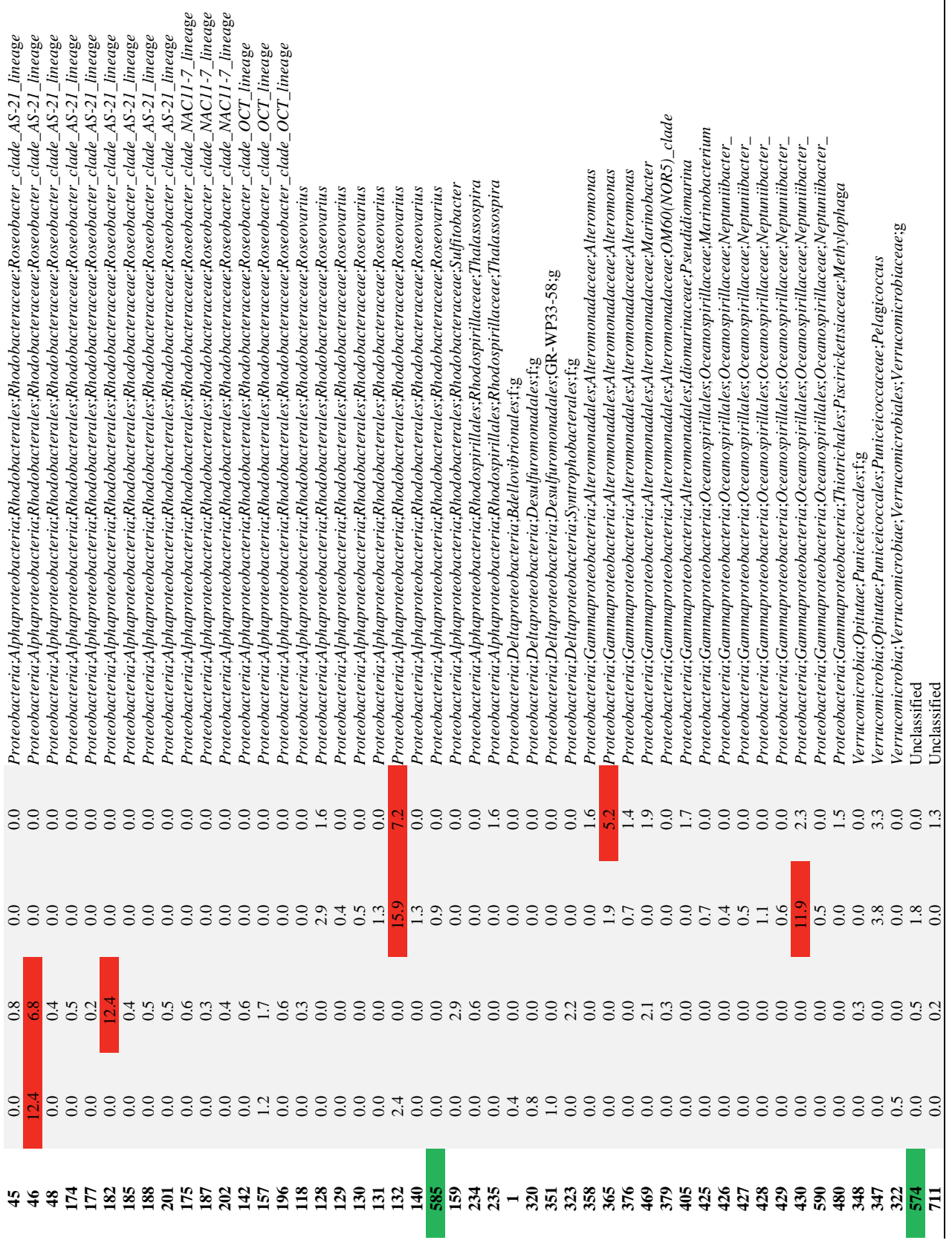





\section{Chapter 6}

G eneral discussion 


\subsection{Overview of the thesis}

This thesis investigated the bacterial community composition in cultures of 12 strains of Botryococcus braunii obtained from six culture collections and the bacterial community composition of cultures of Nannochloropsis sp. CCAP211/78 maintained in different reactor types using 16S rRNA gene amplicon sequencing on an Illumina MiSeq platform This was complemented by a co-cultivation study in microplates using axenic Nannochloropsis sp. CCAP211/78 and cultivable bacterial strains isolated from two outdoor reactors. In addition, a literature review was done to summarise the current knowl edge on al gal-bacterial interactions and biotechnological applications. A brief overview of results obtained from each chapter is presented in Figure 6.1, which will be further elaborated in the following sections.
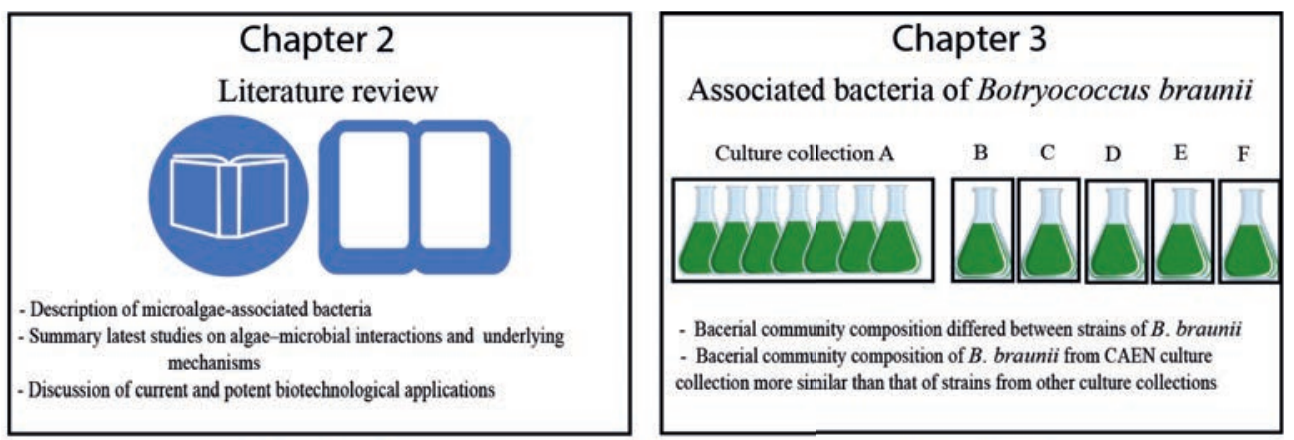

\section{Chapter 4}

Associated bacteria of Nannochloropsis sp. in indoor and outdoor reactors
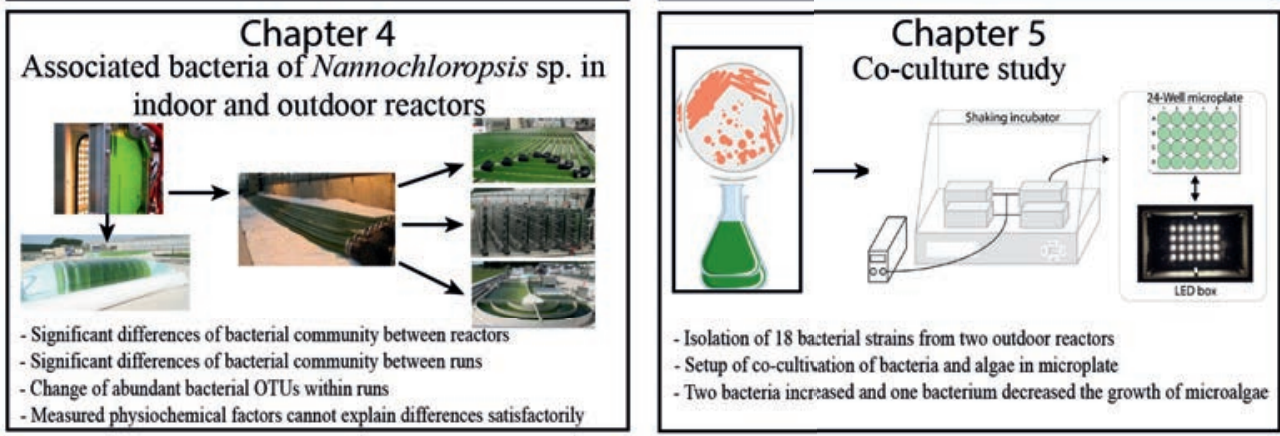

Figure 6.1. A brief overview of results obtained in Chapters 2 - 5. 


\subsection{M icroalgae-associated bacteria}

Numerous studies over the past 100 years have shown that bacteria are involved in complex interactions with microal gae [96]. Particularly the rapid and ongoing developments in nextgeneration sequencing technologies have led to an increase of research on the bacterial communities associated with microal gae [71]. However, as microal gae arean extremely diverse group of eukaryotic organisms and comprise of tens of thousands of species, only a few model al gal species or algae of biotechnological or ecological interest have been surveyed for their associated bacterial communities to date[ $69,118,252,359,360]$.

Among all the microalgae, diatoms are the best studied taxa with respect to their associated bacteria[306, 361]. A mol ecular survey of bacterial diversity from cultures of six di atomgenera (Ditylum Thalassiosira, Asterionella, Chaetoceros, Leptocylindrus, and Coscinodiscus) revealed distinct bacterial phylotypes associated with each species. However, Alphaproteobacteria (including the genera Sulfitobacter, Roseobacter, Ruegeria, and Erythrobacter), Bacteroidetes and to a lesser extent Betaproteobacteria were among the most prominent taxa across all diatoms examined [361]. In a number of other studies it was shown that with respect to the bacterial communities of diatom cultures the Proteobacteria and Bacteroidetes are the main bacterial phyla associated with diatoms. At the genus level, Sul fitobacter, Roseobacter, Alteromnas and Flavobacteriumhave been repeatedl y found to be associated with diatoms $[16,306,359,360,362,363]$.

For this thesis, weobserved that even at thestrain level B. braunii cultures wereassociated with distinct bacterial communities. Interestingly, seven B. braunii strains obtained from the CAEN culture collection harbored more similar bacterial communities as compared to strains from other cul ture collections (C hapter 3, Figure 3.3A), suggesting that observed differences are at least in part due to different maintenance approaches exerted by those culture collections. Our 
results are consistent with a previous study that showed that the bacterial communities of different strains of the diatom species Thal assiosira rotula were significantly different [359]. Sapp et al. [363] also demonstrated that diatom cultures exhibited differences in bacterial community composition over time after isolation, suggesting that changes in environmental conditions may be important drivers of bacterial community composition.

In addition, we examined similarities and differences in bacterial community composition between Botryococcus braunii (Chapter 3) and Nannochloropsis sp. CCAP211/78 (C hapter 4). To this end, we compared the cultures of 12 strains of B. braunii with Nannochloropsis sp. CCAP211/78 cultured in a flat panel reactor (FP), as only for this reactor, strain CCAP211/78 was grown in a small volume with sterilized medium, similar to conditions of B. braunii cultures. Nevertheless, it should be noted that the growth medium for both microal gae was different - a fact that is ignored here, but which should receive more attention in futurestudies. At the phylum level, Proteobacteria and Bacteroidetes were the most predominant bacterial taxa with both Nannochloropsis sp. CCAP211/78 and B. braunii. However, at family level, distinct predominant families were found to be associated with Nannochloropsis sp. CCAP211/78 and B. braunii. Rhizobiaceae, Erythrobacteraceae and Cytophagaceae were the most abundant families in cultures of B. braunii (Chapter 3, Figure 3.1), whereas Rhodobacteraceae, Flammeovirgaceae and Oceanospirillaceae predominated the bacterial community of Nannochloropsis sp. CCAP211/78 cultures in FP (C hapter 4, FigureS4.4).

There is an ongoing debate ongoing about whether the associations of bacteria with al gae are species-specific. Jasti et al. [364] observed that Alexandriumstrains isol ated from the Gulf of Maine shared many bacterial phylotypes with other Alexandrium cultures, as based on denaturing gradient gel electrophoresis of PCR-amplified 16S rRNA genefragments, regardless of geographic origin, whereas bacteria associated with Alexandriumwere different from those found associated with other phytoplankton species isolated from the same habitat. Likewise, 
another study demonstrated that two axenic marine diatoms (Thalassiosira rotula and Skeletonema costatum) incubated with the same natural bacterial assemblages exhibited very different bacterial community composition and were dominated by distinct phylogenetic groups [306]. Our results generally reinforce the notion that different microalgae harbour specific bacterial communities as we observed highly different bacterial communities associated with Nannochl oropsis sp. (mai nly Rhodobacteraceae, Flammeovirgaceae and Oceanospirillaceae), and B. braunii (mainly Rhizobiaceae, Erythrobacteraceae and Cytophagaceae), which also differed from bacterial communities previously reported to be associated with different diatom species (mainly Rhodobacteraceae, Flavobacteraceaeand Alteromonadaceae). Somebacterial taxa, such as the family Rhodobacteraceae are found together with Nannochloropsis sp., diatoms [96, 306, 319, 359] and many surveyed phytoplankton samples [96, 304, 336, 365], but conservation is in general only observed at the family level. Overall, it seems that the composition of the bacterial communities is species-specific for microal gae.

One hypothesis to explain the existence of species-specific interactions between algae and bacteria is the niche hypothesis: if one al gal species provides a defined and stable niche for a long period of time, the same well-adapted bacterial species will outcompete others when present [366]. Species-specific association of bacteria with al gae may depend on various factors such as al gal exudates [361, 367], surfacestructureand cel lular components of al gae [364, 368], cellular storage products and antibiotic production by al gae [364]. Among these factors, al gal exudates may play the most important role in structuring the bacterial community [359]. This assumption is supported by studies that several microal gal cultures secrete distinct exudates especially with regard to polysaccharides [369, 370]. Therefore, microalgae that share similarities in the composition of exudates might also be associated with similar bacterial communities [359]. In this context it should be noted that in our experiments we did not find correlations between bacterial community composition and the type of hydrocarbons produced 
by different strains of, al though B. braunii can be subclassified to different races (races A, B, and $L$ ) based on the type of hydrocarbons produced (C hapter 3). A future study to further investigate the effects of other microal gal exudates, e.g. carbohydrates and amino acids, on the composition and function of al gal-associated bacteria would be of interest.

\subsection{Reactor types and bacterial community composition}

We surveyed bacterial community composition of Nannochloropsis sp. taken from different reactor types, ranging from a small laboratory reactor to largescal e outdoor reactors (C hapter 4). At the phylum level, generally a similar bacterial community composition was observed between each reactor type. However, at the OTU level we observed that each reactor type contained significantly different bacterial communities except a horizontal tubular reactor (HT) and a vertical tubular reactor (VT).

Reactor types varied in a number of physicochemical factors, which may be responsiblefor the observed differences in bacterial community composition between reactors. Our assumption is supported by a previous study showing that bacterial community composition of Nannochloropsis salina was significantly different between small indoor reactors (Volume: 5 mL-4L), mediumindoor reactors (V olume: 20-60 L) and a largeoutdoor reactor (Volume: 200 L) [69]. Differences in numerous environmental factors and aspects of reactor configuration (for instance, temperature, the ratio of surface area to volume and light intensity) during cultivation at small, medium, and large scales might affect bacterial populations and cause distinct bacterial communities to dominate different reactor systems [69]. HT and VT were not different in bacterial community composition, which may be due to their comparable configuration, which was indeed reflected by the small variation of physicochemical factors between these two reactors (Chapter 4). However, none of the physicochemical factors measured in our experiment al one could satisfactorily explain the shifts in the associated 
bacterial communities in different reactors (Chapter 4, Figure 4.4A). The distinct bacterial communities in different reactor types are probably determined by the combination of environmental variables and reactor configuration/operation, which makes it more difficult to exactly pinpoint the factors responsible for bacterial community structuring. Furthermore, in principle we only have data from a handful of reactors and two reactor runs, which means that the number of independent experimental units is very small. The latter may lead to a rather big impact of stochastic effects during thereactor operation that may affect the bacterial community development. Altogether, at this point it is challenging to discern in a statistically sound way the impact of environmental factors. Nevertheless, additional research that includes more controlled experiments where environmental conditions are varied needs to be done, and multiple reactors from different locations over multiple runs can be monitored and compared.

\subsection{A pplying defined co-cultures to understand algal-bacterial interactions}

Instead of ignoring them or treating bacteria as contaminants as a whole, investigating their interactions with microal gae coul d enable expl oration of the concept of "synthetic ecology" as a microal gae (co-)cultivation technique [371, 372].

Co-cul tivation is not a novel idea in biotechnol ogy [372-374], although much of the focus has been on bacterial interactions [375]. In traditional microbially-based processes such as anaerobic digestion, fermentation, and bioremediation, the most efficient microbial assemblages are often selected and subsequently carefully maintained. With the exception of wastewater treatment with microalgae and bacteria, this approach is not common in algal biotechnology, however, the awareness of harnessing algae-bacteria interactions to enhance productivity and increase the financial and environmental benefits of cult tivating al gae has been accepted by the research community in recent years [372]. A number of examples have been reviewed in chapter $\mathbf{2}$. In chapter 5, by applying a co-culture method we showed that two 
bacteria could significantly enhance thegrowth of a microal ga. However, as the bacterial strains tested in co-culture only accounted for $10 \%$ of the bacterial community in terms of relative abundance in the algal cultures, many more potent bacterial candidates remain to be isolated and tested for their potential to affect the growth of microal gae.

In addition to co-culturing microal gae with one bacterium, a synthetic community approach could be used to select and test different defined microbial assemblages for their potential to increase productivity as well as resistance to contamination. To my knowledge, there are no studies related to this concept. To this end, random combinations of isolated bacterial strains could be grown with algae in the microplate system we developed, and the co-cultures with highest productivity could be selected and tested for large-scal e cult tivation. However, it can be antici pated that this approach will al so facea range of challenges such as how much complexity of such engineered consortia is requi red and how the stability of synthetic communities can be maintained. Considering the highly complex and dynamic nature of bacterial communities observed in al gal cultures, these natural communities may well harbour functional redundancy, and experiments will have to show to what extent such redundancy can be reduced to simplify communities, or whether functional redundancy is required to ensure culture stability when facing dynamic environmental conditions in large scal e outdoor production systems.

\subsection{New opportunities for the deployment of algal-bacterial interactions}

As mentioned in Chapter 1 and Chapter 2, competition and antagonistic interactions are prevalent rel ationships between phytoplankton and bacteria [2, 96, 376]. However, our ai mwas to explore mutualistic interactions between algae and bacteria for applications in algal biotechnology. Thus, in this chapter wefocus more on the beneficial effects of bacteria on al gae. One of the most widely studied mutualistic interactions is the obligate relationship between vitamin-synthesizing bacteria and al gal species that cannot synthesize several of the vitamins 
that are essential for their growth [2]. For example, $\sim 50 \%$ of 326 al gal species examined in a study requi red exogenous supply of vitamins $B_{1}, B_{7}$ or $B_{12}[26]$, whereas bacteria can synthesize these vitamins to sustain al gal growth in exchange for organic carbon $[17,22,26,27]$. Another common obligatemutual ism involves nitrogen-fixing cyanobacteria and microal gae, wherethe cyanobacteria provide fixed nitrogen to the algae in exchange for amino acids and organic carbon [141, 321, 377]. Many marine bacteria, such as Marinobacter species, can all leviateiron limitation of diatoms, dinoflagel lates and coccolithophores by excreting si derophores that have exceptionally high iron affinity [378]. In tum, al gae rel ease di ssolved organic carbon to sustain bacterial growth [98]. In another example, Sulfitobacter sp. SA11 was shown to use diatomderived tryptophan to produce the hormone indole-3-acetic acid that promotes the cell division of the diatom Pseudo-nitzschia multiseries [16]. Interestingly, the molecular exchanges in a range of algal-bacterial interactions bear resemblance to interactions that dominate the rhizosphere of plants [2]. Therefore, the methods and knowledge on plant-microbe interactions might gui de and accelerate the research on al gal-bacterial interactions.

Although some bacterial isolates have been shown to exert a positive effect on the growth of microal gae in laboratory Erlenmeyer flasks [83, 105, 120, 123, 270], it does not mean that under conditions in alarge-scal ebioreactor these bacteria continueto exert the same effect. Therefore, bacteria that are beneficial to microal gae in flasks must be tested in large-scale cultures. For instance, once we have gained mechanistic insight into the abovementioned synthetic communities, the co-cultures with higher productivity could be transferred to larger-scale reactors for further validation. If such co-cultures of higher productivity were to be employed successfully at large scale, a lower production cost of algal biomass would be achieved [71, 372]. Nevertheless, scientists should further seek potential applications for al gae-bacteria coculturing technology. For instance, would co-cultures of microalgae and bacteria have the possibility to produce high added value molecules more cost-effective than other conventional 
production methods? A case in point is that an algae-bacterial co-culture was found more efficient in $\mathrm{H}_{2}$ production than al gae and bacteria separately [379]. Or would such co-culture all ow production of molecules that could otherwise not be produced? Such a molecule could be the potent broad-spectrum antibiotic tropodithietic acid that can only be produced by cocultivation of Emiliania huxleyi and Phaeobacter gallaeciensis [46].

On the other hand, advantages of al gal-bacterial interactions through co-cultivation could be decreased contamination. When microalgae are co-cultured with symbiotic bacteria, the invasion by other bacteria may be decreased because invading bacteria would be less likely to establish in an al ready occupied niche [27]. Furthermore, studies of antagonistic or al gicidal bacteria are also useful because of the potential application in mitigating harmful al gal blooms, and more relevantly, in preventing the growth of al gicidal bacteria when al gae are grown at large scal e for aquaculture or other val uable products [380]. Related to the latter, Ganuza et al. [381] investigated the possi bility to alleviate bacterial infection of the green al ga Chlorella by the parasitic bacterium Vampi rovibrio through decreasing $\mathrm{pH}$ of the medi um for $15 \mathrm{~min}$ in the presence of acetate. The treatment was successful in prolonging algal cultivation, and the al gicidal bacteriumappeared to be unabl eto buil d up immunity to this treatment. Bagwell et al. [382] also investigated the possibility of preventing Vampirovibrio infection of Chlorella cultures. In this case, the infection was prevented by inducing the production of bioactive small peptides and glycosides by Chl orella under iron limitation.

\subsection{Novel methodologies to study algae-associated bacteria and algae-bacterial interactions}

\subsubsection{New primer set to characterize algae-associated bacteria}

A common approach to characterizethe composition of al gæe-associated bacterial communities comprises PCR amplification and sequencing of 16S rRNA genes using a universal bacterial 
primer set [383]. Routine sampling strategies for studying algal microbiomes do not often separate al gal and bacterial cells, which results in the combination of bacterial and al gal DNA in the samples. However, as al gal plastid genomes encode 165 rRNA closely related to that of cyanobacteria, sequencing data sets frequently comprise more than $75 \%$ plastid sequences (Chapter 4). As a result, bacterial diversity may be largely underrepresented due to the decreased sequencing depth.

Thomas et al. [384] eval uated several primer sets to amplify a 450 bp fragment spanning the V3-V4 region while minimizing the amplification of plastid sequences. The new primer set NOCHL was shown to have lower coverage for plastids and cover a significantly higher bacterial richness than other tested primer sets. This primer set is a potent altemative to study bacterial communities in environments where plastid contamination can be an issue such as terrestrial plants and microalgae.

\subsubsection{M ass spectrometry imaging}

Information obtained from (meta)genomic/transcriptomic and proteomic approaches is a prerequisite for a systems-level understanding of symbiont physiology [385], but is not sufficient to provide direct evidence of potential metabolic signatures because microbial interactions often involve a dynamic metabolic crosstalk and chemical communication [386, 387]. Therefore, a metabolomics approach has been devel oped as a powerful tool to unravel the means and consequences of microbial interaction at the metabolic level. Recent advances in mass spectrometry imaging (MSI) technologies allow the localization of specific metabolites of various dynamic processes and biotic interactions at the microscal elevel and, consequently, monitoring of metabolic changes at high spatiotemporal resolution [388]. MSI has been widely used to study the metabolic footprints of host-associated bacteria [385], bacterial population dynamics [389] and to detect pathogens [390]. Likewise, MSI is applicable to study al gal- 
bacterial interactions. For instance, targeted metabolic profiling could facilitate the quantification of known compounds (for instance, vitamins and auxins) exchanged between microal gae and bacteria, and untargeted metabolic profiling would enable the identification of novel molecules mediating algae-bacterial interactions.

A more recent study investigated metabolic alteration (mainly lipids) during virus infection (EhV) of the microalga Emiliania huxleyi. A culture of E. huxleyi was mixed with infectious EhV virions in agarose, and the mixture was then poured into a peri dish. When the plaques were formed, one plaque sample was bl otted onto a filter and analysed directly using MALDIMS or Flow-probe-MS. This experimental approach needs much smaller samples (one plaque or colony) as compared to conventional metabolomic approaches that require bulk liquid cultures (from milli-liters to liters) [388].

A

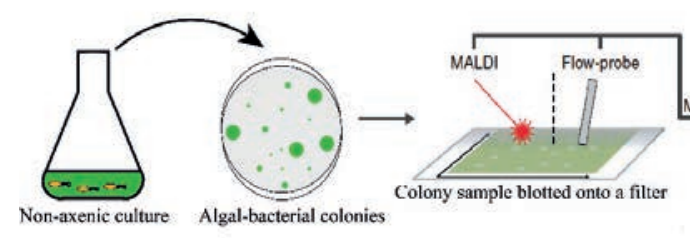

B

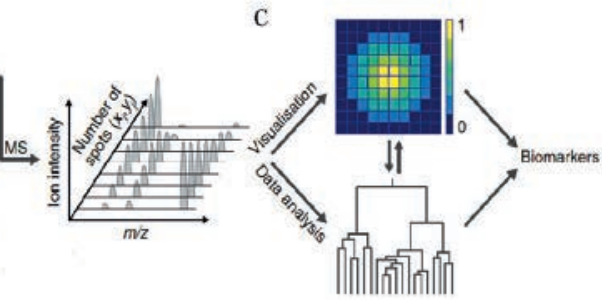

Figure 6.2. Overview of the workflow of MSI analysis. A, For the agar plate assay, a nonaxenic al gal culture can be di luted and mixed in agarose, and poured into a Petri di sh, which is then incubated until the formation of colonies. B, A col ony sample is blotted onto a filter. MSI techniques can be used to analyse colony samples: MALDI-MS or Flow-probe-MS. C, The collected spectra can be used for visualization of specific metabolic biomarkers for algalbacterial interactions, as well as for untargeted data anal ysis using spatial ly aware unsupervised clustering (Flow-probe-MS) and colocalization (MALDI-MS). B and C were adopted from [388]

Inspired by this study, we propose here a comparable experimental approach to investigate metabolomes of algae-bacteria interactions (Figure 6.2). Non-axenic algal cultures or field samples can be directly used, for example by first separating al gal and bacterial cells through 
filtration or cell sorting, and then mixing fractions again at the desired ratio (algae: bacteria = 1:1) using bead- or microdroplet based approaches. The droplets are then spread on an agar plate and incubated under desired conditions until the formation of colonies. Theoretically, the algal col onies would contain on average one bacterial species, and the metabol omes of al gae and specific bacteria can be anal ysed following the methods in Figure $2 \mathrm{~B}$ and $\mathrm{C}$. In addition to abovementioned samples, the samples of doubleagar plate assays (C hapter 5, Figure 5.2) can be directly analysed following the same protocol as well. Compared to the double-agar plate assay used in C hapter 5, thesamplepreparation method (Figure6.2A) skips thelaborious work of bacterial isolation, and co-culturing al gae and bacteria together on agar plates may increase the possibility of testing otherwise uncultivable bacteria. Furthermore, differently sized colonies of microal gae on the agar plate may be an indicator that co-existing bacteria have growth promoting/inhibiting ability, which can be directly picked for MSI analysis. With these advantages, this method combines screening of al gae associated bacteria and metabolomes together, which stands for an efficient and fast way to studying metabolic shifts during algalbacterial interactions.

\subsubsection{M icrofluidics and Raman-activated microbial cell sorting}

Marine bacteria have evolved strategies to exploit exudates from living and dead microal gae. To forage such resources bacteria are guided by a chemoattractant leaking from al gae [391]. This process is called chemotaxis and is a prerequisite for bacteria to sense and interact with microalgæe [314, 392]. The advancement made in the fields of microfluidics enables the interrogation of the chemical ly mediated interactions between microal gae and bacteria.

As proposed by Lambert et al. [393], the ISCA (in situ chemotaxis assay) device is a robust device that can be used to study algae-bacterial interactions (Figure 6.3A). Algal cultures or any molecules produced by microal gae can be loaded into wells, and then the device can be 
depl oyed in the ocean or photobioreactor, for instance. Upon depl oyment, chemicals in the well produce transient nutrient pul ses, attracting chemotactic bacteria to swimming into the well of the device. After collection, those samples can be enumerated by flow cytometry, identified by sequencing and used for bacterial isolation.

A

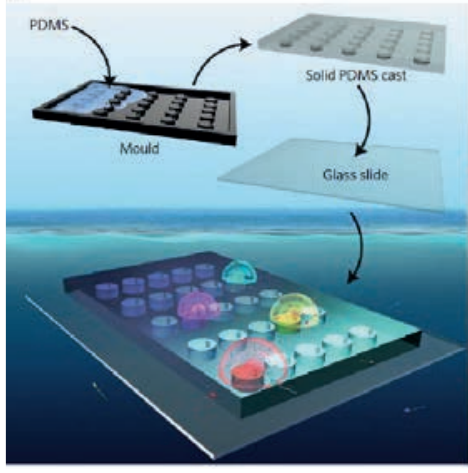

B

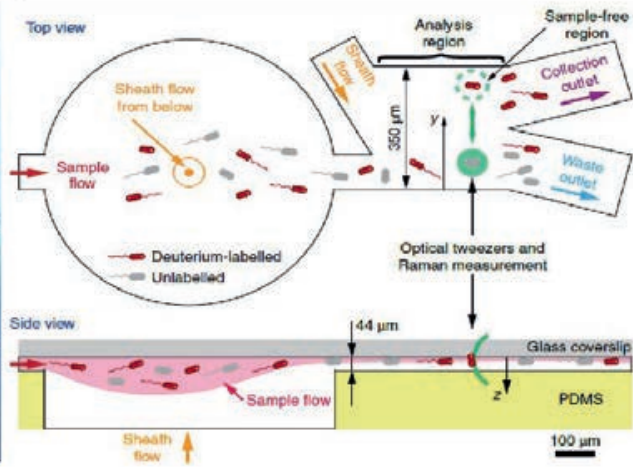

Figure 6.3. Fabrication of the in situ chemotaxis assay (ISCA) and laboratory tests. (A) Polydimethylsil loxane (PDMS) is cast onto a 3D printed mould and cured overnight. The solid PDMS, containing multiple wells, is then excised and plasma-bonded onto a glass slide (100 $\mathrm{mm} \times 76 \mathrm{~mm} \times 1 \mathrm{~mm}$ ). Each well has an independent connection to the external environment via a port, through which chemicals can diffuseand microorgani sms enter. Adapted from [393]. (B) Adapted from [394]

The captured bacteria from the ISCA device can be further subjected to an optofluidic platform for Raman-activated microbial cell sorting (RACS) (Figure 6.3B). Unlike previous RACS approaches, this method is applicable to a wide range of cells not containing compounds that enhance measurement sensitivity (for example, carotenoids and chlorophyll). Furthermore, this approach detects all metabolically active cells with no need for cell fixation and is thus a nondestructive method. For example, this approach could be used for cells that are active when incubated in the presence of a specific substrate that do not need to be labell led themselves. The RACS can analyse up to 200-500 cells $\mathrm{h}^{-1}$ and is thus suitable for function-based cell culturing and metagenomics, or as a front end to standard singlecell genomics platforms [394]. This 
method is appropriate for analysing algae-associated bacteria and isolating active bacterial representatives for further growth essay in the co-culture platform we developed (C hapter 5, Figure 5.1). In combination with MSI, thesemethods represent powerful tools to identify al gaeassociated bacteria and di sentangle the mechanisms behind the interactions. 

R eferences 


\section{References}

1. Armbrust, E.V., et al., The genome of the diatom Thalassiosira pseudonana: ecology, evolution, and metabolism Science, 2004. 306(5693): p. 79-86.

2. Seymour, J.R., et al., Zooming in on the phycosphere: the ecological interface for phytoplankton-bacteria relationships. Nature microbiology, 2017. 2(7): p. 17065.

3. Falkowski, P.G., The role of phytoplankton photosynthesis in global biogeochemical cycles. Photosynthesis research, 1994. 39(3): p. 235-258.

4. Field, C.B., et al., Primary production of the biosphere: integrating terrestrial and oceanic components. science, 1998. 281(5374): p. 237-240.

5. Pal mer, J.D., D.E. Soltis, and M.W. Chase, The plant tree of life: an overview and some points of view. American J oumal of Botany, 2004. 91(10): p. 1437-1445.

6. Müller, D.B., et al., The plant microbiota: systems-level insights and perspectives. Annual review of genetics, 2016. 50: p. 211-234.

7. Parniske, M., Arbuscul ar mycorrhiza: the mother of plant root endosymbioses. Nature Reviews Microbiology, 2008. 6(10): p. 763.

8. Udvardi, M. and P.S. Poole, Transport and metabolismin legume-rhizobia symbioses. Annual review of plant biology, 2013. 64: p. 781-805.

9. Berendsen, R.L., C.M. Pieterse, and P.A. Bakker, The rhizosphere microbiome and plant health. Trends in plant science, 2012. 17(8): p. 478-486.

10. Bulgarelli, D., et al., Structure and functions of the bacterial microbiota of plants. Annual review of plant biology, 2013. 64: p. 807-838.

11. Mendes, R., P. Garbeva, and J.M. Raaijmakers, The rhizosphere microbiome: significance of plant beneficial, plant pathogenic, and human pathogenic microorganisms. FEMS microbiology reviews, 2013. 37(5): p. 634-663.

12. Vorholt, J.A., Microbial life in the phyllosphere. Nature Reviews Microbiology, 2012. 10(12): p. 828.

13. Hiltner, L., Uber nevere Erfahrungen und Probleme auf dem Gebiet der Boden Bakteriologie und unter besonderer Beurchsichtigung der Grundungung und Broche. Arbeit. Deut. Landw. Ges. Berlin, 1904. 98: p. 59-78.

14. Hartmann, A., M. Rothballer, and M. Schmid, Lorenz Hiltner, a pioneer in rhizosphere microbial ecology and soil bacteriology research. Plant Soil, 2008. 312(1-2): p. 7-14.

15. Bell, W. and R. Mitchell, Chemotactic and growth responses of marinebacteria to al gal extracellular products. The Biological Bulletin, 1972. 143(2): p. 265-277.

16. Amin, S., et al., Interaction and signall ling between a cosmopolitan phytoplankton and associated bacteria. Nature, 2015. 522(7554): p. 98-101.

17. Durham, B.P., et al., Cryptic carbon and sul fur cycl ing between surface ocean plankton. Proceedings of the National Academy of Sciences, 2015. 112(2): p. 453-457.

18. Lucas, C., The ecological effects of external metabolites. Biological Reviews, 1947. 22(3): p. 270-295.

19. Provasoli, L., Nutrition and ecology of protozoa and algae. Annual review of microbiology, 1958. 12(1): p. 279-308.

20. Watanabe, K., et al., Symbiotic association in Chlorella culture. FEMS microbiology ecology, 2005. 51(2): p. 187-196.

21. Krohn-Molt, I., et al., Insights into Microalga and Bacteria Interactions of Selected PhycosphereBiofilms Using Metagenomic, Transcriptomic, and Proteomic Approaches. Frontiers in Microbiology, 2017. 8: p. 1941.

22. Grant, M.A., et al., Direct exchange of vitamin B12 is demonstrated by model ling the growth dynamics of algal-bacterial cocultures. ISME J, 2014. 8(7): p. 1418-27. 
23. Landa, M., et al., Shifts in bacterial community composition associated with increased carbon cycling in a mosaic of phytoplankton blooms. ISME J , 2016. 10(1): p. 39-50.

24. Xie, B., et al., Chlamydomnas reinhardtii thermal tolerance enhancement mediated by a mutual istic interaction with vitamin B12-producing bacteria. ISME J, 2013. 7(8): p. 1544-55.

25. Ramanan, R., et al., Algae-bacteria interactions: evolution, ecology and emerging applications. Biotechnology advances, 2016. 34(1): p. 14-29.

26. Croft, M.T., et al., Algae acquire vitamin B12 through a symbiotic relationship with bacteria. Nature, 2005. 438(7064): p. 90-3.

27. Kazamia, E., etal., Mutualistic interactions between vitamin B12 - dependent al gaeand heterotrophic bacteria exhibit regulation. Environmental microbiology, 2012. 14(6): p. 1466-1476.

28. Hernandez, J.-P., et al., Growth promotion of the freshwater microalga Chlorella vulgaris by the nitrogen-fixing, plant growth-promoting bacterium Bacillus pumilus fromarid zone soils. European J ournal of Soil Biology, 2009. 45(1): p. 88-93.

29. Cho, D.H., et al., Enhancing microalgal biomass productivity by engineering a microal gal-bacterial community. Bioresour Technol, 2014. 175c: p. 578-585.

30. Zapal ski, M.K., Is absence of proof a proof of absence? Comments on commensalism Pal aeogeography, Palaeocl imatology, Pal aeoecol ogy, 2011. 302(3-4): p. 484-488.

31. Mai-Prochnow, A., et al., Biofilm devel opment and cell death in the marine bacterium Pseudoalteromonas tunicata. Applied and environmental microbiology, 2004. 70(6): p. 3232-3238.

32. Ivanova, J., G. Stoyancheva, and I. Pouneva, Lysis of Antarctic al gal strains by bacterial pathogen. Antonie Van Leeuwenhoek, 2014. 105(6): p. 997-1005.

33. Zheng, $X$., et al., A marine algicidal actinomycete and its active substance against the harmful algal bloom species Phaeocystis globosa. Applied microbiology and biotechnology, 2013. 97(20): p. 9207-9215.

34. Hertweck, C., et al ., Antagonistic bacteria di srupt cal ciumhomeostasis and immobilize algal cells. Nature communications, 2017. 8: p. 1756.

35. Wang, B., et al., A marine bacterium producing protein with al gicidal activity against Alexandriumtamarense. Harmful Algae, 2012. 13: p. 83-88.

36. Kim, M.-J., S.-Y. J eong, and S.-J. Lee, Isolation, identification, and al gicidal activity of marine bacteria against Cochlodini umpolykrikoi des. Journal of Applied Phycology, 2008. 20(6): p. 1069-1078.

37. Lee, Y.-K., et al., Cyanobactericidal effect of Rhodococcus sp. isolated fromeutrophic lake on Microcystis sp. Biotechnology letters, 2010. 32(11): p. 1673-1678.

38. Bai, S.J., et al., Algicidal effects of a novel marine actinomycete on the toxic dinoflagellate Alexandrium tamarense. Current Microbiology, 2011. 62(6): p. 1774 1781.

39. Anderson, D.M., A.D. Cembella, and G.M. Hallegraeff, Progress in understanding harmful algal blooms: paradigmshifts and new technologies for research, monitoring, and management. Annual review of marine science, 2012. 4: p. 143-176.

40. Buchan, A., et al., Master recyclers: features and functions of bacteria associated with phytoplankton blooms. Nature Reviews Microbiology, 2014.

41. Heisler, J., et al., Eutrophication and harmful algal blooms: a scientific consensus. Harmful al gae, 2008. 8(1): p. 3-13.

42. Landsberg, J.H., The effects of harmful algal blooms on aquatic organisms. Reviews in Fisheries Science, 2002. 10(2): p. 113-390.

43. Grattan, L.M., S. Holobaugh, and J.G. Morris Jr, Harmful algal blooms and public health. Harmful al gae, 2016. 57: p. 2-8. 
44. Brodie, J., et al., Biotic interactions as drivers of algal origin and evolution. New Phytologist, 2017. 216(3): p. 670-681.

45. Wagner-Döbler, I., et al., The complete genome sequence of the algal symbiont Dinoroseobacter shi bae: a hitchhiker's gui deto life in the sea. The ISME journal, 2010. 4(1): p. 61-77.

46. Seyedsayamdost, M.R., et al., The Jekyll-and-Hyde chemistry of Phaeobacter gallaeciensis. Nature chemistry, 2011. 3(4): p. 331-335.

47. Dittami, S.M., D. Eveillard, and T. Tonon, A metabolic approach to study algalbacterial interactions in changing environments. Molecular ecology, 2014. 23(7): p. 1656-1660.

48. Cooper, M.B. and A.G. Smith, Exploring mutualistic interactions between microal gae and bacteria in the omics age. Current opinion in plant biology, 2015. 26: p. 147-153.

49. Krupke, A., et al., Distribution of a consortium between unicellular algae and the N2 fixing cyanobacterium UCYN - A in the North Atlantic Ocean. Environmental microbiology, 2014. 16(10): p. 3153-3167.

50. Wijffels, R.H., M.J. Barbosa, and M.H. Eppink, Microal gae for the production of bulk chericals and biofuels. Biofuels, Bioproducts and Biorefining, 2010. 4(3): p. 287-295.

51. Draaisma, R.B., et al., Food commodities from microalgae. Current opinion in biotechnology, 2013. 24(2): p. 169-177.

52. Norsker, N.-H., et al., Microalgal production-a close look at the economics. Biotechnology advances, 2011. 29(1): p. 24-27.

53. Mascarelli, A.L., Gold rush for algae. 2009, Nature Publishing Group.

54. Chew, K.W., et al., Microalgae biorefinery: high value products perspectives. Bioresourcetechnology, 2017. 229: p. 53-62.

55. Eppink, M.H., et al., From current algae products to future biorefinery practices: a review, in Biorefineries. 2017, Springer. p. 99-123.

56. Wijffels, R.H. and M.J. Barbosa, An outlook on microalgal biofuels. Science, 2010. 329(5993): p. 796-799.

57. Ruiz, J., et al., Towards industrial products frommicroal gae. Energy \& Environmental Science, 2016. 9(10): p. 3036-3043.

58. Ugwu, C., H. Aoyagi, and H. Uchiyama, Photobioreactors for mass cultivation of al gae. Bioresource technology, 2008. 99(10): p. 4021-4028.

59. deVree, J.H., Outdoor production of microal gae. 2016: Wageningen University.

60. Kumar, K., et al., Recent trends in the mass cultivation of al gae in raceway ponds. Renewable and Sustainable Energy Reviews, 2015. 51: p. 875-885.

61. Grobbelaar, J.U., Factors governing algal growth in photobioreactors: the "open" versus “ closed" debate. Journal of applied phycology, 2009. 21(5): p. 489.

62. Slade, R. and A. Bauen, Micro-algae cultivation for biofuels: cost, energy balance, environmental impacts and future prospects. Biomass and bioenergy, 2013. 53: p. 2938.

63. Norsker, N.H., et al., Microalgal production - A close look at the economics. 2011. 29(1): p. 24-27.

64. Sousa, C., et al., Growth of the microalgae Neochloris oleoabundans at high partial oxygen pressures and sub-saturating light intensity. Bioresourcetechnol ogy, 2012. 104: p. 565-570.

65. Ugwu, C., J. Ogbonna, and H. Tanaka, Design of static mixers for inclined tubular photobioreactors. Journal of Applied Phycology, 2003. 15(2-3): p. 217-223.

66. Wolf, J., et al., Multifactorial comparison of photobioreactor geometries in paralle microal gae cultivations. Algal research, 2016. 15: p. 187-201. 
67. Xu, L., etal., Microalgal bioreactors: challenges and opportunities. Engineering in Life Sciences, 2009. 9(3): p. 178-189.

68. Gupta, P.L., S.-M. Lee, and H.-J. Choi, A mini review: photobioreactors for large scale algal cultivation. World J ournal of Microbiology and Biotechnology, 2015. 31(9): p. 1409-1417.

69. Ful bright, S.P., et al., Bacterial community changes in an industrial al gae production system Algal Research, 2018. 31: p. 147-156.

70. Newby, D.T., et al., Assessing the potential of polyculture to accelerate algal biofue production. Algal research, 2016. 19: p. 264-277.

71. Lian, J., etal., The effect of thealgal microbiomeon industrial production of microalgae. Microbial Biotechnology, 2018. 11(5): p. 806-818.

72. Wolf, F.R., Botryococcus braunii an unusual hydrocarbon-producing alga. Applied Biochemistry and Biotechnology Advances, 1983. 8(3): p. 249.

73. Fernandes, $\mathrm{H}_{\text {., }}$ et al., Biosynthesis of high concentrations of an exopolysaccharide during the cultivation of the microalgaBotryococcus braunii. Biotechnology letters, 1989. 11(6): p. 433-436.

74. Gouveia, J.D., et al., Botryococcus braunii strains compared for biomass productivity, hydrocarbon and carbohydratecontent J ournal of applied phycology, 2017. 248: p. 7786.

75. Metzger, P. and C. Largeau, Botryococcus braunii: a rich source for hydrocarbons and related ether lipids. A pplied microbiology biotechnology, 2005. 66(5): p. 486-496.

76. Kawachi, M., et al., Relationship between hydrocarbons and molecular phylogeny of Botryococcus braunii. Algal Research, 2012. 1(2): p. 114-119.

77. Eroglu, E., S. Okada, and A. Melis, Hydrocarbon productivities in different Botryococcus strains: comparative methods in product quantification. Journal of applied phycology, 2011. 23(4): p. 763-775.

78. Cabanelas, I.T.D., et al., Botryococcus, what to do with it? Effect of nutrient concentration on bi orefinery potential. Algal Research, 2015. 11: p. 43-49.

79. Dayananda, C., et al., Autotrophic cultivation of Botryococcus braunii for the production of hydrocarbons and exopolysaccharides in various media. Biomass and Bioenergy, 2007. 31(1): p. 87-93.

80. Rivas, M.O., P. Vargas, and C.E. Riquelme, Interactions of Botryococcus braunii cultures with bacterial biofilms. Microbial ecology, 2010. 60(3): p. 628-635.

81. Sambles, C., et al., Metagenomic analysis of the complex microbial consortium associated with cultures of the oil-rich al ga Botryococcus braunii. MicrobiologyOpen, 2017. 6(4): p. 6196-6206.

82. Chirac, C., et al., Bacterial influence upon growth and hydrocarbon production of the green al ga Botryococcus braunii 1. J ournal of Phycology, 1985. 21(3): p. 380-387.

83. Tanabe, Y., et al., A novel al phaproteobacterial ectosymbiont promotes the growth of the hydrocarbon-rich green al ga Botryococcus braunii. Scientific Reports, 2015. 5: p. 10467.

84. Gouveia, J.D., et al., Effect of removal of bacteria on the biomass and extracellular carbohydrate productivity of Botryococcus braunii. Journal of Applied Phycology, 2019: p. 1-11.

85. Rodolfi, L., et al., Microalgaefor Oil: Strain Sel ection, Induction of Lipid Synthesis and Outdoor Mass Cultivation in a Low-Cost Photobioreactor. Biotechnology Bioengineering, 2010. 102(1): p. 100-112.

86. Dipasmita, P., et al., The effect of light, salinity, and nitrogen availability on lipid production by Nannochl oropsis sp. A pplied Microbiology Biotechnology, 2011. 90(4): p. 1429. 
87. Wang, $\mathrm{H}_{\text {., }}$ et al., Novel bacterial isolate from Permian groundwater, capable of aggregating potential biofuel-producing microalga Nannochloropsis oceanica IMET1. Appl Environ Microbiol, 2012. 78(5): p. 1445-53.

88. Skjermo, J. and O. Vadstein, Techniques for microbial control in the intensive rearing of marinelarvae. Aquaculture, 1999. 177(1-4): p. 333-343.

89. Salvesen, I., J. Skjermo, and O. Vadstein, Growth of turbot (Scophthal mus maximus L.) during first feeding in relation to the proportion of $\mathrm{r} / \mathrm{K}$-strategists in the bacterial community of the rearing water. Aquaculture, 1999. 175(3-4): p. 337-350.

90. Nakase, G. and M. Eguchi, Analysis of bacterial communities in Nannochloropsis sp. cultures used for larval fish production. Fisheries science, 2007. 73(3): p. 543-549.

91. Carney, L.T., et al., Pond Crash Forensics: Presumptive identification of pond crash agents by next generation sequencing in replicate raceway mass cultures of Nannochloropsis salina. Algal Research, 2016. 17: p. 341-347.

92. Sharifah, E.N. and M. Eguchi, The phytoplankton Nannochloropsis oculata enhances the ability of Roseobacter clade bacteria to inhibit the growth of fish pathogen Vibrio anguillarum PLoS One, 2011. 6(10): p. e26756.

93. Sharma, N.K., et al., Sustainability and cyanobacteria (bluegreen algae): facts and challenges. J ournal of applied phycology, 2011. 23(6): p. 1059-1081.

94. Shields, R.J. and I. Lupatsch, Algaefor aquacultureand animal feeds. J A nimSci, 2012. 21: p. 23-37.

95. Hom, E.F., et al., A chemical perspective on microalgal-microbial interactions. Trends in plant science, 2015. 20(11): p. 689-693.

96. Amin, S.A., M.S. Parker, and E.V. Armbrust, Interactions between diatoms and bacteria. Microbiol Mol Biol Rev, 2012. 76(3): p. 667-84.

97. Bowler, C., et al., The Phaeodactylum genome reveals the evolutionary history of diatomgenomes. Nature, 2008. 456(7219): p. 239-244.

98. Amin, S.A., et al., Photolysis of iron-siderophore chelates promotes bacterial-al gal mutualism Proceedings of the National Academy of Sciences, USA, 2009. 106(40): p. 17071-17076.

99. Bruhn, J.B., L. Gram, and R. Belas, Production of antibacterial compounds and biofilm formation by Roseobacter species are influenced by culture conditions. Applied and environmental microbiology, 2007. 73(2): p. 442-450.

100. Wahl, M., et al., The second skin: ecological role of epibiotic biofilms on marine organisms. Frontiers in microbiology, 2012. 3: p. 292.

101. Natrah, F.M.I., etal., Significance of microal gal-bacterial interactions for aquaculture. Reviews in Aquaculture, 2013. 6(1): p. 48-61.

102. Danchin, A. and S. Braham, CoenzymeB12 synthesis as a baseline to study metabolite contribution of animal microbiota. Microbial biotechnology, 2017. 10(4): p. 688-701.

103. Dittami, S.M., et al., Host-microbe interactions as a driver of acclimation to salinity gradients in brown al gal cultures. The ISME journal, 2016. 10(1): p. 51-63.

104. Le Chevanton, M., et al., Screening and selection of growth-promoting bacteria for Dunaliella cultures. Algal Research, 2013. 2(3): p. 212-222.

105. Kim, B.-H., et al., Role of Rhizobium a plant growth promoting bacterium in enhancing al gal bi omass through mutualistic interaction. Biomass and Bioenergy, 2014. 69(0): p. 95-105.

106. Carney, L.T. andT.W. Lane, Parasites in al gaemass culture Frontiers in microbiology, 2014. 5: p. 278.

107. Mendes, L.B.B. and A.B. Vermelho, Allelopathy as a potential strategy to improve microal gae cultivation. Biotechnology for biofuels, 2013. 6(1): p. 1. 
108. Su, Y., A. Mennerich, and B. Urban, Synergistic cooperation between wastewater-born algae and activated sludge for wastewater treatment: influence of algae and sludge inoculation ratios. Bioresource technology, 2012. 105: p. 67-73.

109. Luo, S., et al., Pyrene degradation accelerated by constructed consortium of bacterium and microal ga: effects of degradation products on the microalgal growth. Environ Sci Technol, 2014. 48(23): p. 13917-24.

110. Cavaliere, M., et al., Cooperation in microbial communities and their biotechnological applications. Environmental microbiology, 2017. 19(8): p. 2949-2963.

111. Wilson, W.H., G. Tarran, and M.V. Zubkov, Virus dynamics in a coccolithophore dominated bloom in the North Sea. Deep Sea Research Part II: Topical Studies in Oceanography, 2002. 49(15): p. 2951-2963.

112. Chen, Z., et al., First report of Pseudobodo sp, a new pathogen for a potential energyproducing al gae: Chl orella vil garis cultures. PLoS One, 2014. 9(3): p. e89571.

113. Lenneman, E.M., P. Wang, and B.M. Barney, Potential application of al gicidal bacteria for improved lipid recovery with specific al gae. FEMS Microbiol Lett, 2014. 354(2): $p$. 102-10.

114. Sun, L., et al., A novel membrane bioreactor inocul ated with symbiotic sludge bacteria and al gae: Performance and microbial community analysis. Bioresource technology, 2018. 251: p. 311-319.

115. Y ang, J., et al., Potential of wastewater treatment using a concentrated and suspended algal-bacterial consortium in a photo membrane bioreactor. Chemical Engineering Journal, 2018. 335: p. 154-160.

116. García, D., et al., Comparative evaluation of piggery wastewater treatment in algalbacterial photobioreactors under indoor and outdoor conditions. Bioresource technology, 2017. 245: p. 483-490.

117. Krohn-Molt, I., et al ., Metagenome survey of a multispecies and al ga-associated biofilm revealed key elements of bacterial-algal interactions in photobioreactors. A pplied and environmental microbiology, 2013. 79(20): p. 6196-6206.

118. Biondi, N., et al ., The bacterial community associated with Tetrasel mis suecica outdoor mass cultures. J ournal of Applied Phycology, 2017. 29(1): p. 67-78.

119. Sison-Mangus, M.P., et al., Host-specific adaptation governs the interaction of the marine diatom Pseudo-nitzschia and their microbiota. The ISME journal, 2014. 8(1): p. 63-76.

120. Lakaniemi, A.M., et al., Growth of Chlorella vulgaris and associated bacteria in photobioreactors. Microb Biotechnol, 2012. 5(1): p. 69-78.

121. Park, Y., et al., Growth promotion of Chlorella ellipsoidea by co-inoculation with Brevundimonas sp. isolated from the microalga. Hydrobiologia, 2007. 598(1): p. 219228.

122. Grossart, H.-P. and M. Simon, Interactions of planktonic algae and bacteria: effects on algal growth and organic matter dynamics. Aquatic Microbial Ecology, 2007. 47(2): p. 163.

123. Bruckner, C.G., et al., Growth and release of extracellular organic compounds by benthic diatoms depend on interactions with bacteria. Environmental microbiology, 2011. 13(4): p. 1052-1063.

124. Ras, M., J.-P. Steyer, and O. Bernard, Temperature effect on microal gae: a crucial factor for outdoor production. Reviews in Environmental Scienceand Bio/Technol ogy, 2013. 12(2): p. 153-164.

125. Olsenz, J.L., Stress ecology in Fucus: abiotic, biotic and genetic interactions. Advances in marine biology, 2011. 59(57): p. 37. 
126. Wang, S., etal ., Microalgal assemblages in a poiki lohaline pond. J oumal of Phycology, 2014. 50(2): p. 303-309.

127. Foflonker, F., et al., Genome of the halotolerant green alga Picochlorum sp. reveals strategies for thriving under fluctuating environmental conditions. Environmental microbiology, 2015. 17(2): p. 412-426.

128. Ritter, A., et al., Copper stress proteomics highlights local adaptation of two strains of the model brown al ga Ectocarpus silicul osus. Proteomics, 2010. 10(11): p. 2074-2088.

129. Tonon, T., et al., Toward systems biology in brown algae to explore acclimation and adaptation to the shore environment. Omics: a journal of integrative biology, 2011. 15(12): p. 883-892.

130. Charrier, B., et al., Development and physiology of the brown alga Ectocarpus siliculosus: two centuries of research. New Phytologist, 2008. 177(2): p. 319-332.

131. Schroda, M., The Chlamydomonas genomereveal sits secrets: chaperone genes and the potential roles of their gene products in the chloroplast. Photosynthesis research, 2004. 82(3): p. 221-240.

132. Singh, M. and K. Das, Low Cost Nutrients for Al gaeCultivation, in Al gal Biorefineries. 2014, Springer. p. 69-82.

133. Clarens, A.F., et al., Environmental life cycle comparison of algae to other bioenergy feedstocks. Environmental science \& technology, 2010. 44(5): p. 1813-1819.

134. Putt, R., et al., An efficient system for carbonation of high-rate al gae pond water to enhance CO 2 mass transfer. Bioresource technology, 2011. 102(3): p. 3240-3245.

135. Mouget, J.L., et al., Algal growth enhancement by bacteria: is consumption of photosynthetic oxygen involved? FEMS microbiology ecology, 1995. 18(1): p. 35-43.

136. Subashchandrabose, S.R., et al., Consortia of cyanobacteria/microal gae and bacteria: biotechnological potential. Biotechnol ogy advances, 2011. 29(6): p. 896-907.

137. Bai, X., P. Lant, and S. Pratt, The contribution of bacteria to al gal growth by carbon cycling. Biotechnology and bi oengineering, 2015. 112(4): p. 688-695.

138. Silverstein, R.N., A.M. Correa, and A.C. Baker, Specificity is rarely absolute in coralalgal symbiosis: implications for coral response to climate change. Proceedings of the Royal Society of London B: Biological Sciences, 2012. 279(1738): p. 2609-2618.

139. Reshef, L., et al., The coral probiotic hypothesis. Environmental Microbiology, 2006. 8(12): p. 2068-2073.

140. Fiore, C.L., et al ., Nitrogen fixation and nitrogen transformations in marine symbioses. Trends in microbiology, 2010. 18(10): p. 455-463.

141. Foster, R.A., etal., Nitrogen fixation and transfer in open ocean diatom-cyanobacterial symbioses. TheISME journal, 2011. 5(9): p. 1484-1493.

142. Zhu, Y., et al., Characterization of organic phosphorus in lake sediments by sequential fractionation and enzymatic hydrolysis. Environmental science \& technology, 2013. 47(14): p. 7679-7687.

143. Kononova, S. and M. Nesmeyanova, Phosphonates and their degradation by microorganisms. Biochemistry (Moscow), 2002. 67(2): p. 184-195.

144. Zhao, G., et al., The importance of bacteria in promoting algal growth in eutrophic lakes with limited available phosphorus. Ecological Engineering, 2012. 42: p. 107-111.

145. Sule, P. and R. Belas, A novel inducer of Roseobacter motility is also a disruptor of algal symbiosis. J oumal of bacteriology, 2013. 195(4): p. 637-646.

146. Segev, E., et al., Dynamic metabolic exchange governs a marine algal-bacterial interaction. elife, 2016. 5: p. el7473.

147. Seyedsayamdost, M.R., et al., Hybrid Biosynthesis of Roseobacticides fromAl gal and Bacterial Precursor Molecules. Journal of the American Chemical Society, 2014. 136(43): p. 15150-15153. 
148. Twigg, M.S., et al ., Interference with the germination and growth of Ulva zoospores by quorum - sensing mol ecules fromUlva - associated epiphytic bacteria. Environmental microbiology, 2014. 16(2): p. 445-453.

149. Matsuo, Y., et al., Isolation of an Algal Morphogenesis Inducer from a Marine Bacterium Science, 2005. 307(5715): p. 1598-1598.

150. Andersen, R.A., Algal culturing techniques. 2005: Academic press.

151. Pienkos, P.T. and A. Darzins, The promise and challenges of microalgal-derived biofuels. Biofuels, Bioproducts and Biorefining, 2009. 3(4): p. 431-440.

152. Hoffman, Y., et al., Isolation and characterization of a novel chytrid species (phylum Blastocladiomycota), parasitic on thegreen al ga Haematococcus. mycol ogical research, 2008. 112(1): p. 70-81.

153. Georgianna, D.R. and S.P. Mayfiedd, Expl oiting diversity and synthetic biology for the production of al gal bi ofuels. Nature, 2012. 488(7411): p. 329-335.

154. Brussaard, C.P. and J.M. Martinez, Algal bloom viruses. Plant Viruses, 2008. 2(1): p. 1-13.

155. Schatz, D., et al., Hijacking of an autophagy - like process is critical for the life cycle of a DNA virus infecting oceanic al gal blooms. New Phytologist, 2014. 204(4): p. 854 863.

156. Zozaya - Valdés, E., et al., Microbial community function in the bleaching disease of the marine macroalgae Delisea pulchra. Environmental microbiology, 2017. 19(8): p. 3012-3024.

157. Ashen, J.B. and L.J. Goff, Molecular and ecological evidencefor species specificity and coevol ution in a group of marine al gal-bacterial symbioses. Applied and environmental microbiology, 2000. 66(7): p. 3024-3030.

158. Wang, G., et al., Phylogenetic analysis of epi phytic marine bacteria on Hole-Rotten diseased sporophytes of Laminaria japonica. Journal of Applied Phycology, 2008. 20(4): p. 403-409.

159. Gachon, C.M., et al., Algal diseases: spotlight on a black box. Trends in plant science, 2010. 15(11): p. 633-640.

160. Sarma, S., P.S.L. Jurado, and S. Nandini, Effect of three food types on the population growth of Brachionus calyciflorus and Brachionus patulus $<$ (Rotifera: Brachionidae). International J oumal of Tropical Biology and Conservation, 2001. 49(1): p. 77-84.

161. Moreno-Garrido, I. and J. Canavate, Assessing chemical compounds for controlling predator ciliates in outdoor mass cultures of the green algae Dunaliella salina. Aquacultural engineering, 2001. 24(2): p. 107-114.

162. Camey, L.T., et al., Microbiome analysis of a microalgal mass culture growing in municipal wastewater in a prototype OMEGA photobioreactor. Algal Research, 2014. 4: p. 52-61.

163. Shin, W., S.M. Boo, and J.E. Longcore, Entophlyctis apiculata, a chytrid parasite of Chlamydomonas sp.(Chl orophyceae). Canadianjournal of botany, 2001. 79(9): p. 10831089.

164. Graham, L.E., L.W. Wilcox, and J.J. Knack, Why we need more al gal metagenomes1. J ournal of Phycology, 2015. 51(6): p. 1029-1036.

165. Wichers, J.H., D. Sipkema, and L. Sijtsma, Rapid detection of eukaryotic contaminants in microalgae cultures. 2016.

166. Edvardsen, B., et al., Molecular probes and microarrays for the detection of toxic al gae in the genera Dinophysis and Phalacroma (Dinophyta). Environmental Science and Pollution Research, 2013. 20(10): p. 6733-6750.

167. Stephens, E., et al., Aneconomic and technical evaluation of microal gal bi ofuels. Nature biotechnology, 2010. 28(2): p. 126-128. 
168. Borowitzka, M.A., Commercial production of microalgae: ponds, tanks, tubes and fermenters. Journal of bi otechnology, 1999. 70(1): p. 313-321.

169. Lee, Y.-K., Microalgal mass culturesystems and methods: their limitation and potential. Journal of applied phycology, 2001. 13(4): p. 307-315.

170. Wang, R., É. Gallant, and M.R. Seyedsayamdost, Investigation of the Genetics and Biochemistry of Roseobacticide Production in the Roseobacter Clade Bacterium Phaeobacter inhibens. mBio, 2016. 7(2): p. e02118-15.

171. Woo, J.-H. and Y. Kamei, Antifungal mechanismof an anti-Pythi umprotein (SAP) from the marine bacterium Streptomyces sp. strain AP77 is specific for Pythium porphyrae, a causative agent of red rot disease in Porphyra spp. Applied Microbiology and Biotechnology, 2003. 62(4): p. 407-413.

172. Prajapati, S.K., et al ., Pretreatment of algal bi omass using fungal crude enzymes. Algal Research, 2015. 8: p. 8-14.

173. Ghasemi Naghdi, F., et al., Progress on lipid extraction from wet al gal biomass for biodiesel production. Microbial biotechnology, 2016. 9(6): p. 718-726.

174. Tanzi, C.D., M.A. Vian, and F. Chemat, New procedure for extraction of algal lipids from wet biomass: A green clean and scal able process. Bioresource technology, 2013. 134: p. 271-275.

175. Grossart, H., et al., Interactions between marine snow and heterotrophic bacteria: aggregate formation and microbial dynamics. Aquatic microbial ecology, 2006. 42: p. 19-26.

176. Grossart, H.P., G. Czub, and M. Simon, Algae-bacteria interactions and their effects on aggregation and organic matter flux in the sea. Environmental Microbiology, 2006. 8(6): p. 1074-1084.

177. Gärdes, A., et al., Diatomassociated bacteria are required for aggregation of Thalassiosira weissflogii. The ISME journal, 2011. 5(3): p. 436-445.

178. Rodolfi, L., et al., Growth medium recycling in Nannochl oropsis sp. mass cultivation. Biomolecular engineering, 2003. 20(4): p. 243-248.

179. Manheim, D. and Y. Nelson, Setting and bi oflocculation of two species of al gae used in wastewater treatment and algae biomass production. Environmental Progress \& Sustainable Energy, 2013. 32(4): p. 946-954.

180. Ndikubwimana, T., et al., Harvesting of freshwater microalgae with microbial bioflocculant: a pilot-scal estudy. Biotechnology for biofuels, 2016. 9(1): p. 1.

181. Zhang, J . and B. Hu, A novel method to harvest microal gaevia co-cul ture of filamentous fungi to formcell pellets. Bioresource technology, 2012. 114: p. 529-535.

182. Xie, S., et al., Efficient coagulation of microal gae in cultures with filamentous fungi. Algal Research, 2013. 2(1): p. 28-33.

183. Wrede, D., et al., Co-cultivation of fungal and microalgal cells as an efficient system for harvesting microalgal cells, lipid production and wastewater treatment. PloS one, 2014. 9(11): p. el13497.

184. Muradov, N., et al., Fungal-assisted algal flocculation: application in wastewater treatment and biofuel production. Biotechnology for biofuels, 2015. 8(24): p. 1-23.

185. Prajapati, S.K., et al., A method for simultaneous bioflocculation and pretreatment of algal biomass targeting improved methane production. Green Chem, 2016. 18(19): p. 5230-5238.

186. Olguín, E.J., Dual purpose microal gae-bacteria-based systems that treat wastewater and produce biodiesel and cherical products within a Biorefinery. Biotechnology advances, 2012. 30(5): p. 1031-1046. 
187. Unnithan, V.V., A. Unc, and G.B. Smith, Mini-review: A priori considerations for bacteria-algae interactions in algal biofuel systems receiving municipal wastewaters. Algal Research, 2014. 4(0): p. 35-40.

188. Azim M.E. and D.C. Little, Thebi ofloc technology (BFT) in indoor tanks: water quality, biofloc composition, and growth and welfare of Nile tilapia (Oreochromis niloticus). Aquaculture, 2008. 283(1): p. 29-35.

189. Guieysse, B., et al., Influence of the initial composition of al gal-bacterial microcosms on the degradation of salicylate in a fed-batch culture. Biotechnology letters, 2002. 24(7): p. 531-538.

190. MunOz, R. and B. Guieysse, Algal-bacterial processes for the treatment of hazardous contaminants: a review. Water research, 2006. 40(15): p. 2799-2815.

191. Wang, B. and C.Q. Lan, Biomass production and nitrogen and phosphorus removal by the green alga Neochloris oleoabundans in simulated wastewater and secondary municipal wastewater effluent. Bioresource Technology, 2011. 102(10): p. 5639-5644.

192. González, C., et al., Efficient nutrient removal fromswine manure in a tubular biofilm photo-bioreactor using al gae-bacteria consortia. Water Scienceand Technol ogy, 2008. 58(1): p. 95-102.

193. de Godos, I., et al., A comparative evaluation of microal gae for the degradation of piggery wastewater under photosynthetic oxygenation. Bioresource technology, 2010. 101(14): p. 5150-5158.

194. Gutierrez, T., et al., Polycyclic aromatic hydrocarbon degradation of phytoplanktonassociated Arenibacter spp. and description of Arenibacter algicola sp. nov., an aromatic hydrocarbon-degrading bacterium A pplied and environmental microbiol ogy, 2014. 80(2): p. 618-628.

195. Järup, L., Hazards of heavy metal contamination. British medical bulletin, 2003. 68(1): p. 167-182.

196. Orandi, S., D. Lewis, and N. Moheimani, Biofilm establishment and heavy metal removal capacity of an indigenous mining algal-microbial consortium in a photorotating biological contactor. J oumal of industrial microbiology \& biotechnol ogy, 2012. 39(9): p. 1321-1331.

197. Wang, J., et al., I Inhalation cancer risk associated with exposure to complex polycydic aromatic hydrocarbon mixtures in an electronic waste and urban area in South China. Environmental science \& technology, 2012. 46(17): p. 9745-9752.

198. Muñoz, R., B. Guieysse, and B. Mattiasson, Phenanthrene biodegradation by an al galbacterial consortiumin two-phase partitioning bioreactors. Applied microbiology and biotechnology, 2003. 61(3): p. 261-267.

199. Patel, J.G., et al., Enhancement of pyrene degradation efficacy of Synechocystis sp., by construction of an artificial microalgal-bacterial consortium Cogent Chemistry, 2015. 1(1): p. 1064193.

200. Rawat, I., et al., Dual role of microalgae: phycoremediation of domestic wastewater and biomass production for sustainable biofuels production. Applied Energy, 2011. 88(10): p. 3411-3424.

201. Mobin, S. and F. Alam, Some Promising Microalgal Species for Commercial Applications: A review. Energy Procedia, 2017. 110: p. 510-517.

202. Blanken, W., et al., Optimizing Carbon Dioxide Utilization for Microal gae Biofilm Cultivation. Biotechnology and Bioengineering, 2017. 114(4): p. 769-776.

203. Cabanelas, I.T.D., et al., Sorting cells of the microalga Chlorococcum littorale with increased triacyl glycerol productivity. Biotechnology for Biofuels, 2016. 9(1): p. 183183. 
204. Grima, E.M., et al., Photobi oreactors: light regime, mass transfer, and scal eup. J ournal of Biotechnology, 1999. 70(13): p. 231-247.

205. Posten, C., Design principles of photo - bioreactors for cultivation of microalgae. Engineering in Life Sciences, 2009. 9(3): p. 165-177.

206. Ugwu, C.U., J.C. Ogbonna, and H. Tanaka, Light/dark cyclic movement of al gal culture (Synechocystis aquatilis) in outdoor inclined tubular photobioreactor equipped with static mixers for efficient production of biomass. Biotechnology Letters, 2005. 27(2): $p$. 75-78.

207. JG, Q., Hydrocarbons from Algae, in Handbook of Hydrocarbon and Lipid Microbiology. 2010, Springer: Berlin, Heidel berg. p. 2817-2826.

208. Borowitzka, M.A., High-value products from microalgae -their development and commercialisation. J ournal of A pplied Phycology, 2013. 25(3): p. 743-756.

209. Buono, S., et al., Biol ogical activities of dermatological interest by the water extract of the microalga Botryococcus braunii. Archives of Dermatological Research, 2012. 304(9): p. 755-764.

210. Donot, F., et al., Microbial exopolysaccharides: Main examples of synthesis, excretion, genetics and extraction. Carbohydrate Polymers, 2012. 87(2): p. 951-962.

211. Allard, B. and E. Casadevall, Carbohydrate composition and characterization of sugars fromthe green microal ga Botryococcus Braunii. Phytochemistry, 1990. 29(6): p. 18751878.

212. Metzger P, C.E., Coute A, Botryococcene distribution in strains of the green alga Botryococcus braunii. Phytochemistry 1988. 27(5): p. 1383-1388.

213. Moutel, B., et al., Development of a screening procedure for the characterization of Botryococcus braunii strains for biofuel application. Process Biochemistry, 2016. 51(11): p. 1855-1865.

214. VolovaTG, K.G., Zhilo NO, Plotnikov VF, Physiological and biochemical properties of the alga Botryococcus braunii. J ournal of Plant Physiology, 1998. 45: p. 775-779.

215. Eigemann, F., etal., Bacterial community composition associated with freshwater al gae: species specificity vs. dependency on environmental conditions and source community. FEMS Microbiology Ecology, 2013. 83(3): p. 650-663.

216. Hays, S.G., et al., Better together: engineering and application of microbial symbioses. Current Opinion in Biotechnology, 2015. 36: p. 40-49.

217. Jasti, S., et al., Phylogenetic diversity and specificity of bacteria closely associated with Alexandrium spp. and other phytoplankton. Appl Environ Microbiol, 2005. 71(7): p. 3483-94.

218. Ramanan, R., et al ., Phycosphere bacterial diversity in green al gae reveals an apparent similarity across habitats. Algal Research, 2015. 8: p. 140-144.

219. Cole, J.J., Interactions between bacteria and algae in aquatic ecosystems. Annual Review of Ecology, Evolution, and Systematics, 1982. 13(1): p. 291-314.

220. Guerrini, F., et al., Bacterial-al gal interactions in polysaccharide production. Aquatic Microbial Ecology, 1998. 15(3): p. 247-253.

221. Windler, M., et al., I Ifluence of bacteria on cell size devel opment and morphology of cultivated diatoms. Phycological Research, 2014. 62(4): p. 269-281.

222. Chirac C, C.E., Largeau C, Metzger P, Effect of algal strain and of associated bacteria on hydrocarbon productivity from Botryococcus braunii. Comptes Rendus de I Académie des Sciences-Series III-Sciences dela Vie, 1982. 295: p. 671-674.

223. Tanabe, Y., M. Ioki, and M.M. Watanabe, The fast-growing strain of hydrocarbon-rich green alga Botryococcus braunii, BOT-22, is a vitamin B12 autotroph. Journal of Applied Phycology, 2014. 26(1): p. 9-13. 
224. Largeau, C., et al., Sites of accumulation and composition of hydrocarbons in Botryococcus braunii. Phytochemistry, 1980. 19(6): p. 1043-1051.

225. AM, N., Botryococcus braunii var. Showa. 1988.

226. Hilton, J., E. Rigg, and G. J aworski, In vivo al gal fluorescence, spectral change due to light intensity changes and the automatic characterization of al gae. Freshwater Biology, 1988. 20(3): p. 375-382.

227. Metzger P, B.C., Casadevall E, Coute A, Alkadiene and botryococcene producing races of wild strains of Botryococcus braunii. Phytochemistry, 1985. 24(10): p. 23052312.

228. Metzger P, C.E., Lycopadiene, a tetraterpenoid hydrocarbon from new strains of the green al ga Botryococcus braunii. Tetrahedron Letters, 1987. 28(34): p. 3931-3934.

229. van den Bogert, B., et al., Microarray analysis and barcoded pyrosequencing provide consistent microbial profiles depending on the source of human intestinal samples. Applied and environmental microbiology, 2011. 77(6): p. 2071-2080.

230. Daims, H., et al., The Domain-specific Probe EUB338 is I nsufficient for the Detection of all Bacteria: Development and Evaluation of a more Comprehensive Probe Set. Systematic and Applied Microbiology, 1999. 22(3): p. 434-444.

231. Tian, L., et al., Effects of pectin supplementation on the fermentation patterns of different structural carbohydrates in rats. Molecular nutrition \& food research, 2016. 60(10): p. 2256-2266.

232. Quast, C., et al., The SILVA ribosomal RNA gene database project: improved data processing and web-based tools. Nucleic acids research, 2013. 41(D1): p. D590-D596.

233. Joachimiak, M.P., J.L. Weisman, and B.C. May, JColorGrid: software for the visualization of biological measurements. BMC Bioinformatics, 2006. 7(1): p. 225.

234. Oksanen, J., et al., Vegan: Community Ecology Package Version 2.4-4. 2018.

235. R CoreTeam, R: A languageand environment for statistical computing. Vienna, Austria: R Foundation for Statistical Computing; 2016. 2016.

236. Fenchel, T., Biogeography for Bacteria. Science, 2003. 301(5635): p. 925-926.

237. Chirac, C., et al., Bacterial influence upon growth and hydrocarbon production of the green alga BOTRYOCOCCUS BRAUNII 1. Journal of phycology, 1985. 21(3): p. 380387.

238. Martineau C, V.C., Mauffrey F, Villemur R, Hyphomicrobium nitrativorans sp nov., isolated from the biofilm of a methanol-fed denitrification system treating seawater at the Montreal Biodome. International Joumal of Systematic and Evolutionary Microbiology, 2013. 63(10): p. 3777-3781.

239. De Meyer, S.E. and A. Willems, Multilocus sequence analysis of Bosea species and description of Bosea lupini sp. nov., Bosea lathyri sp. nov. and Bosea robi niaesp. nov., isolated from legumes. International Journal of Systematic and Evolutionary Microbiology, 2012. 62(10): p. 2505-2510.

240. Satola, B., J.H. Wubbeler, and A. Steinbuchel, Metabolic characteristics of the species Variovorax paradoxus. Applied Microbiology and Biotechnol ogy, 2013. 97(2): p. 541560.

241. Yoon, J., et al., Hydrogenophaga bisanensis sp. nov., isolated from wastewater of a textile dye works. International Journal of Systematic and Evolutionary Microbiology, 2008. 58(2): p. 393-397.

242. Krustok, I., et al., Effect of lake water on algal biomass and microbial community structure in municipal wastewater-based lab-scale photobioreactors. Applied Microbiology and Biotechnology, 2015. 99(15): p. 6537-6549. 
243. Tonon LAC, M.A., Thompson F, The family Erythrobacteraceae, in The Prokaryotes: Al phaproteobacteria and Betaproteobacteria. 2014, Springer Berlin Hei del berg: Berlin, Heidel berg. p. 213-235.

244. Fang L, C.L., Liu Y, Tao W, Zhang Z, Liu H, Tang Y, Planktonic and sedimentary bacterial diversity of Lake Sayramin summer. MicrobiologyOpen, 2015. 4(5): p. 814825.

245. Der Kooij, D.V., et al ., Biofilm composition and threshold concentration for growth of Legionella pneumphila on surfaces. A pplied and Environmental Microbiology, 2017. 83(5).

246. Zhou, Y., et al., Description of Sinobacter flavus gen. nov., sp. nov., and proposal of Sinobacteraceae fam nov. International Journal of Systematic and Evolutionary Microbiology, 2008. 58(1): p. 184-189.

247. Gutierrez, T., et al., Polycyclovorans algicola gen. nov., sp. nov., an aromatichydrocarbon-degrading marine bacterium found associated with laboratory cultures of marine phytoplankton. Applied and environmental microbiology, 2013. 79(1): p. 205214.

248. Otsuka, S., et al., Presence of previously undescribed bacterial taxa in non-axenic Chlorella cultures. The J ournal of general and applied microbiology, 2008. 54(4): $p$. 187-193.

249. Abed, R.M.M., et al., Diversity, Distribution and Hydrocarbon Biodegradation Capabilities of Microbial Communities in Oil-Contaminated Cyanobacterial Mats from a Constructed Wetland. PLOS ONE, 2014. 9(12).

250. Lage, O.M. and J. Bondoso, Planctomycetes and macroal gae, a striking association. Frontiers in Microbiology, 2014. 5: p. 267-267.

251. Shu, Q., et al., Molecular progresses of marine Planctomycetes : A review. African J ournal of Microbiology Research, 2011. 5(33).

252. Schwenk, D., L. Nohynek, and H. Rischer, Algae-bacteria association inferred by 165 rDNA similarity in established microal gae cultures. Microbiologyopen, 2014. 3(3): $p$. 356-68.

253. Li, A. and Y. Zhou, Frigidibacter al bus gen. nov., sp. nov., a novel member of thefamily Rhodobacteraceae isolated from lake water. International J ournal of Systematic and Evolutionary Microbiology, 2015. 65(4): p. 1199-1206.

254. Pan, J., et al., Paracoccus sediminis sp. nov., isolated from Pacific Ocean marine sediment. Intemational Journal of Systematic and Evolutionary Microbiology, 2014. 64(8): p. 2512-2516.

255. Newton, R.J., et al., A Guide to the Natural History of Freshwater Lake Bacteria. Microbiology and Molecular Biology Reviews, 2011. 75(1): p. 14-49.

256. Tang, $\mathrm{X}$., et al., Construction of an artificial microalgal-bacterial consortium that efficiently degrades crude oil. J ournal of Hazardous Materials, 2010. 181(1): p. 11581162.

257. Alves CML, D.S.J., Varani A., The prokaryotes: Alphaproteobacteria and Betaproteobacteria. Springer Berlin Heidel berg, 2014

258. Bomfet, C.A., et al., Exopolysaccharides produced by the symbiotic nitrogen-fixing bacteria of leguminosae. Revista Brasileira De Ciencia Do Solo, 2011. 35(3): p. 657671.

259. Freitas, F., V.D. Alves, and M.D.C.F.M. Reis, Advances in bacterial exopolysaccharides: from production to biotechnological applications. Trends in Biotechnology, 2011. 29(8): p. 388-398.

260. Flemming H-C, N.T., Wozniak DJ, The EPS matrix: the "house of biofilm cells". Journal of Bacteriology 2007. 189(22): p. 7945-7947. 
261. Lee, J., et al., Microal gae-associated bacteria play a key role in the flocculation of Chlorella vulgaris. Bioresource Technology, 2013. 131: p. 195-201.

262. Weiss, T.L., et al., Colony Organization in the Green Al ga Botryococcus braunii (Race B) Is Specified by a Complex Extracellular Matrix. Eukaryotic Cell, 2012. 11(12): p. 1424-1440.

263. Stephens, E., et al., Future prospects of microal gal bi ofuel production systems. Trends in plant science, 2010. 15(10): p. 554-564.

264. Mata, T.M., A.A. Martins, and N.S. Caetano, Microal gae for biodiesel production and other applications: A review. Renewableand SustainableEnergy Reviews, 2010. 14(1): p. 217-232.

265. de Vree, J.H., et al., Turbidostat operation of outdoor pilot-scale photobioreactors. Algal Research, 2016. 18: p. 198-208.

266. Zittelli, G.C., et al., Photobioreactors for mass production of microalgae. Handbook of Microalgal Culture: Applied Phycology and Biotechnology, Second Edition, 2013: p. 225-266.

267. Wen, X., et al., Effective cultivation of microalgae for biofuel production: a pilot-scale evaluation of a novel oleaginous microalga Graesiella sp. WBG-1. Biotechnology for biofuels, 2016. 9(1): p. 123.

268. Scott, S.A., et al., Biodiesel fromal gae: challenges and prospects. Current opinion in biotechnology, 2010. 21(3): p. 277-286.

269. Furusawa, G., et al., Algicidal activity and gliding motility of Saprospira sp. SS98-5. Canadian journal of microbiology, 2003. 49(2): p. 92-100.

270. Dao, G.-H., et al., Enhanced microal gae growth through stimul ated secretion of indole acetic acid by symbiotic bacteria. Algal research, 2018. 33: p. 345-351.

271. Lupette, J., et al., Marinobacter dominates the bacterial community of the Ostreococcus tauri phycosphere in culture. Frontiers in microbiology, 2016. 7: p. 1414.

272. Vree, J.H., et al., Comparison of four outdoor pilot-scale photobioreactors. Biotechnology for bi ofuels, 2015. 8(1): p. 215.

273. Bosma, R., et al., Design and construction of the microal gal pilot facility AlgaePARC. Algal Research, 2014. 6, Part B: p. 160-169.

274. Ramiro-Garcia, J., et al., NG-Tax, a highly accurate and validated pi pel ine for analysis of 16S rRNA amplicons from complex biomes [version 1; referees: 2 approved with reservations, 1 not approved]. Vol. 5. 2016.

275. Edgar, R.C., Search and clustering orders of magnitude faster than BLAST. Bioinformatics, 2010. 26(19): p. 2460-2461.

276. Benjamini, $\mathrm{Y}$. and $\mathrm{Y}$. Hochberg, Controlling the false discovery rate: a practical and powerful approach to multiple testing. Journal of the royal statistical society. Series B (Methodological), 1995: p. 289-300.

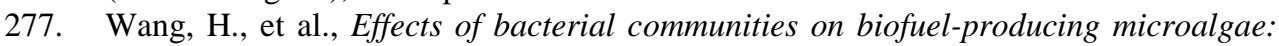
stimulation, inhibition and harvesting. Crit Rev Biotechnol, 2014: p. 1-12.

278. Kimbrel, J.A., etal., Host selection and stochastic effects influence bacterial community assembly on the microalgal phycosphere. Algal Research, 2019. 40: p. 101489.

279. Geng, H., et al., Longitudinal analysis of microbiota in microalga Nannochloropsis salina cultures. Microbial ecology, 2016. 72(1): p. 14-24.

280. Rosana, A.R.R., et al., Draft genome sequences of seven bacterial strains isolated from a polymicrobial culture of coccolith-bearing (C-Type) Emiliania huxleyi M217. GenomeAnnounc., 2016. 4(4): p. e00673-16.

281. Chen, Z., et al., Phaeodactyli bacter xiamenensis gen. nov., sp. nov., a member of the family Saprospiraceae isolated from the marine alga Phaeodactylum tricornutum 
International joumal of systematic and evolutionary microbiology, 2014. 64(10): p. 3496-3502.

282. Meziti, A., et al ., Spatially uniformbut temporally variable bacterioplankton in a semienclosed coastal area. Systematic and A pplied Microbiology, 2015. 38(5): p. 358-367.

283. Marshall, K., et al., Effect of Marine Bacterial I solates on the Growth and Morphology of Axenic Plantlets of the Green Alga Ulva linza. Microbial Ecology, 2006. 52(2): p. 302-310.

284. Burke, C., et al., Composition, uniqueness and variability of the epiphytic bacterial community of the green al ga Ulva australis. The ISME journal, 2011. 5(4): p. 590-600.

285. Ismail, A., et al., Antimicrobial Activities of Bacteria Associated with the Brown Alga Padina pavonica. Frontiers in Microbiology, 2016. 7: p. 1072.

286. Kim, B.-H., et al., Role of Rhizobium a plant growth promoting bacterium in enhancing al gal biomass through mutualistic interaction. biomass and bioenergy, 2014. 69: p. 95-105.

287. Zulkifly, S., et al., The epiphytic microbiota of the globally widespread macroal ga Cladophora glomerata (Chlorophyta, Cladophorales). American journal of botany, 2012. 99(9): p. 1541-1552.

288. Wang, Y., et al., Seasonal dynamics of bacterial communities in the surface seawater around subtropical Xiamen Island, China, as determined by 165 rRNA gene profiling. Marine Pollution Bulletin, 2019. 142: p. 135-144.

289. Kirchman, D.L., et al., Biogeography of major bacterial groups in the Delaware Estuary. 2005. 50(5): p. 1697-1706.

290. Campbell, B.J. and D.L. Kirchman, Bacterial diversity, community structure and potential growth rates along an estuarine salinity gradient. The ISME joumal, 2013. 7(1): p. 210-220.

291. Converti, A., et al., Effect of temperatureand nitrogen concentration on the growth and lipid content of Nannochloropsis oculata and Chlorella vulgaris for biodiesel production. Chemical Engineering and Processing: Process Intensification, 2009. 48(6): p. 1146-1151.

292. Pal, D., et al., The effect of light, salinity, and nitrogen availability on lipid production by Nannochloropsis sp. A pplied microbiol ogy and biotechnology, 2011. 90(4): p. 14291441.

293. Alonso-Sáez, L., et al., Effect of natural sunlight on bacterial activity and differential sensitivity of natural bacterioplankton groups in northwestern Mediterranean coastal waters. Appl. Environ. Microbiol., 2006. 72(9): p. 5806-5813.

294. Bartley, M.L., et al., pH effects on growth and lipid accumulation of the biofuel microalgae Nannochloropsis salina and invading organisms. Journal of applied phycology, 2014. 26(3): p. 1431-1437.

295. Garcia, N.S., J.A. Bonachela, and A.C. Martiny, Interactions between growthdependent changes in cell size, nutrient supply and cel lular elemental stoichiometry of marine Synechococcus. The ISME journal, 2016. 10(11): p. 2715-2724.

296. Zhou, J., et al., Microbial community structure and associations during a marine dinoflagellate bloom Frontiers in microbiology, 2018. 9: p. 1201.

297. Jiang, X., H. Dang, and N. Jiao, Ubiquity and diversity of heterotrophic bacterial nasA genes in diverse marine environments. PloS one, 2015. 10(2).

298. Diner, R.E., et al., Genetic manipulation of competition for nitrate between heterotrophic bacteria and diatoms. Frontiers in microbiology, 2016. 7: p. 880.

299. ZorZ, J.K., et al., Drivers of regional bacterial community structure and diversity over depth and time in the Northwest Attantic Ocean. Frontiers in microbiology, 2019. 10: p. 281. 
300. Hou, D., et al., Environmental factors shape water microbial community structure and function in shrimp cultural enclosure ecosystems. Frontiers in microbiology, 2017. 8: p. 2359.

301. Milici, M., et al., Low diversity of planktonic bacteria in the tropical ocean. Scientific reports, 2016. 6(1): p. 1-9.

302. Wemheuer, B., et al., Impact of a phytoplankton bloom on the diversity of the active bacterial community in the southern North Sea as revealed by metatranscriptomic approaches. FEMS Microbiology Ecology, 2014. 87(2): p. 378-389.

303. Y ang, C., et al., Illumina sequencing-based analysis of freeliving bacterial community dynamics during an Akashiwo sanguine bl oom in Xiamen sea, Chi na. Scientific reports, 2015. 5: p. 8476.

304. Teeling, $H_{.}$, et al., Substrate-controlled succession of marine bacterioplankton populations induced by a phytoplankton bloom Science, 2012. 336(6081): p. 608-611.

305. Fuhman, J.A., et al., Annually reoccurring bacterial communities are predictable from ocean conditions. Proceedings of the National Academy of Sciences, 2006. 103(35): p. 13104-13109.

306. Grossart, H.P., et al., Marine diatom species harbour distinct bacterial communities. Environmental Microbiology, 2005. 7(6): p. 860-873.

307. Williams, T.J ., et al., The role of planktonic $F$ lavobacteria in processing al gal organic matter in coastal $E$ ast A ntarctica reveal ed using metagenomics and metaproteomics. Environmental microbiology, 2013. 15(5): p. 1302-1317.

308. Buchan, A., J.M. González, and M.A. Moran, Overview of the marine Roseobacter lineage. Appl. Environ. Microbiol., 2005. 71(10): p. 5665-5677.

309. Simon, M., et al., Phylogenomics of Rhodobacteraceae reveal s evolutionary adaptation to marine and non-marine habitats. The ISME journal, 2017. 11(6): p. 1483-1499.

310. Mancuso, F.P., et al., Diversity and Temporal Dynamics of the Epiphytic Bacterial Communities Associated with the Canopy-Forming Seaweed Cystoseira compressa (Esper) Gerloff and Nizamuddin. Front Microbiol, 2016. 7: p. 476.

311. Berthold, D.E., et al., Enhancing al gal biomass and lipid production through bacterial co-culture. Biomass and bioenergy, 2019. 122: p. 280-289.

312. Biondi, N., et al., Tetraselmis suecica F\&M - M33 growth is influenced by its associated bacteria. Microbial bi otechnology, 2018. 11(1): p. 211-223.

313. Gouveia, J.D., et al., Associated bacteria of Botryococcus braunii (Chlorophyta). Peer) , 2019. 7: p. e6610.

314. Smriga, S., et al., Chemotaxis toward phytoplankton drives organic matter partitioning among marine bacteria. Proceedings of the National Academy of Sciences, 2016. 113(6): p. 1576-1581.

315. Liu, H., et al., Shifting nutrient-mediated interactions between al gae and bacteria in a microcosm evidencefromalkaline phosphatase assay. Microbiological research, 2012. 167(5): p. 292-298.

316. Le Chevanton, M., et al., Effects of nitrogen limitation on Dunaliella sp.-Alteromnas sp. interactions: from mutualistic to competitive reationships. Frontiers in Marine Science, 2016. 3: p. 123.

317. Paul, C. and G. Pohnert, Interactions of the al gicidal bacterium Kordia al gicida with diatoms: regulated protease excretion for specific al gal lysis. PloS one, 2011. 6(6): p. e21032.

318. Zubkov, M.V., et al., Microbial control of phosphate in the nutrient - depleted North Atlantic subtropical gyre Environmental Microbiology, 2007. 9(8): p. 2079-2089.

319. van Tol, H.M., S.A. Amin, and E.V. Armbrust, Ubiquitous marine bacterium inhibits diatomcell division. The ISME journal, 2017. 11(1): p. 31. 
320. Bolch, C.J., T.A. Subramanian, and D.H. Green, The toxic dinoflagellate Gymodinium catenatum (Dinophyceae) requires marine bacteria for growth. Journal of phycology, 2011. 47(5): p. 1009-1022.

321. Thompson, A.W., et al., Unicellular cyanobacterium symbiotic with a single-celled eukaryotic al ga. Science, 2012. 337(6101): p. 1546-50.

322. Amin, S.A., et al., Boron binding by a siderophore isolated from marine bacteria associated with the toxic dinoflagellate Gymodinium catenatum Journal of the American Chemical Society, 2007. 129(3): p. 478-479.

323. Hom E.F.Y., et al., A Chemical Perspective on Microalgal-Microbial Interactions. Trends in Plant Science, 2015. 20(11): p. 689-693.

324. Yao, S., et al., Microalgae-bacteria symbiosis in microalgal growth and biofuel production: a review. J oumal of applied microbiology, 2019. 126(2): p. 359-368.

325. Lutzu, G.A. and N. Turgut Dunford, Interactions of microalgae and other microorganisms for enhanced production of high-valuecompounds. Front Biosci, 2018. 23: p. 1487-1504.

326. van den Bogert, B., et al., Microarray analysis and barcoded pyrosequencing provide consistent microbial profiles depending on thesource of human intestinal samples. Appl Environ Microbiol, 2011. 77(6): p. 2071-80.

327. Daims, H., et al., The Domain-specific Probe EUB338 is I nsufficient for the Detection of all Bacteria: Development and Evaluation of a more Comprehensive Probe Set. Systematic and Applied Microbiology, 1999. 22(3): p. 434-444.

328. Tian, L., et al., Effects of pectin supplementation on the fermentation patterns of different structural carbohydrates in rats. Mol Nutr Food Res, 2016. 60(10): p. 22562266.

329. Ramiro-Garcia, J., et al., NG-Tax, a highly accurate and validated pi pel ine for analysis of 16S rRNA amplicons fromcomplex biomes. F1000Research, 2016. 5: p. 1791.

330. Dat, T.T.H., et al., Archaeal and bacterial diversity and community composition from 18 phylogenetically divergent sponge species in Vietnam Peer, , 2018. 6.

331. Edgar, R.C., Search and clustering orders of magnitude faster than BLAST. Bioinformatics, 2010. 26(19): p. 2460-1.

332. Quast, C., et al., The SILVA ribosomal RNA gene database project: improved data processing and web-based tools. Nucleic Acids Res, 2013. 41(Databaseissue): p. D5906.

333. Y ilmaz, P., et al., The SILVA and "All-species Living Tree Project (LTP)" taxonomic frameworks. Nucleic Acids Res, 2014. 42(Database issue): p. D643-8.

334. Holm, S., A Simple Sequentially Rejective Multiple Test Procedure. Scandinavian J oumal of Statistics, 1979. 6(2): p. 65-70.

335. van Tol, H.M., S.A. Amin, and E.V. Armbrust, Ubiquitous marine bacteriuminhibits diatomcell division. ISME J, 2016.

336. Goecke, F., et al., Algae as an important environment for bacteria-phylogenetic relationships among new bacterial species isol ated fromal gae. Phycologia, 2013. 52(1): p. 14-24.

337. Wang, $\mathrm{H}_{\text {., }}$ et al., I dentification of genetic modules mediating the J ekyll and Hyde interaction of Dinoroseobacter shi bae with the dinoflagel late Prorocentrum minimum Frontiers in Microbiology, 2015. 6.

338. Weber, C.F. and G.M. King, Physiological, ecological, and phylogenetic characterization of Stappia, a marine CO-oxidizing bacterial genus. Applied and environmental microbiology, 2007. 73(4): p. 1266-1276.

339. Coates, C.J . and M. Wyman, A denitrifying community associated with a major, marine nitrogen fixer. Environmental microbiology, 2017. 19(12): p. 4978-4992. 
340. Han, J., et al., Co-culturing bacteria and microal gae in organic carbon containing medium J oumal of Biological Research-Thessal oniki, 2016. 23(1): p. 8.

341. Sandhya, S. and K. Vijayan, Symbiotic association among marine microalgae and bacterial flora: a study with special reference to commercially important Isochrysis gal bana culture. J ournal of Applied Phycology, 2019: p. 1-8.

342. Chen, Z., et al., Influence of plaque forming bacterium, Rhodobacteraceae sp. on the growth of Chlorella vulgaris. Bioresource Technology, 2014. 169: p. 784-788.

343. Fukui, Y., et al., Maritalea porphyrae sp. nov., isolated from a red alga (Porphyra yezoensis), and transfer of Zhangella mobilis to Maritalea mobilis comb. nov. International journal of systematic and evolutionary microbiology, 2012. 62(1): p. 4348.

344. Chung, E.J., et al ., Hoeflea suaedaesp. nov., an endophytic bacteriumisol ated fromthe root of the halophyte Suaeda maritima. International journal of systematic and evolutionary microbiology, 2013. 63(6): p. 2277-2281.

345. Fukui, Y., et al., I solation of Hyphomonas strains that inducenormal morphogenesis in protoplasts of the marine red alga Pyropia yezoensis. Microbial ecology, 2014. 68(3): p. 556-566.

346. Bentzon-Tilia, M., L. Riemann, and L. Gram, Draft genome sequence of Hoeflea sp. strain BAL378, a potential producer of bioactive compounds. Genome announcements, 2014. 2(6): p. e01213-14.

347. Xamxidin, M., etal., Aquaticitalea lipolytica gen. nov., sp. nov., isolated fromAntarctic seawater. International journal of systematic and evolutionary microbiology, 2016. 66(7): p. 2657-2663.

348. Meseck, S., et al., Nutrient interactions between phytoplankton and bacterioplankton under different carbon dioxide regimes. J ournal of A pplied Phycology, 2006(3): p. 229237.

349. Danger, M., et al., Control of phytoplankton-bacteria interactions by stoichiometric constraints. 2007. 116(7): p. 1079-1086.

350. Fukami, K., T. Nishijima, and Y. Ishida, Stimulative and inhibitory effects of bacteria on the growth of microal gae. Hydrobiol ogia, 1997. 358(1): p. 185-191.

351. Mitsutani, A., et al., Analysis of algicidal proteins of a diatomlytic marine bacterium Pseudoalteromonas sp. strain A25 by two-dimensional electrophoresis. Phycologia 2001(3): p. 286-291.

352. Nedashkovskaya, O.I., et al., Maribacter gen. nov., a new member of the family Flavobacteriaceae, isolated from marine habitats, containing the species Maribacter sedimenticola sp. nov., Maribacter aquivivus sp. nov., Maribacter orientalis sp. nov. and Maribacter ulvicola sp. nov. International joumal of systematic and evolutionary microbiology, 2004. 54(4): p. 1017-1023.

353. Lee, Y.-S. and Y.-L. Choi, Complete genome sequence and analysis of three kinds of $\beta$ agarase of Cellulophaga Iytica DAU203 isolated from marine sediment Marine genomics, 2017. 35: p. 43-46.

354. Chi, W.-J., Y.-K. Chang, and S.-K. Hong, Agar degradation by microorganisms and agar-degrading enzymes. Applied microbiology and biotechnology, 2012. 94(4): p. 917-930.

355. Velu, P., M.J. Peter, and E. Sanniyasi, Effect of various carbon sources on biochemical production in marine microalgae Nannochloropsis salina (Eustigmatophyceae), Dunaliella tertiolecta (Chlorophyceae) and Tetraselmis suecica (Chl orodendrophyceae). Int. J. Curr. Microbiol. A pp. Sci, 2015. 4(3): p. 207-215. 
356. Vu, H.T., et al., Cocultivated bacteria can increase or decrease the culture lifetime of Chlorella vulgaris. The Joumal of general and applied microbiology, 2010. 56(5): p. 413-418.

357. Tumer, S., et al., Investigating deep phylogenetic relationships among cyanobacteria and plastids by small subunit rRNA sequence analysis 1. Journal of Eukaryotic Microbiology, 1999. 46(4): p. 327-338.

358. Apprill, A., et al., Minor revision to V4 region SSU rRNA 806R gene primer greatly increases detection of SAR11 bacterioplankton. Aquatic Microbial Ecology, 2015. 75(2): p. 129-137.

359. Sapp, M., et al., Species-specific bacterial communities in the phycosphere of microal gae? Microbial ecology, 2007. 53(4): p. 683-699.

360. Behringer, G., et al., Bacterial Communities of Diatoms Display Strong Conservation Across Strains and Time. Frontiers in microbiology, 2018. 9: p. 659.

361. Schäfer, H., et al ., Genetic diversity of 'satel lite' bacteria present in cultures of marine diatoms. FEMS Microbiology Ecology, 2002. 42(1): p. 25-35.

362. Sapp, M., et al., Bacterial community dynamics during the winter-spring transition in the North Sea. FEMS Microbiology Ecology, 2007. 59(3): p. 622-637.

363. Sapp, M., A. Wichels, and G. Gerdts, Impacts of cultivation of marine diatoms on the associated bacterial community. A pplied and environmental microbiology, 2007. 73(9): p. 3117-3120.

364. Jasti, S., et al., Phylogenetic diversity and specificity of bacteria cl osely associated with Alexandrium spp. and other phytoplankton. Appl. Environ. Microbiol., 2005. 71(7): p. 3483-3494.

365. Green, D.H., et al., Bacterial Diversity Associated with the Coccolithophorid Algae Emiliania huxleyi and Coccolithus pelagicus f. braarudii. BioMed Research International, 2015. 2015: p. 194540-194540.

366. Hardin, G., The competitive exclusion principle. science, 1960. 131(3409): p. 12921297.

367. Šimek, K., etal., Alga-derived substrates select for distinct betaproteobacterial lineages and contributeto nicheseparation in Limnohabitans strains. Appl. Environ. Microbiol., 2011. 77(20): p. 7307-7315.

368. Dang, H. and C.R. Lovell, Bacterial primary colonization and early succession on surfaces in marine waters as determined by amplified rRNA gene restriction analysis and sequence analysis of 16S rRNA genes. A ppl. Environ. Microbiol., 2000. 66(2): p. 467-475.

369. Myklestad, S., Release of extracellular products by phytoplankton with special emphasis on polysaccharides. Science of The Total Environment, 1995. 165: p. 155164.

370. Villacorte, L.O., et al., Characterisation of algal organic matter produced by bloom forming marine and freshwater algae. Water Research, 2015. 73: p. 216-230.

371. Kazamia, E., D.C. Aldridge, and A.G. Smith, Synthetic ecology - A way forward for sustainable algal bi ofuel production? J ournal of Biotechnology, 2012. 162(1): p. 163169.

372. Kazamia, E., et al., An engineered community approach for industrial cultivation of microal gae. Industrial Biotechnology, 2014. 10(3): p. 184-190.

373. Bader, J., \& al., Relevance of microbial coculture fermentations in biotechnology. Journal of applied microbiology, 2010. 109(2): p. 371-387.

374. Sabra, W., et al., Biosystems analysis and engineering of microbial consortia for industrial biotechnology. Engineering in Life Sciences, 2010. 10(5): p. 407-421. 
375. Goers, L., P. Freemont, and K.M. Polizzi, Co-culture systems and technologies: taking synthetic biology to the next level. J ournal of the Royal Society Interface, 2014. 11(96): p. 20140065.

376. Mayali, X. and F. Azam, Algicidal Bacteria in theSea and their Impact on Algal Blooms. J ournal of Eukaryotic Microbiology, 2004. 51(2): p. 139-144.

377. Hilton, J.A., et al., Genomic deletions disrupt nitrogen metabolism pathways of a cyanobacterial diatomsymbiont. Nature Communications, 2013. 4(1): p. 1767-1767.

378. Vraspir, J.M. and A. Butder, Chemistry of marine ligands and siderophores. Annual Review of MarineScience, 2009. 1(1): p. 43-63.

379. Fakhimi, N., et al., Acetic acid is key for synergetic hydrogen production in Chlamydomonas-bacteria co-cultures. Bioresource Technology, 2019. 289: p. 121648.

380. Mayali, X., Metabolic Interactions Between Bacteria and Phytoplankton. Frontiers in microbiology, 2018. 9: p. 727.

381. Ganuza, E., et al., A novel treatment protects Chlorella at commercial scale from the predatory bacterium Vampi rovibrio chl orellavorus. Frontiers in microbiology, 2016. 7: p. 848.

382. Bagwell, C.E., et al., Discovery of bioactive metabolites in bi ofuel microal gaethat offer protection against predatory bacteria. Frontiers in microbiology, 2016. 7: p. 516.

383. Klindworth, A., et al., Evaluation of general 165 ribosomal RNA gene PCR primers for classical and next-generation sequencing-based diversity studies. Nucleic acids research, 2013. 41(1): p. el-el.

384. Thomas, F., et al., Evaluation of a new primer combination to minimize plastid contamination in 165 rDNA metabarcoding analyses of alga - associated bacterial communities. Environmental microbiology reports, 2019.

385. Ryffel, F., et al., Metabolic footprint of epiphytic bacteria on Arabidopsis thaliana leaves. ISME J, 2016. 10(3): p. 632-43.

386. Olive, A.J . and C.M. Sassett, Metabol ic crosstalk between host and pathogen: sensing, adapting and competing. Nature reviews Microbiology, 2016. 14(4): p. 221.

387. Magnúsdóttir, S. and I. Thiele, Modeling metabolism of the human gut microbiome. Current opinion in biotechnology, 2018. 51: p. 90-96.

388. Schleyer, G., et al., In plaque-mass spectrometry imaging of a bloomforming alga during viral infection reveals a metabolic shift towards odd-chain fatty acid lipids. Nature Microbiology, 2019. 4(3): p. 527-538.

389. Watrous, J.D., et al., Microbial metabolic exchange in 3D. The ISME journal, 2013. 7(4): p. 770.

390. Lasch, P., et al., I dentification of highly pathogenic microorganisms by matrix-assisted laser desorption ionization-time of flight mass spectrometry: results of an interlaboratory ring trial. J ournal of clinical microbiology, 2015. 53(8): p. 2632-2640.

391. Seymour, J.R., et al., Chemoattraction to dimethylsulfoni opropionate throughout the marine microbial food web. Science, 2010. 329(5989): p. 342-345.

392. Sonnenschein, E.C., et al., Chemotaxis of Marinobacter adhaerens and its impact on attachment to the diatom Thalassiosira weissflogii. Appl. Environ. Microbiol, 2012. 78(19): p. 6900-6907.

393. Lambert, B.S., et al., A microfluidics-based in situ chemotaxis assay to study the behaviour of aquatic microbial communities. Naturemicrobiology, 2017. 2(10): p. 1344.

394. Lee, K.S., et al., An automated Raman-based platform for the sorting of live cells by functional properties. Nature microbiology, 2019. 4(6): p. 1035. 

Thesis summary 


\section{Summary}

Research described in this thesis aimed to investigate the microalgal microbial ecology by integrating both cultivation-dependent and cultivation-independent approaches. In addition, we examined effects of bacteria on growth of microalgae by developing a coculture system. Understanding the bacterial community composition and functional associations between microalgae and bacteria will provide important insights for both aquatic ecology and algal biotechnology.

Microal gae are living with di versemicrobial communities and interactions between microal gae and bacteria are prevalent and strongly influence carbon and nutrient cycling in aquatic ecosystems. A brief overview of the current knowledge of algae-bacteria interactions and current research methodologies was given in chapter 1 . This chapter furthermore introduced the microalgae production facilities at AlgaePARC, and highlighted two research objects (Nannochloropsis sp. and Botryococcus braunii), and current knowledge on their associated bacteria.

In chapter $\mathbf{2}$ we comprehensively reviewed the recent research progress on al gae-bacteria interactions and summarized the current knowledge on functional aspects of al gae-associated microbiomes. In addition, we discussed the applications of knowledge on al gae-bacteria interactions in al gal biomass production and various other related biotechnol ogical innovations. Finally, we concluded that principles of al gae-bacteria interactions can be integrated into many aspects of the al gal production chain, which may help push the limit of the al gal industry.

In chapter 3, westudied the bacterial community associated with 12 strains of B. braunii. The changes of bacterial community composition were monitored over a period of 12 days. It was clear from this study that B. braunii hosts a wide variety of bacterial species, among which the bacterial families Rhizobiaceae, Bradyrhizobiaceae and Comamonadaceae were found in all 
12 strains. These families that all belong to the phylum Proteobacteria could have important interactions with B. braunii. Additionally, although each strain displayed a different bacterial community composition, all the strains from the CAEN culture collection had more similar bacterial communities, suggesting that the al gae culture collection could have an influence on the bacterial community composition. Several bacterial genera were shown to be exclusively abundant in CAEN strains including Rhizobium spp. and Porphyrobacter spp.

In chapter 4, we compared bacterial community composition in cultures of Nannochloropsis sp. CCAP211/78 grown simultaneously in four outdoor large-scale bioreactors. We observed that the bacterial community composition significantly differed between all reactor types except for horizontal and vertical tubular bioreactors. Although the bacterial communities varied within each bioreactor at different cultivation stages, we found that a member of the family Saprospiraceae was the most abundant taxon (OUT_1261) in all large non-sterilized bioreactors. This indicates that Saprospiraceae may play important roles in Nannochloropsis cultures.

In chapter 5, we isolated bacteria from one horizontal tubular bioreactor and one vertical tubular bi oreactor. A mong all the isolates eighteen bacteria were phylogenetically classified as different species/strains based on their 16S rRNA gene sequence. Axenic cultures of Nannochloropsis sp. CCAP211/78 were successfully obtained by treatment with antibiotics. A micropl ate-based assay system coupled with a custom-made LED box was devel oped to assess the growth of axenic Nannochloropsis sp. CCAP211/78 with addition of isolated bacterial strains. Out of 18 strains, one Maritalea porphyrae strain (DMSP31) and one Labrenzaa aggregata strain (Y P26) were highlighted as having a significantly positive effect on microal ga growth, whereas oneflavobacterial strain (YP206) was shown to reducethis growth. YP26 was also found to substantially enhance the growth of Nannochloropsis sp CCAP211/78 using the 
doubleagar plate assay, which indicates that YP26 has strong positive impacts on Nannochloropsis sp CCAP211/78.

Finally, chapter 6 el aborated on theimplications of findings fromtheresearch described in this thesis. Bacterial community composition of Nannochloropsis sp CCAP211/7 and B. braunii was compared, and the results generally supported that bacterial communities are al gal species specific. Additionally, I suggested that the combination of environmental variables and reactor configuration/operation (in addition to stochastic effects) may be responsiblefor the differences in bacterial community composition observed between different reactor types and between runs. Further exploration and exploitation of algae-bacteria interactions is needed. Therefore, I proposed several new techniques, including using a new primer set to better characterize bacteria living with microal gae, using advanced mass spectrometry to tap into the metabolic changes of microal gae when they interact with bacteria, and using microfluidics coupled with Raman-based cell sorting to isolate bacteria of interest. Future research should consider these approaches in combination with coculture experiments in order to gain better understanding on bacterial community composition and functional interactions between microal gre and bacteria. 


\section{Appendices}




\section{Acknowledgements}

After spending more than fiveyears in Wageningen, it is timeto say goodbye to everyonel met here. Before doing that, I would like to acknowledge many people for their guidance and support during my PhD adventure.

Dear H auke, thanks for giving me the opportunity to join the MIB family. I will never forget every discussion we had, you al ways gave me suggestions on a new perspective and made me think out of box. You are so critical and passionate on science, I could not imagine how my PhD journey would end up if you were not involved in my project.

Detmer, you arethe best supervisor ever! I am so lucky to join themarinegroup and work with you. Every timewhen I encountered troubles, you wereal ways patient to explain meeverything in detail. Your friendliness and humour often led me to think you are not a supervisor, but a close and knowledgeable friend. I was so encouraged by your attitude towards science, your dedication and persistence. Being supervised by you is by all means the best adventure of my lifel could imagine.

Dear R ené, thank you for participating in my project. I al ways appreciate your comprehensive knowledge on microal gae and all the indispensable inputs to my thesis you provided.

I was really honoured to be part of the MIB with so many excellent professors and talent colleagues and students. Thanks W illem, you are the captain of MIB. Y our leadership and vision aretruly inspiring. Many thanks to the supportivetechnician team of MIB: Ineke, Steven, Philippe, Merlijn, Tom, Ton, Sjon and Wim. Anja, thanks for helping me arrange all bureaucratic things.

MolEco group is a warm international family. I enjoyed a lot of all the meetings, discussions and group activities (MolEco cakes, Christmas dinner, lab trips). The PhD trip in 2017 to Germany, Denmark and Sweden was so much fun. Many thanks to the committee for organisation. I al so want to thank my team members during this trip: Daan, Sudarshan, A lex and I oannis. I would also like to thank all friends and colleagues from Bacgen, MicFys, and SSB for your kindness and friendship. J avier, J asper and Bart, thanks for your assistance on bioinformatics.

I would al so liketo thank peopl efromBPE, J eroen, thank you for nicecollaboration on chapter 4. J oao, you are always energetic and passionate, it is nice to work with you on chapter 3. 
Snezana, W endy, R ouke and R ick, thank all of you for help when I was working in BPE and AlgaePARC. Xiao \& Y imin, I often feel so late to meet this great couple, thanks for the good food and wine you provided. Y imin, many thanks for organi sing tea tasting events. F engzheng and C hunzhe, thanks for your help and fun talks we had in Radix.

It was great pleasure to work with $\mathrm{M}$ arine $\mathbf{G}$ roup members: Dennis, J ohanna, Indra, Tika, Dat, G eorg, M enia, Catarina, L eyre and G rant. Indra, I will remember all the happy chats with you and the delicious Indonesian food you cooked whileyou werestill in Asserpark. Y our constantly positive attitude impressed me so much, thank you for all the help and advice. I am surethat I will visit you and Titi at Bali soon. Dennis, I will miss the "movienight" and "office chat" with you and Indra. G eorg, you werekind of another supervisor to me, thanks for hel ping meso much on data analysis and all. G rant, you are such a nice guy, it is so great to meet you and thanks for hosting mein Naples. J ohanna, you are the source of happiness, your laughing will beal ways missed. Dat and Tika, it was happy to teach the master course with you, I wish both of you all the best and would get PhD dipl oma soon. C atarina, thanks for introducing me into bouldering, I wish to do more sports with you. M enia and Leyre, thank you for all the discussions and help.

I was happy to supervisePatrick and Selene for your master theses. Thanks for your hard work that contributed significantly to this thesis. I am so glad that both of you are doing PhD now. Best wishes to you.

I would like to thank all my officemates during the past years: A lexzandr, M ark, Indra, Peng, Dennis, Dat, Sudarshan, LooW ee, J ohanna, Y ue, Atsushi, Leyre, M enia and O uyang. Y ou guys are all so nice and we had a great time together.

Leiden would be one of the Dutch cities I visited most frequently, thanks Xiao \& C hao for hosting meso many times with del icious food and all the anecdotes we exchanged. I wish you all the best of luck.

I would especially like to thank Chinese community in MIB: Y e, Y ue, Y ifan, Y ing, Y uan, Peng, Ran, C aifang, $C$ hen \& $Y$ ing, Taojun, $O$ uyang, Zhuang, $Z$ hifei and $Y$ ing. Thanks for your support and help, you areall my family members. I would givemy special thanks to $Y$ ifan. You are the master chef, thanks for inviting me to join the dinner with you so many times. I will always remember the wine tasting nights you organised, and we travelled together to expl ore many cities in the Netherlands and Europe. 
During living in Wageningen for more than fiveyears, I met a large number of Chinesefriends. Y inxing, Xu, J uncai, Y in, Xing, W ei, Ningjing, Peiyu, H ao, J ingbin, L ei, M an, Ya, Peng, Y uxing, J ie, Y ale. Thank you for all your care, advice and friendship. I enjoyed every minute spent with you all, which made my life in Wageningen so joyful.

It was great memories to meet many Chinese friends from Plant Breeding Group: Huayi, I cannot thank you enough for your kindness and warm heart. Thanks again for being my close friend and having hol idays with me in Italy, Morocco and Croatia. Xinfang and M in, I shared many sweet memories with you, thanks for your friendship and support. Hongmei, Lina and Ning, I consider myself super lucky to meet you in Wageningen, your friendship is very precious to me. Thanks for your care and support.

I lived in Asserpark44, 8B5 for more than 5 years since I moved to Wageningen. I never had the idea to move out thanks to all easy-going corridor mates. I would give my special thanks to $\mathrm{Y}$ ujue, $\mathbf{Z}$ hiW ei, He, Sibong and $\mathrm{Y}$ angyang. All the memorable moments with you guys will be missed.

Last but not least, I would like to thank all my family members. My dearest parents, you gave the power and freedom to pursue my dream. My love to you will never goes end. My lovely sister, thanks for everything you have done to support me. Other family members fromboth my father's side and my mom's side must be acknowl edged as well, thanks for all your love and care. 


\section{A bout the author}

Jie Lian was born on the $16^{\text {th }}$ of J une 1989 in Wuxi, Jiangsu Province, China. After completing his primary and secondary education at Wuxi in 2007, hecontinued his study with BSc in Biotechnology at Jiangsu University, Zhenjiang. His BSc thesis

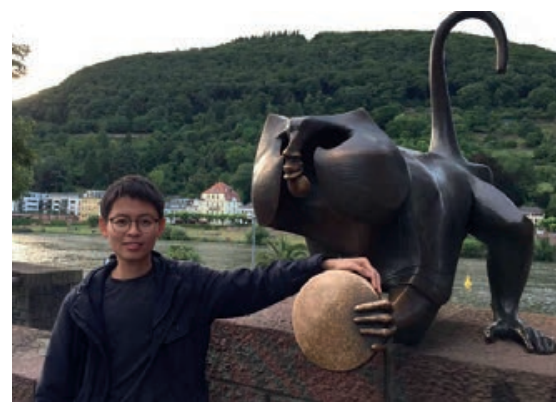
investigated the effect of salicylic acid on the germi nation of Oryza sativa. In 2011, he moved to Xiamen for the MSc education in Aquatic biology. Under the supervision of Dr J un Zhang atXiamen University, his research focused on unravelling themolecular mechanism of motility in cyanobacteria Synechococcus sp. and Microcystis aeruginosa. After obtaining his MSc degree in 2014, he moved to the Netherlands and started his PhD at the Laboratory of Microbiology supervised by Detmer Sipkema, as well as Prof. Hauke Smidt and Prof. René Wijffels (Bioprocess Engineering Group). His PhD Research, which is described in this book, investigated the interactions between microal gaeand associated bacteria, and its ecological and biotechnological implications. 


\section{List of publications}

Lian, J ., Wijffels, R.H., Smidt, H., and Sipkema, D. (2018) The effect of the al gal microbiome on industrial production of microal gae, Microbial biotechnology 11: 806-818.

Gouveia, J.D. ', Lian, J. ', Steinert, G., Smidt, H., Si pkema, D., Wijffels, R.H., Barbosa, M.J . 2019. Associated bacteria of Botryococcus braunii (Chlorophyta) Peer] 7:e6610 https://doi.org/10.7717/peej.6610

Lian, J ., Steinert, G, deVree, J.H, Meijer S., Heryanto, C., Bosma, R., Wijffes, R.H., Barbosa, M.J., Smidt, H., and Sipkema, D. Bacterial diversity in outdoor pilot plant production of the microal ga Nannochloropsis sp. CCAP211/78. M anuscript in preparation.

Lian, J., Schimmel, P., Sanchez-Garcia, S., Wijffels, R.H., Smidt, H., Sipkema, D. Enhanced or decreased growth of Nannochloropsis sp. CCAP211/78 cultivated with diverse bacteria. M anuscript submitted.

Lian, J., Nijsse, B., Koehorst, J.J., Wijffels, R.H., Smidt, H., Sipkema, D. Dual RNA-Seq unveils interactions between Nannochloropsis sp. CCAP211/78 and two associated bacteria. M anuscript in preparation.

Other publications:

Lian, J. . , Zheng, X. ', Chen, Y., Zhuo, X., He, C, Shi, Q., Zheng, Q., Lin, TH., Sun, J., Guo, WD., Cai, R., Jiao, N. Microbial transformation of distinct exogenous substrates into anal ogous refractory compounds. M anuscript Submitted.

${ }^{*}$ These authors contributed equally. 


\section{Overview of completed training activities}

\section{Discipline specific activities}

\section{Courses}

SIAM Metagenomics Course, Nijmegen, NL 2016

BluePharmT rain Summer school: Statistic analysis using R, Wageningen, NL 2016

$\begin{array}{ll}\text { Big data course, Wageningen, NL } & 2017\end{array}$

Advance course in Bioprocess design, Wageningen, NL 2018

\section{Meetings}

KNVM Spring Meeting, Arnhem, NL 2017

New Approaches and Concepts in Microbiology, Heidelberg, DE 2017

SAME15, Zagreb, HR 2017

Prospects and chal lenges for the development of al gal biotechnology, Bielefeld, DE 2017

$\begin{array}{ll}\text { Microbiology centennial conference, Wageningen, NL } & 2017\end{array}$

KNVM Microbial Ecology symposium, Wageningen, NL 2017

Young al gaeneers symposium, Oban, UK 2018

Wageningen meets Ghent symposium, Ghent, BE 2018

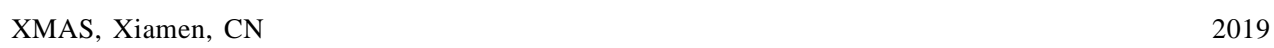

\section{General courses}

VLAG PhD week, Baarlo, NL $\quad 2015$

Project and Time management, Wageningen, NL 2015

$\begin{array}{ll}\text { Scientific Writing, Wageningen, NL } & 2016\end{array}$

$\begin{array}{ll}\text { Reviewing a scientific paper, Wageningen, NL } & 2017\end{array}$

Adobelllustrator for scientists, Wageningen, NL 2018

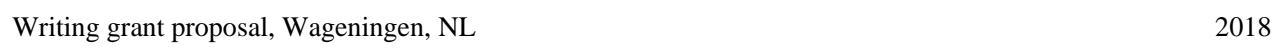

\section{Optional}

$\begin{array}{ll}\text { Preparing project proposal } & 2014\end{array}$

Molecular Ecology group meeting and Marine Microbiology group meeting 2014-2018

$\begin{array}{ll}\text { PhD meeting in Microbiology } & \text { 2014-2018 }\end{array}$

$\begin{array}{ll}\text { Microbiology PhD trip } & 2017\end{array}$ 
The research described in this thesis was financially supported by the Laboratory of Microbiology. The scholarship for the author was provided by the China Scholarship Council. Financial support from Wageningen University for printing this thesis is gratefully acknowledged.

Cover design by: JieLian \& Qiuhui Pang

Layout design by: J ieLian \& Digiforce

Printed by: Digiforce 



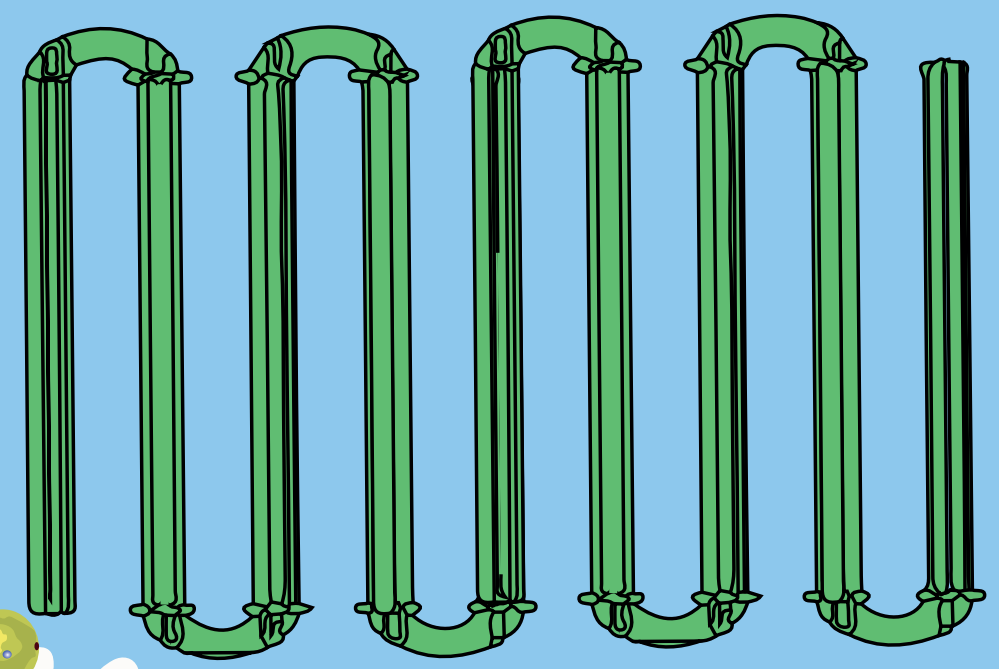

